\title{
Understanding fatigue in multiple sclerosis : from a psychological perspective
}

Citation for published version (APA):

Bol, Y. (2010). Understanding fatigue in multiple sclerosis : from a psychological perspective. [Doctoral Thesis, Maastricht University]. NeuroPsych Publishers. https://doi.org/10.26481/dis.20100305yb

Document status and date:

Published: 01/01/2010

DOI:

10.26481/dis.20100305yb

Document Version:

Publisher's PDF, also known as Version of record

\section{Please check the document version of this publication:}

- A submitted manuscript is the version of the article upon submission and before peer-review. There can be important differences between the submitted version and the official published version of record.

People interested in the research are advised to contact the author for the final version of the publication, or visit the DOI to the publisher's website.

- The final author version and the galley proof are versions of the publication after peer review.

- The final published version features the final layout of the paper including the volume, issue and page numbers.

Link to publication

\footnotetext{
General rights rights.

- You may freely distribute the URL identifying the publication in the public portal. please follow below link for the End User Agreement:

www.umlib.nl/taverne-license

Take down policy

If you believe that this document breaches copyright please contact us at:

repository@maastrichtuniversity.nl

providing details and we will investigate your claim.
}

Copyright and moral rights for the publications made accessible in the public portal are retained by the authors and/or other copyright owners and it is a condition of accessing publications that users recognise and abide by the legal requirements associated with these

- Users may download and print one copy of any publication from the public portal for the purpose of private study or research.

- You may not further distribute the material or use it for any profit-making activity or commercial gain

If the publication is distributed under the terms of Article $25 \mathrm{fa}$ of the Dutch Copyright Act, indicated by the "Taverne" license above, 


\section{Understanding fatigue in multiple sclerosis}

From a psychological perspective

Yvonne Bol

NeuroPsych Publishers Maastricht, the Netherlands 
(C) Copyright: Y. Bol, Maastricht 2010

Cover drawing

Ik op de ladder (1997). Patty Habraken (1967-2006)

www.pattyhabraken.nl

Lay-out and production

Datawyse BV

Publisher

NeuroPsych Publishers

ISBN

978-90-75579-41-3

Neuropsych Publishers is a non-profit organization, which aims at promoting the science of 'Brain and Behaviour' and improving the application of the products of this science in health care and education. Neuropsych Publishers accomplishes these aims by publishing books, dissertations and other products of scientific activity, by disseminating educational materials and publication of tests, assessment scales and other psychometric instruments in the field of Neuropsychology, Neuropsychiatry and other areas within the domain of Brain and Behaviour.

Postal address: Neuropsych Publishers, Department of Psychiatry and Neuropsychiatry, Maastricht University, P.O. Box 616, NL-6200 MD Maastricht, The Netherlands, www-np.unimaas.nl 


\title{
Understanding fatigue in multiple sclerosis From a psychological perspective
}

\author{
PROEFSCHRIFT \\ Ter verkrijging van de graad van doctor aan de Universiteit Maastricht, \\ op gezag van de Rector Magnificus, Prof. mr. G.P.M.F. Mols, \\ volgens het besluit van het College van Decanen, \\ in het openbaar te verdedigen \\ op vrijdag 5 maart 2010 om 16.00 uur \\ door
}

Yvonne Bol

Geboren op 12 april 1975 te Vlissingen 


\section{Promotores}

Prof. dr. F.R. J. Verhey

Prof. dr. R.M.M. Hupperts

Prof. dr. J.W.S. Vlaeyen

\section{Copromotor}

Dr. A.A. Duits

\section{Beoordelingscommissie}

Prof. dr. J.J. van Os (voorzitter)

Prof. dr. L. Fasotti (Radboud Universiteit Nijmegen)

Prof. dr. M.J.H. Huibers

Dr. E.A.C.M. Sanders (Amphia Ziekenhuis Breda)

Prof. dr. R.J.E.M. Smeets

The research described in this thesis was performed at the Maastricht University Medical Centre, School for Mental Health and Neuroscience, in collaboration with the Department of Clinical Psychological Science, Faculty of Psychology and Neuroscience, Maastricht University, Maastricht, the Netherlands.

Financial support for the publication of this thesis was kindly provided by:

sanofi-aventis Netherlands B.V., Teva Pharma Nederland, Merck Serono, Bayer Schering Pharma, Biogen Idec International B.V., Science Plus Group, Van Lierop Orthopedie B.V. and Heckert Orthopedische hulpmiddelen B.V. 


\section{Contents}

$\begin{array}{lll}\text { Chapter } 1 \text { General introduction } & 7\end{array}$

Chapter 2 The psychology of fatigue in patients with multiple sclerosis: 17 A review

Chapter 3 The impact of fatigue on cognitive functioning in patients with multiple sclerosis

Chapter 4 Subjective and objective assessment of mental fatigue in patients with multiple sclerosis

Chapter 5 The contribution of disease severity, depression and negative affectivity to fatigue in multiple sclerosis: A comparison with ulcerative colitis

Chapter 6 Fatigue and physical disability in patients with multiple sclerosis: A structural equation modelling approach

$\begin{array}{lll}\text { Chapter } 7 & \text { Concluding remarks } & 93\end{array}$

Summary 111

Samenvatting $\quad 115$

Dankwoord 119

$\begin{array}{ll}\text { Curriculum vitae } & 123\end{array}$ 


CHAPTER 1 


\section{Multiple sclerosis}

Multiple sclerosis (MS) is a chronic inflammatory demyelinating disease of the central nervous system (CNS) and the most common neurological disorders affecting young adults [1]. It was the neurologist Jean-Martin Charcot (1825-1893) who first scientifically described, documented, and named the disease process which we still call MS [2]. Despite the bulk of research that has been done, the exact cause of MS remains unknown. The aetiology of MS is most likely multi-factorial and caused by a complex interaction of auto-immune, environmental, and multiple genetic factors [1]. Women are affected more often than men, with approximately three women to every man diagnosed. The global distribution of MS can be generalized as increasing with the distance north or south of the equator [1]. The disease affects 1 in 1000 persons in North European countries; while in (sub)tropical countries the prevalence is relatively low, affecting only 0,2 to 0,3 in 1000 people. Approximately 16000 people suffer from MS in the Netherlands (www.atlasofms.org).

$\mathrm{MS}$ is a disease in which the immune system attacks the myelin sheath surrounding the axons of neurons in the CNS. Inflammation of myelin is associated with the formation of hard plaques (sclerosis) in the CNS that disrupts neural transmission and results in the loss of many functions of the body. Plaques may appear anywhere in the CNS, but there is a predilection for the optic nerves, corpus callosum, spinal cord, brainstem and cerebellum [1]. Although MS is generally considered a disease of the white matter, more recent research has shown that areas of demyelination coexist with diffuse axonal and neuronal degeneration [3, 4].

$\mathrm{MS}$ is a disease with an unpredictable clinical course that can follow different patterns [1]. When the disease course is characterized by periods of relapses and remissions with either partial or absolute recovery, the disease is subtyped as relapsing remitting MS (RRMS). These periods of relapses and remissions are called exacerbations. In between the exacerbations the disease is stable. Approximately $80 \%$ of the patients are diagnosed with RRMS at onset of the disease. In around $65 \%$ of the cases this disease type evolves into a more progressive type called secondary progressive MS (SPMS). In SPMS a period of exacerbations is followed by a progression of symptoms. A minority of about $20 \%$ is diagnosed with primary progressive MS (PPMS), a disease type in which a constant progression in symptoms is noticeable since onset of the disease.

The individual prognosis of MS patients is difficult to predict, but there are several factors that indicate an unfavourable prognosis, such as: an initially progressive course; motor, cerebellar, and sphincter involvement at onset; a high number of early relapses; a short inter-relapse interval; and early residual disability [5]. Consistent with the variable disease course, also the clinical picture of MS is diverse, including both physical and neuropsychiatric symptoms. Frequent symptoms are visual problems (optic neuritis, diplopia, nystagmus), loss of function or feeling in limbs, difficulties with coordina- 
tion and balance (ataxia), problems with speech (dysarthria), as well as bowel and bladder dysfunction. Also cognitive impairment, mood disorder, sexual dysfunction, and fatigue are frequent in MS [6-8].

Although the availability of immunomodulatory and immunosuppressive drug treatment has ameliorated the perspective for a lot of MS patients, MS is still an incurable disease [9]. Besides pharmacological treatment focused on the pathophysiologic mechanisms of MS, multidisciplinary symptom management can also improve the quality of life of MS patients [7].

\section{Fatigue in MS}

Up to $92 \%$ of patients with MS complain of fatigue and characterize it as one of the most common and troubling problems [10]. Usually, fatigue presents itself as a chronic symptom, but it may also precede or accompany MS exacerbations [11]. Fatigue is frequently the first symptom of MS [12] and it is even reported as the only symptom of an acute relapse [13]. Fatigue can severely affect the ability to perform activities of daily life and is a major reason for unemployment. Therefore, fatigue is associated with excess disability and a poor quality of life [12, 14-19].

The following case reports illustrate the clinical aspects of fatigue and its impact on daily functioning in two MS patients.

\section{Case 1}

Ms. A. is a single 29-year old woman with a three-year history of relapsing-remitting MS. Her first and second exacerbations presented with visual symptoms, limb weakness, and severe fatigue. Besides some visual deficits due to an optic neuritis and mild feelings of fatigue after a whole working day, she recovered well and was able to work for six hours a day as a secretary at the university. For about five weeks, she has been experiencing a substantial increase of fatigue. Her energy level has deteriorated, she is sleeping a lot and she perceives great difficulties during mental activities, such as reading. Because she is concerned about having a new exacerbation, she consults her neurologist. He cannot discover any new neurological symptoms during neurological examination and also a new magnetic resonance imaging scan shows no changes. Despite the reassurance of the neurologist that the MS is under control, Ms. A. is very worried about her increasing fatigue and her cognitive complaints. Finally, the neurologist refers her to the department of medical psychology for clinical assessment and psychological support. 


\section{Case 2}

Mrs. B. is a married 43-year old woman who was diagnosed with primary progressive MS nine years ago. She is moderately disabled. Outside, she can only walk with the assistance of her husband, but at home she is mostly independent because of the unimpaired function of her upper limbs. At every half-year visit to her neurologist she utters complaints of fatigue. Since a few months, the fatigue has become markedly aggravated and it is not possible anymore for her to run her household on her own. She has to ask for assistance from her husband more often, and outside she now has to use her electrical wheelchair. Mrs. B. feels very embarrassed and irritated about the increase of her dependency. She has experienced a loss of appetite and has lost 6 pounds in weight in the last four months. Furthermore, she lacks interest, is slow in speech and has memory problems. Her husband describes her as always having been a very precise and nervous person, who is often distressed. He asks the neurologist for advice about handling his wife's increased fatigue.

Several questions that are important for clinical practice arise from these two cases:

- What is MS-related fatigue and is it related to psychological factors?

- Is cognitive functioning negatively affected by fatigue?

- How disease specific is fatigue in MS? Is fatigue associated with disease-related factors and is the contribution of disease severity and psychological factors in MS different from that in patients with a non-neurological chronic auto-immune disease?

- $\quad$ Are depression and negative affectivity risk factors for fatigue in MS?

- Does worrying about fatigue increase MS-related fatigue and physical disability?

These questions form the basis for the research described in this thesis.

\section{Aims, research questions, and outline of thesis}

Although fatigue is a common and troublesome symptom in MS, its pathogenesis is still poorly understood. Previous studies and reviews on its aetiology have largely focused on the biological underpinnings of fatigue in MS [11, 20-23], but until now the evidence for explanatory pathophysiological factors is at best conflicting. Effective pharmacological treatments for MS-related fatigue are hardly available so far. Alternatively, a psychological approach may be helpful in providing further explanations. Insight into the impact of psychological factors on fatigue in MS would be helpful in improving our overall understanding of MS-related fatigue. This in turn might be helpful when it comes to the development of interventions to treat those patients with this frequent and disabling symptom. 
The general aim of this thesis is to better understand the concept of MS-related fatigue from a psychological perspective. As such the focus is on identifying relevant psychological factors in explaining MS-related fatigue and their added value to biological factors such as disease severity and cerebral white matter lesions.

The results described in this thesis are based on a review of the recent literature and on the data of two samples. We will answer the following research questions:

1. What is MS-related fatigue and what is currently known about the contribution of psychological factors to fatigue in MS patients?

In Chapter 2, we will start with a critical review that focuses on whether psychological factors can help to explain MS-related fatigue. We will begin by defining fatigue in MS and discussing how it is measured. Next, conceptual issues and the relationships between MS-related fatigue and respectively mood, anxiety, cognition, personality, and cognitive behavioural factors will be discussed. Finally, the implications for clinical practice and research will be presented.

2. What is the impact of fatigue on subjective and objective cognitive functioning in MS patients?

In Chapter 3, we will investigate the contribution of fatigue to both cognitive complaints and cognitive performance in MS patients. Fatigue will be operationalized with the help of self-reported measures of both physical and mental fatigue. A relatively extensive neuropsychological assessment battery will be used which includes a number of tasks that require effortful information processing. We hypothesize that fatigue, together with anxiety and depression, contributes to cognitive complaints. Furthermore, we expect to discover that fatigue is related to cognitive performance in neuropsychological tests that require attention and executive functioning.

3. Is mental fatigue a primary symptom of MS and associated with disease-related factors?

In Chapter 4, we will focus on mental fatigue in MS and its disease specificity by comparing its levels and correlates with those of two control groups. The first group we will include is composed of healthy control participants. The second group is composed of patients with ulcerative colitis (UC), viz. an inflammatory bowel disease without known underlying cerebral pathology. Like MS, UC is a chronic, intermittent, and functionally disabling disease characterized by a lifetime risk of relapses and including this group will help us to control for non-specific aspects of chronic disease. Mental fatigue will be assessed as well subjectively as objectively. First of all, we will compare the levels of mental fatigue in the three groups of participants. Secondly, we will explore the associations between mental fatigue and disease severity in both of the patient samples. 
Finally, we will examine how mental fatigue is respectively associated to cerebral white matter lesion load measured by MRI (cWML) and to depressive complaints in all of the three groups. We expect to find that the levels of both subjective and objective assessment of mental fatigue are higher in MS patients than those in both control groups. Furthermore, we hypothesize that in the case of all participants depressive complaints are related to subjective assessment of mental fatigue, whereas both cWML and disease severity are related to objective assessment of mental fatigue.

4. How disease specific is MS-related fatigue? Is the contribution of disease severity, depression and negative affectivity different in MS patients from that in patients with a non-neurological chronic auto-immune disease?

In Chapter 5, we will again examine the specificity of fatigue to MS by comparing MS patients with UC patients, but we will now focus on the impact of disease severity, depression, and negative affectivity on both subjective physical and mental fatigue. First, we will compare the levels of fatigue in both patient groups. Next, we will explore the relative contribution of disease severity, depression, and negative affectivity, to fatigue in MS patients and compare this to their contribution in the case of UC patients. Besides overall relevance in both patient samples, we expect to find that both disease severity and depression contribute more to fatigue in MS patients than they do to fatigue in UC patients. We also expect to find that negative affectivity contributes less to fatigue levels in MS patients than to fatigue levels in UC patients.

5. Is MS-related fatigue a consequence of the disease severity or does the negative interpretation of fatigue perpetuate or aggravate the experience of fatigue?

In Chapter 6, we will investigate the role of catastrophic (mis)interpretations of fatigue on fatigue and physical disability in MS patients. We will compare a cognitive behavioural model with a traditional biomedical model by using structural equation modelling (SEM). The hypothesis based on the cognitive behavioural model is that patients who catastrophically interpret their fatigue also report more fatigue-related fear and avoidance behaviour, and hence are more physically disabled and depressed. In contrast, the biomedical model assigns a more prominent role to disease severity in the case of fatigue as well as depression. Hence, it considers catastrophizing about fatigue, and fatigue-related fear and avoidance behaviour, as consequences rather than as precursors of physical disability. By applying SEM, we will test whether structural relationships between substantively meaningful variables show a better fit with either of the theoretical models. In line with evidence in other populations, we expect to find that the overall test of the cognitive behavioural model will show a better fit than that of the traditional biomedical model. 
Finally, in Chapter 7 (Concluding remarks) the main findings will be summarized, discussed, and placed into perspective within the context of this thesis and the recent literature. We will discuss the methodological issues related to the studies and make recommendations for future research and clinical practice. 


\section{References}

1. Compston A, Coles A. Multiple sclerosis. Lancet 2008;372:1502-1517.

2. McDonald WI. The dynamics of multiple sclerosis. The Charcot Lecture. J Neurol 1993;240:28-36.

3. Peterson LK, Fujinami RS. Inflammation, demyelination, neurodegeneration and neuroprotection in the pathogenesis of multiple sclerosis. J Neuroimmunol 2007;184:37-44.

4. Pirko I, Lucchinetti CF, Sriram S, Bakshi R. Gray matter involvement in multiple sclerosis. Neurology 2007;68:634-642.

5. Bergamaschi R. Prognostic factors in multiple sclerosis. Int Rev Neurobiol 2007;79:423-447.

6. Feinstein A. The neuropsychiatry of multiple sclerosis. Can J Psychiatry 2004;49:157-163.

7. Krupp LB. Fatigue in Multiple Sclerosis. A Guide to Diagnosis and Management. New York: Demos Medical Publishing; 2004.

8. Schmidt EZ, Hofmann P, Niederwieser G, Kapfhammer HP, Bonelli RM. Sexuality in multiple sclerosis. J Neural Transm 2005;112:1201-1211.

9. Clerico M, Rivoiro C, Contessa G, Viglietti D, Durelli L. The therapy of multiple sclerosis with immunemodulating or immunosuppressive drug. A critical evaluation based upon evidence based parameters and published systematic reviews. Clin Neurol Neurosurg 2008;110:878-885 .

10. Branas P, Jordan R, Fry-Smith A, Burls A, Hyde C. Treatments for fatigue in multiple sclerosis: a rapid and systematic review. Health Technol Assess 2000;4:1-61.

11. Comi G, Leocani L, Rossi P, Colombo B. Physiopathology and treatment of fatigue in multiple sclerosis. J Neurol 2001;248:174-179.

12. Krupp LB, Alvarez LA, LaRocca NG, Scheinberg LC. Fatigue in multiple sclerosis. Arch Neurol 1988; 45:435437.

13. Flachenecker $\mathrm{P}$, Meissner $\mathrm{H}$. Fatigue in multiple sclerosis presenting as acute relapse: subjective and objective assessment. Mult Scler 2008;14:274-277.

14. Amato MP, Ponziani G, Rossi F, Liedl CL, Stefanile C, Rossi L. Quality of life in multiple sclerosis: the impact of depression, fatigue and disability. Mult Scler 2001;7:340-344.

15. Aronson KJ. Quality of life among persons with multiple sclerosis and their caregivers. Neurology 1997; 48:74-80.

16. Janardhan V, Bakshi R. Quality of life in patients with multiple sclerosis. The impact of fatigue and depression. J Neurol Sci 2002;205:51-58.

17. Ford H, Trigwell P, Johnson M. The nature of fatigue in multiple sclerosis. J Psychosom Res 1998; 45:3338.

18. Fisk JD, Pontefract A, Ritvo PG, Archibald CJ, Murray TJ. The impact of fatigue on patients with multiple sclerosis. Can J Neurol Sci 1994;21:9-14.

19. Schwartz CE, Coulthard-Morris L, Zeng Q. Psychosocial correlates of fatigue in multiple sclerosis. Arch Phys Med Rehab 1996;77:165-170.

20. Bakshi R. Fatigue associated with multiple sclerosis: diagnosis, impact and management. Mult Scler 2003;9:219-227.

21. Kos D, Kerckhofs E, Nagels G, D'Hooghe MB, Ilsbroukx S. Origin of fatigue in multiple sclerosis: review of the literature. Neurorehabil Neural Repair 2008;22:91-100.

22. Krupp LB, Christodoulou C. Fatigue in multiple sclerosis. Curr Neurol Neurosci Rep 2001;1:294-298.

23. Schwid SR, Covington M, Segal BM, Goodman AD. Fatigue in multiple sclerosis: current understanding and future directions. J Rehabil Res Dev 2002;39:211-224. 



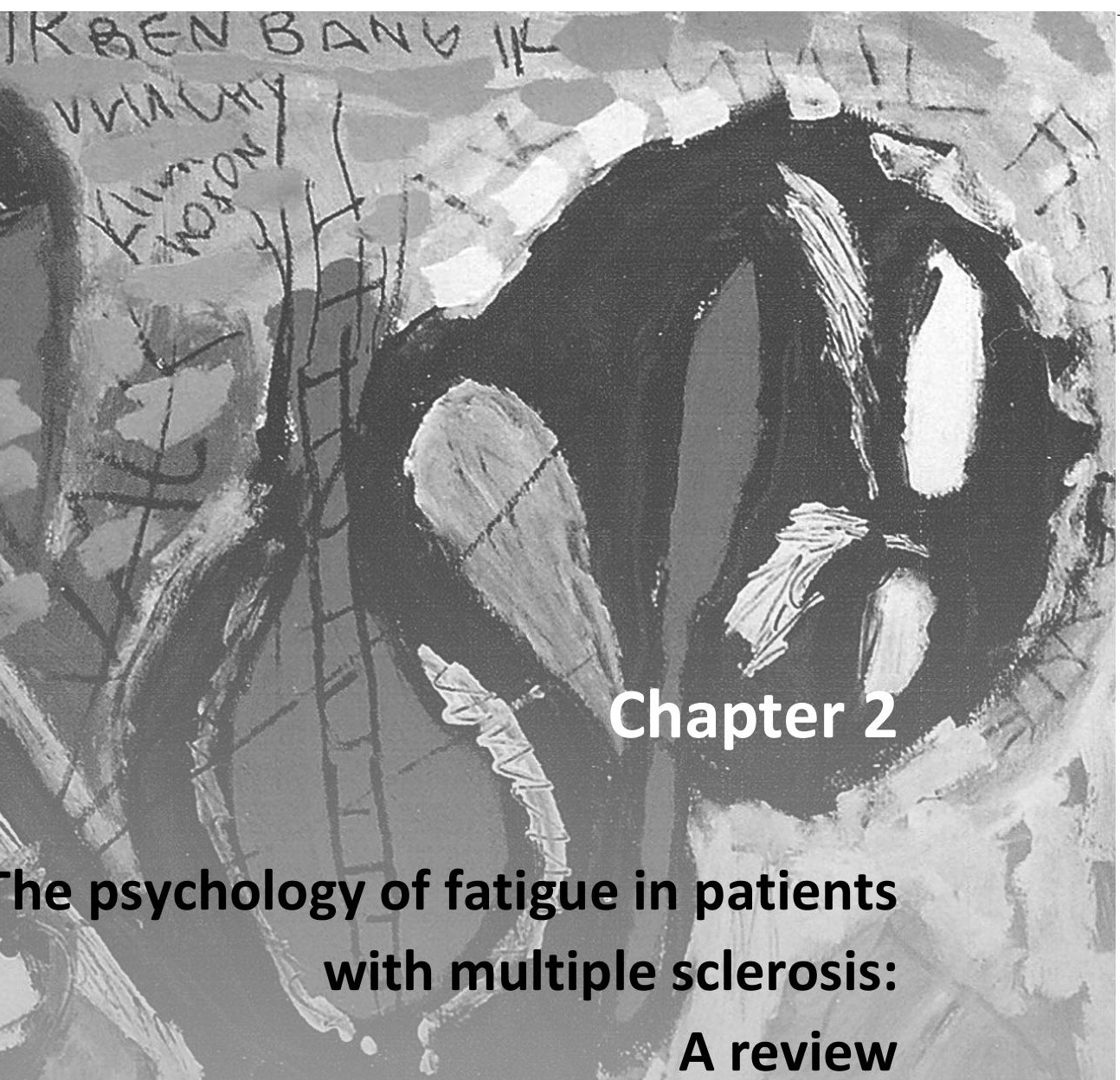

Y Bol, AA Duits, RMM Hupperts, JWS Vlaeyen \& FRJ Verhey

Published in Journal of Psychosomatic Research, 2009, 66 (1), 3-11. 


\begin{abstract}
Fatigue is a frequent and disabling symptom in patients with multiple sclerosis (MS), but it is difficult to define and measure. Today, MS-related fatigue is not fully understood and the evidence related to explanatory pathophysiological factors is conflicting. Here, we evaluate whether psychological factors can help to explain MS-related fatigue. Insight into the possible underlying psychological mechanisms might help us to develop adequate psychological interventions and to improve the overall management of fatigue. Conceptual issues and the relationships between MS-related fatigue and mood, anxiety, cognition, personality, and cognitive behavioural factors are discussed and the implications for clinical practice and research are presented.
\end{abstract}




\section{Introduction}

Multiple sclerosis (MS) is a chronic and unpredictable inflammatory demyelinating disease of the central nervous system (CNS), and it is one of the most common neurological disorders affecting young adults [1]. Consistent with variations in the distribution of pathological white matter lesions in the CNS, the clinical symptoms of MS are diverse and can include visual problems, loss of function or feeling in limbs, bowel and bladder incontinence, and loss of balance. In addition, non-focal neurological symptoms, such as cognitive and behavioural problems, are frequently reported [2]. Up to $92 \%$ of patients with MS complain of fatigue and characterize it as one of the most common and troubling problems [3]. Fatigue can severely affect the ability to perform activities of daily life and is a major reason for unemployment. Therefore, fatigue is related to disability and poor quality of life [4-10].

Although fatigue is a common and troublesome symptom, its pathogenesis is poorly understood. Studies on the aetiology of fatigue and reviews about this topic have largely focused on the biological factors [11-16]. If fatigue were directly related to the underlying pathophysiology of MS, and thus were a primary somatic manifestation of MS, then we would expect to see a significant relationship between fatigue and disease-related variables. A number of studies have investigated the relationship between fatigue and disease course, disease duration, and neurological impairment, yet no consensus has been reached [13]. Furthermore, several studies failed to establish an association between MS-related fatigue and typical magnetic resonance imaging (MRI) markers of the disease, such as $\mathrm{T}_{2}$ lesion load, gadolinium-enhancing lesion activity, and brain atrophy [17-21]. Other studies found significant but small relationships using functional neuroimaging techniques [22-26]. Because fatigue often occurs during disease exacerbations and is also reported to be a side effect of disease-modifying medication, such as interferon- $\beta$, a relationship with auto-immune dysregulation has been suggested [14, 27]. However, the results of studies concerning the relationship between MS-related fatigue and pathophysiological mechanisms, including auto-immune and neuroendocrine dysregulation, autonomic system dysfunction, and peripheral muscular mechanisms, are contradictory [28-33] (see Kos et al. [13] for a review of the biological mechanisms of MS-related fatigue).

While one might expect to find a biological explanation for MS-related fatigue, none of the proposed pathophysiological mechanisms can fully explain MS-related fatigue. In this critical review, our aim is to evaluate the contribution of psychological factors in explaining fatigue in MS. In line with findings related to other somatic symptoms [34-37], it is possible that fatigue in MS is determined by psychological factors such as mood, anxiety, and cognitive impairment, which also are common sequelae in MS [38-40]. Furthermore, because it is known that the patients' perception and interpretation of their illness and the way they behave are important predictors of disability 
[41], it follows that personality and cognitive behavioural factors could contribute to MS-related fatigue. Insight into the psychological correlates or mechanisms of fatigue might help us to develop adequate interventions and to improve its overall management.

We begin by defining fatigue in MS and discussing how it is measured. Next, we focus on conceptual issues including the relationships between MS-related fatigue and mood, anxiety, and cognitive impairment, and the impact of both personality and cognitive behavioural factors on MS-related fatigue. We conclude with remarks about the implications for clinical practice and future research.

\section{Search strategies}

In order to ensure that we presented a complete overview of the potential contribution of psychological factors to fatigue in MS, we identified relevant studies by searching on MEDLINE, Pubmed, PsycLIT, Cochrane databases, and by consulting references from relevant articles (until January 2008). The following searching terms were used: multiple sclerosis, fatigue, tiredness, depression, anxiety, fear, mood, cognition, cognitive, neuropsychological, psychological, personality, coping, neuroticism, emotional instability, negative affect(ivity), illness cognitions, beliefs, catastrophizing, cognitive behavio(u)ral, treatment.

\section{Definition and measurement of fatigue in MS}

In 1998, the Multiple Sclerosis Council for Clinical Practice Guidelines reached consensus on the following definition of fatigue in MS [42] "a subjective lack of physical and/or mental energy that is perceived by the individual or caregiver to interfere with usual and desired activities." This definition implies that fatigue is a subjective experience, based on a patient's self-report, and refers to the perception of exhaustion - physically, mentally, or both. The Multiple Sclerosis Council for Clinical Practice Guidelines further differentiated between acute (newly occurring in the past 6 weeks) and chronic (lasting longer than 6 weeks) fatigue.

Chaurdhuri and Behan [43] proposed a distinction based on physiology, differentiating between central and peripheral fatigue. Central fatigue, in contrast to neuromuscular or peripheral fatigue, represents a failure to complete physical and mental tasks that require self-motivation and internal cues in the absence of demonstrable cognitive failure or motor weakness. A feeling of constant exhaustion is a characteristic of central fatigue, which is typically seen in MS and might be related to lesions in pathways of arousal and attention, such as the reticular and limbic systems, and the basal ganglia 
[44]. However, there is no direct evidence that this mechanism is relevant. Therefore, the distinction between central and peripheral fatigue remains hypothetical, and the definition of fatigue as suggested by the Multiple Sclerosis Council for Clinical Practice Guidelines remains [42].

Although there are a wide variety of self-report measures for MS-related fatigue (see Christodoulou [45] for an overview), there remains no consensus about clinically relevant, reliable, and responsive outcome measures for fatigue in MS. Given the physical and mental aspects of MS-related fatigue, the measurement should be multidimensional. Questionnaires such as the Multidimensional Fatigue Inventory [46] and the Checklist of Individual Strength [47] have been specifically designed to assess multiple aspects of fatigue, including physical and mental fatigue.

Even though the definition of MS-related fatigue implies self-report, the most obvious problem with self-report questionnaires is their retrospective bias. Several attempts have been made to assess fatigue objectively in order to overcome this limitation [48]. Physical fatigue is measured objectively by quantifying reductions in force, rate, or persistence of motor responses over time or following exposure to some event. Worsening of performance on a mental task over time or after some defined cognitive effort could be used to quantify mental or cognitive fatigue, but there are few studies on this topic [49].

So far, there is only consensus on the definition of MS-related fatigue. In order to facilitate future research it is important to reach consensus on the method of assessment as well. MS-related fatigue has both physical and mental aspects that can be measured subjectively and objectively. Fatigue in MS, especially the mental aspects of it, is sometimes indistinguishable from feelings of depression, anxiety, or cognitive deficits. Therefore, the concept of fatigue needs to be further evaluated by exploring its possible relationship with depression and anxiety as well as with cognition.

\section{The relationship between fatigue and mood/anxiety in MS}

Depression is the most common psychiatric disorder in MS, and the estimated prevalence is high, ranging between $27 \%$ and $54 \%$ [39, 50-52]. The association between depression and MS is widely recognized, and it is not surprising to find depressive symptoms in people coping with a chronic and highly variable disease course and an uncertain prognosis [53]. Both psychological adjustment and pathophysiological mechanisms, including impaired mood-influencing biological systems, may underlie the frequency of depression in MS; however, the exact nature of this relationship is complex (see the reviews of Dalton and Heinrichs [53] and Siegert and Abernethy [54] for further depth and details of this topic). 
Because fatigue is a common symptom of depression [55], we would expect to see a relationship between fatigue and depression in MS. However, this overlap represents the first methodological problem affecting the validity of assessments for both depression and fatigue. Self-report measures often share the component of fatigue which might explain the significant relationship between fatigue and depression that has been found in several studies $[4,56,57]$. Therefore, it has been recommended that fatigue items be removed from the depression questionnaires $[58,59]$ or that instruments designed for patients with chronic illnesses - such as the Hospital Anxiety and Depression Scale [60], in which no items assessing somatic symptoms are included - be used for assessment. Using this so-called exclusive approach, a recent cross-sectional study [61] of $739 \mathrm{MS}$ patients reported that subjects with clinically significant depressive symptoms were much more likely to report disabling fatigue. The authors concluded that fatigue is highly sensitive and specific for clinically significant depressive symptoms, and they recommended screening for depression in MS patients who report disabling fatigue.

Most of the relevant studies have reported significant associations between depression and fatigue $[4,8-10,56,57,61-69]$, although most of these studies were crosssectional and there were great variations in the assessment methods used. Other studies have found no significant relationship [7, 47, 70-72], possibly due to small sample sizes $[7,71,72]$.

It is possible that sleep disturbances, also a symptom of depression, could account for the significant relationship between depression and fatigue. Sleep disturbances are common in patients with MS and are often related to the presence of fatigue and depression [73-76]. Although the prevalence of sleep complaints is three times higher in patients with MS than in healthy controls [73], the evidence for disturbed sleep-wake rhythms in these patients is contradictory $[77,78]$. In addition to depression, several other disease-related factors including pain and urinary symptoms, can influence the quality of sleep $[74,76]$. It is possible that sleep disturbances mediate the relationship between depression and fatigue, but there is also evidence that sleep disturbances and depression are independent contributors to fatigue [67]. Strober and Arnett [67] found that both sleep disturbances and depression, together with disease severity, accounted for $43 \%$ of the variance, with sleep disturbances being the largest contributor.

While anxiety is a common affective symptom and frequently accompanies depression in MS patients $[8,38,79-81]$, much less attention has been paid to its relationship with fatigue than to that of depression. In a recent study on mental and physical fatigue in MS [82], stress was an important correlate of mental fatigue only, while physical activity was an important correlate of physical fatigue, showing the importance of conceptualizing fatigue as multidimensional. However, in the study by Skerret and MossMorris [69], both depression and anxiety were significantly related to mental and physical fatigue. Other studies have found significant but modest associations between anxi- 
ety and MS-related fatigue $[8,70,81]$. Chwastiak et al. [61] did not find a relationship between fatigue and anxiety, but anxiety was assessed by asking a single question about the presence of an anxiety attack in the past month.

On the other hand, the association between both depression and anxiety with fatigue could be the result of the same underlying pathophysiological mechanism, such as the disruption of dopaminergic, histaminergic, and serotonergic pathways [83] and the dysfunction of the hypothalamic-pituitary-adrenal (HPA) axis [84]. Moreover, serotonin levels are influenced by the HPA axis, which in turn interacts with stress and fatigue [85]. In addition, the paradigm of cytokine-induced sickness behaviour provides an explanatory mechanism $[84,86]$. Proinflammatory cytokines that are produced in response to infection induce the development of common symptoms of sickness, such as loss of appetite, sleepiness, withdrawal from normal social activities, and fatigue. This syndrome is defined as sickness behaviour and is now recognized as a motivational system that reorganizes the organism's priorities to facilitate recovery from infection [86].

Finally, the use of disease-modifying medication, such as interferon- $\beta$, could put MS patients at a risk for an increase in depressed mood, especially those with a history of depression [87-89], and this might indirectly cause fatigue. Therefore, it is important to describe patients' characteristics in all studies that focus on fatigue and/or to specify inclusion criteria regarding medication use.

Unfortunately, the studies discussed here were cross-sectional and were not always based on an exclusive approach, which complicates interpretation and the drawing of conclusions. In addition, longitudinal and randomized controlled studies are needed to infer causality and, in particular, to gain insight into the direction of influence (i.e. whether depression causes fatigue or visa versa). To the best of our knowledge, there are no available intervention studies that have focused on reduction of fatigue and its effect on depression in patients with MS. As of now, there are only two available intervention studies that have focused on the treatment of depression in MS, and both suggest that fatigue is caused by depression. In the one that investigated the efficacy of group therapy for treating depression in patients with MS, fatigue levels in MS patients declined slightly, whereas fatigue levels of control patients increased during the trial [90]. In the other intervention study, patients received either cognitive behavioural or supportive group therapy or sertraline, a selective serotonin reuptake inhibitor [91]. While this was an uncontrolled study, its findings also suggest that treatment for depression is associated with reductions in the subjective severity of fatigue symptoms and that this relationship is due primarily to treatment-related changes in mood. In contrast, in their prospective study, Schreurs et al. [68] concluded that the presence of depression did not predict physical or mental fatigue after 1 year, nor was depression predicted by preceding fatigue experiences. 


\section{The relationship between fatigue and cognition in MS}

The methodological problem that occurs when studying the relationship between fatigue and depression also occurs when studying the relationship between fatigue and cognition. Both subjective and objective mental or cognitive fatigue share a component of cognition, either as cognitive performance [49] or cognitive complaints, such as problems with attention and concentration $[46,47]$. Therefore, when studying the relationship between mental fatigue and cognition in MS, construct validity is an area of concern.

Similar to depression, anxiety and fatigue, complaints of cognitive dysfunction are often reported by patients with MS [92], and $45 \%-65 \%$ of patients show measurable cognitive deficits $[93,94]$. All cognitive domains can be impaired, but impairment of mental speed, cognitive flexibility, sustained attention, and memory retrieval, is quite common in MS [95]. Although MS patients typically report that their cognitive functioning is negatively affected by fatigue [7], there is limited evidence for this relationship. Only two cross-sectional studies have focused on the relationship between fatigue and cognitive complaints in MS $[96,97]$ and their results suggest that fatigue, together with emotional complaints and neurological impairment, contributes to cognitive complaints. In addition, in other populations, noncognitive factors such as mood and anxiety are important correlates of cognitive complaints [98-105].

Furthermore, there is little evidence available regarding the impact of fatigue on cognitive performance based on neuropsychological assessments. Several studies did not find a relationship between subjective fatigue and cognitive performance [10, 106112]. In some studies, it is possible that no relationship was found because the neuropsychological assessment was reduced to a global screening battery with tasks that required minimal cognitive effort. Such screening batteries might not be appropriate for measuring how fatigue affects cognitive performance. In line with recent evidence in other populations [113-117], it is plausible that fatigue in MS is related to tasks that require sustained attention and executive control. Such tasks are often not assessed in MS patients because they are time consuming and can be enervating for this population. Alternatively, effortful information-processing tasks, such as reaction tests, might depend on fine motor and visual functions, which can also produce noise in the studies.

To overcome the limitations of self-report measures, several techniques have been developed to objectively measure mental fatigue, also referred to as cognitive fatigue [49]. Cognitive fatigue can be conceptualized as a decrease in performance over a prolonged period, such as a working day, but can also be viewed as decreased performance during acute but sustained mental effort.

Although several attempts have been made, no studies have shown that worsening cognitive functioning over time is a correlate of objective or mental fatigue in MS. In most of the studies [108, 110,118-120], a prolonged effort produced an increase in the 
subjective experience of MS-related fatigue but this increase was not related to a decline in cognitive performance. Jennekens-Schinkel et al. [109] examined reaction times before and after a 4-h neuropsychological evaluation in a group of MS patients and healthy controls. Although both reaction times and subjective fatigue increased in both groups, the magnitude of these changes did not differ between the groups. Other studies $[107,119,121]$ have detected cognitive fatigue in MS, defined as a decrease in performance on tasks for sustained attention. However, only one study [119] could distinguish between MS patients and healthy controls. Because of this lack of specificity and the problem of construct validity, the usefulness of objective measures of fatigue in clinical practice and research is dubious. Even if we can find measures that can sensitively detect objective mental in MS patients, the experience of fatigue must be the starting point in daily clinical practice.

\section{The impact of personality factors}

There is substantial evidence that the personality trait of negative affectivity plays an important role in the experience and manifestations of chronic illness [34, 37, 122]. Negative affectivity, also called neuroticism or emotional instability, is one of the Big Five personality traits and is defined as a stable disposition to experience psychological distress across time and situations [41]. Individuals who score high on questionnaires that assess negative affectivity are likely to interpret bodily sensations in terms of illness, also referred to as the symptom-perception theory [41].

There is some empirical evidence that increased levels of negative affectivity in healthy individuals, as well as in clinical populations (e.g. cancer), predispose to develop or maintain symptoms of fatigue [123-127]. Likewise, significant relationships between negative affectivity and fatigue have been found in patients with MS [128, 129].

Besides negative affectivity, relationships between fatigue and other Big Five personality traits, including (high) conscientiousness and (low) extraversion, have been documented [127, 128]. However, the scientific evidence supporting relationships between these traits and fatigue is less clear-cut than that for negative affectivity [127]. Moreover, most of these findings must be interpreted with caution due to the crosssectional design of the studies, their lack of control groups, and potential confounding by affective co-morbidity. Because depression and anxiety are very common in MS, it is likely that these symptoms significantly influence the outcome of personality assessments and in particular the level of negative affectivity [130]. Furthermore, MS, like all diseases of the CNS, may affect personality due to underlying pathophysiological changes in the frontal cerebral areas [131, 132]. 
In conclusion, although there is some evidence that personality is related to fatigue in patients with MS, numerous methodological issues preclude drawing definite conclusions at this time.

\section{A cognitive behavioural perspective}

As an extension of the symptom-perception theory [41], a cognitive behavioural model was recently proposed to explain fatigue and disability levels in patients with MS [69]. In the cognitive behavioural perspective on fatigue, emphasis is placed on illness cognitions, referring to the way patients think about and interpret their fatigue experience. From this perspective, the individuals' perception of what causes the symptoms, rather than the actual cause of the symptoms, determines their behaviour [69]. Although there is evidence that cognitive factors play a less significant role in physical and psychosocial functioning in MS than in CFS [133], others report similar illness cognitions and behaviour profiles for both groups of patients [134, 135]. In line with studies in other populations $[136,137]$, negative thoughts like helplessness and somatic attributions have also been found to contribute to both fatigue and disability levels in MS patients $[69,138,139]$. If fatigue is attributed to a physical illness, patients are more likely to focus on their fatigue and to interpret the consequences of fatigue in a negative way, such as a sign of physiological damage [69].

It is plausible that, as in the case of CFS and chronic pain [140-142], these negative illness cognitions in MS patients lead to inadequate responses to their fatigue. Although no causality has been proved, mental fatigue is strongly related to both avoidance resting behaviour and all-or-nothing behaviour [69]. This means that MS patients who respond to their symptoms by either engaging in excessive rest or avoidance of activity or who push themselves hard when feeling well and then crash, are more fatigued and disabled [69].

Although few randomized clinical trials (RCTs) have evaluated the effects of exercise and cognitive behavioural therapy on fatigue in MS, there is some evidence that physical exercise and behavioural therapy can reduce fatigue [143-146]. One recent RCT found that a multidisciplinary fatigue management program improved the impact of fatigue [147]. The MS patients received energy saving methods and strategies, psychosocial support, and physiotherapy during four sessions of $2 \mathrm{~h}$ each. Surprisingly, the intervention group did not differ from the placebo group that received general information about MS. It is possible that the physiotherapy was insufficiently intensive and its duration too short to elicit effects different from those resulting from regular daily exercise. Furthermore, it is interesting to note that the placebo intervention also influenced the perceived impact of fatigue and patients' self-efficacy [147]. Self-efficacy, the belief that one can effectively manage a challenging situation, is an important variable 
in coping with an unpredictable chronic disease and also seems related to fatigue in MS [82].

There is some evidence that exercise training and energy saving strategies reduce fatigue and increase self-efficacy $[145,146]$. In patients with MS, the feeling that that they have little control can induce negative cognitions, promoting higher levels of depression and fatigue. Additionally, exercise not only increases endurance and strength, but also improves sleep and reduces stress and depressive symptoms, thereby preventing a vicious circle $[82,144]$. These positive effects of exercise contradict the general advice given to MS patients to avoid exercise [148]. Such advice is detrimental because it can contribute to the persistence of fatigue.

In summary, there is increasing evidence that illness cognitions and behaviour play significant roles in how patients with MS adjust to fatigue. While it is legitimate for patients with an unpredictable and incurable disabling disease to worry about their health, those patients who are depressed and score high on negative affectivity are especially at risk for negative cognitions [135]. Future research should focus on discerning the cognitive behavioural mechanisms, and evaluating the efficacy of cognitivebehavioural therapy for MS-related fatigue.

\section{Implications for clinical practice and future research}

Chronic fatigue has long been recognized as a major problem for MS patients and has to be seen as a multidimensional experience that can be related to such symptoms as depression, anxiety, and cognitive impairment. Future longitudinal studies and RCTs in which fatigue is conceptualized and operationalized multidimensionally, are needed in order to clarify the causal relationships between mood, anxiety, cognition, and MSrelated fatigue. These studies should (a) use adequate sample sizes; (b) specify the inclusion criteria adequately; (c) control for cointerventions and comorbidities; and (d) use clinically relevant, reliable, and responsive fatigue assessment tools as outcome measures, preferably based on international consent. High-quality studies might help to prevent confusion and provide answers to the very complex problem of fatigue in MS.

MS-related fatigue is probably multifactorial and it is likely that the relative contribution of the different biological and psychological factors, varies in each MS patient who experiences fatigue. However, in clinical practice, MS patients are not helped by having their fatigue validated as an uncontrollable correlate of their disease. Psychological factors can contribute to fatigue reporting and play a role in its persistence. Patients and health care providers should be informed that the way patients perceive and cope with their fatigue could influence how they experience fatigue. Fatigued MS patients should be screened for depression and anxiety and, when present, these psychiatric co-morbidities should be treated. Neuropsychological assessment is recom- 
mended when fatigued MS patients experience cognitive complaints. Furthermore, negative fatigue-related thoughts should be detected and adjusted. Physical activity and exercise should be encouraged in general.

Because of the lack of an effective pharmacotherapy for MS-related fatigue [149, 150], future strategies for managing fatigue in MS patients should be extended to include psychological screening and treatment in addition to the regular medical therapy, occupational therapy, and physiotherapy. Future research integrating both biological and psychological mechanisms might answer the question of who is at risk for chronic fatigue and give rise to specific interventions that would help patients to achieve their goals in daily functioning. 


\section{References}

1. Compston A, Coles A. Multiple sclerosis. Lancet 2002;359:1221-1231.

2. Feinstein A. The clinical neuropsychiatry of multiple sclerosis. Cambridge: University Press; 1999.

3. Branas P, Jordan R, Fry-Smith A, Burls A, Hyde C. Treatments for fatigue in multiple sclerosis: a rapid and systematic review. Health Technol Assess 2000;4:1-61.

4. Amato MP, Ponziani G, Rossi F, Liedl CL, Stefanile C, Rossi L. Quality of life in multiple sclerosis: the impact of depression, fatigue and disability. Mult Scler 2001;7:340-344.

5. Aronson KJ. Quality of life among persons with multiple sclerosis and their caregivers. Neurology 1997;48:74-80.

6. Janardhan V, Bakshi R. Quality of life in patients with multiple sclerosis. The impact of fatigue and depression. J Neurol Sci 2002;205:51-58.

7. Krupp LB, Alvarez LA, LaRocca NG, Scheinberg LC. Fatigue in multiple sclerosis. Arch Neurol 1988;45:435437.

8. Ford H, Trigwell P, Johnson M. The nature of fatigue in multiple sclerosis. J Psychosom Res 1998;45:3338.

9. Fisk JD, Pontefract A, Ritvo PG, Archibald CJ, Murray TJ. The impact of fatigue on patients with multiple sclerosis. Can J Neurol Sci 1994;21:9-14.

10. Schwartz CE, Coulthard-Morris L, Zeng Q. Psychosocial correlates of fatigue in multiple sclerosis. Arch Phys Med Rehabil 1996;77:165-170.

11. Bakshi R. Fatigue associated with multiple sclerosis: diagnosis, impact and management. Mult Scler 2003;9:219-227.

12. Comi G, Leocani L, Rossi P, Colombo B. Physiopathology and treatment of fatigue in multiple sclerosis. J Neurol 2001;248:174-179.

13. Kos D, Kerckhofs E, Nagels G, D'Hooghe M B, Ilsbroukx S. Origin of fatigue in multiple sclerosis: review of the literature. Neurorehabil Neural Repair 2008;22:91-100.

14. Krupp LB. Fatigue in multiple sclerosis: definition, pathophysiology and treatment. CNS Drugs 2003;17:225-234.

15. Krupp LB, Christodoulou C. Fatigue in multiple sclerosis. Curr Neurol Neurosci Rep 2001;1:294-298.

16. Schwid SR, Covington M, Segal BM, Goodman AD. Fatigue in multiple sclerosis: current understanding and future directions. J Rehabil Res Dev 2002;39:211-224.

17. Codella M, Rocca MA, Colombo B, Martinelli-Boneschi F, Comi G, Filippi M. Cerebral grey matter pathology and fatigue in patients with multiple sclerosis: a preliminary study. J Neurol Sci 2002;194:71-74.

18. Codella M, Rocca MA, Colombo B, Rossi P, Comi G, Filippi M. A preliminary study of magnetization transfer and diffusion tensor MRI of multiple sclerosis patients with fatigue. J Neurol 2002;249:535-537.

19. Bakshi R, Miletich RS, Henschel K, Shaikh ZA, Janardhan V, Wasay M, Stengel LM, Ekes R, Kinkel PR. Fatigue in multiple sclerosis: cross-sectional correlation with brain MRI findings in 71 patients. Neurology 1999;53:1151-1153.

20. Mainero C, Faroni J, Gasperini C, Filippi M, Giugni E, Ciccarelli O, Rovaris M, Bastianello S, Comi G, Pozzilli C. Fatigue and magnetic resonance imaging activity in multiple sclerosis. J Neurol 1999;246:454-458.

21. Van der Werf SP, Jongen PJ, Lycklama a Nijeholt GJ, Barkhof F, Hommes OR, Bleijenberg G. Fatigue in multiple sclerosis: interrelations between fatigue complaints, cerebral MRI abnormalities and neurological disability. J Neurol Sci 1998;160:164-170.

22. Filippi M, Rocca MA, Colombo B, Falini A, Codella M, Scotti G, Comi G. Functional magnetic resonance imaging correlates of fatigue in multiple sclerosis. Neuroimage 2002;15:559-567.

23. Roelcke U, Kappos L, Lechner-Scott J, Brunnschweiler H, Huber S, Ammann W, Plohmann A, Dellas S, Maguire RP, Missimer J, Radu EW, Steck A, Leenders KL. Reduced glucose metabolism in the frontal cortex and basal ganglia of multiple sclerosis patients with fatigue: a 18F-fluorodeoxyglucose positron emission tomography study. Neurology 1997;48:1566-1571. 
24. Tartaglia MC, Narayanan S, Francis SJ, Santos AC, De Stefano N, Lapierre Y, Arnold DL. The relationship between diffuse axonal damage and fatigue in multiple sclerosis. Arch Neurol 2004;61:201-207.

25. Niepel G, Tench Ch R, Morgan PS, Evangelou N, Auer DP, Constantinescu CS. Deep gray matter and fatigue in MS: a T1 relaxation time study. J Neurol 2006;253:896-902.

26. Tellez N, Alonso J, Rio J, Tintore M, Nos C, Montalban X, Rovira A. The basal ganglia: a substrate for fatigue in multiple sclerosis. Neuroradiology 2008;50:17-23.

27. Greim B, Engel C, Apel A, Zettl UK. Fatigue in neuroimmunological diseases. J Neurol 2007;254:102-106.

28. Flachenecker P, Bihler I, Weber F, Gottschalk M, Toyka KV, Rieckmann P. Cytokine mRNA expression in patients with multiple sclerosis and fatigue. Mult Scler 2004;10:165-169.

29. Flachenecker P, Rufer A, Bihler I, Hippel C, Reiners K, Toyka KV, Kesselring J. Fatigue in MS is related to sympathetic vasomotor dysfunction. Neurology 2003;61:851-853.

30. Giovannoni G, Thompson AJ, Miller DH, Thompson EJ. Fatigue is not associated with raised inflammatory markers in multiple sclerosis. Neurology 2001;57:676-681.

31. Gottschalk M, Kumpfel T, Flachenecker P, Uhr M, Trenkwalder C, Holsboer F, Weber F. Fatigue and regulation of the hypothalamo-pituitary-adrenal axis in multiple sclerosis. Arch Neurol 2005;62:277-280.

32. Heesen C, Koehler G, Gross R, Tessmer W, Schulz KH, Gold SM. Altered cytokine responses to cognitive stress in multiple sclerosis patients with fatigue. Mult Scler 2005;11:51-57.

33. Heesen C, Nawrath L, Reich C, Bauer N, Schulz KH, Gold SM. Fatigue in multiple sclerosis: an example of cytokine mediated sickness behaviour? J Neurol Neurosurg Psychiatry 2006;77:34-39.

34. Comijs HC, Deeg DJ, Dik MG, Twisk JW, Jonker C. Memory complaints; the association with psychoaffective and health problems and the role of personality characteristics. A 6-year follow-up study. J Affect Disord 2002;72:157-165.

35. Costa PT, Jr. Influence of the normal personality dimension of neuroticism on chest pain symptoms and coronary artery disease. Am J Cardiol 1987;60:20J-26J.

36. Costa PT, Jr., Krantz DS, Blumenthal JA, Furberg CD, Rosenman RH, Shekelle RB. Psychological risk factors in coronary artery disease. Circulation 1987;76:I145-149.

37. Tanum L, Malt UF. Personality and physical symptoms in nonpsychiatric patients with functional gastrointestinal disorder. J Psychosom Res 2001;50:139-146.

38. Korostil M, Feinstein A. Anxiety disorders and their clinical correlates in multiple sclerosis patients. Mult Scler 2007;13:67-72.

39. Minden SL, Schiffer RB. Affective disorders in multiple sclerosis. Review and recommendations for clinical research. Arch Neurol 1990;47:98-104.

40. Rao SM. Neuropsychology of multiple sclerosis: a critical review. J Clin Exp Neuropsychol 1986;8:503-542.

41. Watson D, Pennebaker JW. Health complaints, stress, and distress: exploring the central role of negative affectivity. Psychol Rev 1989;96:234-254.

42. Multiple Sclerosis Council of Clinical Practice Guidelines. Fatigue and multiple sclerosis: evidence-based management strategies for fatigue in multiple sclerosis. Washington D.C.: Paralyzed Veterans of America; 1998.

43. Chaudhuri A, Behan PO. Fatigue and basal ganglia. J Neurol Sci 2000;179:34-42.

44. Chaudhuri A, Behan PO. Fatigue in neurological disorders. Lancet 2004;363:978-988.

45. Christodoulou C. The assessment and measurement of fatigue. In: DeLuca J. (eds): Fatigue as a window to the brain. Cambridge: The MIT press; 2005, p.19-35.

46. Smets EM, Garssen B, Bonke B, De Haes JC. The Multidimensional Fatigue Inventory (MFI); Psychometric qualities of an instrument to assess fatigue. J Psychosom Res 1995;39:315-325.

47. Vercoulen JH, Hommes OR, Swanink CM, Jongen PJ, Fennis JF, Galama JM, Van der Meer JW, Bleijenberg G. The measurement of fatigue in patients with multiple sclerosis. A multidimensional comparison with patients with chronic fatigue syndrome and healthy subjects. Arch Neurol 1996;53:642-649.

48. Beatty WW, Goretti B, Siracusa G, Zipoli V, Portaccio E, Amato MP. Changes in neuropsychological test performance over the workday in multiple sclerosis. Clin Neuropsychol 2003;17:551-560. 
49. DeLuca J. Fatigue, cognition and mental effort. In: Deluca J. (eds): Fatigue as a window to the brain. Cambridge: The MIT press; 2005, p.37-57.

50. Minden SL, Orav J, Reich P. Depression in multiple sclerosis. Gen Hosp Psychiatry 1987;9:426-434.

51. Sadovnick AD, Remick RA, Allen J, Swartz E, Yee IM, Eisen K, Farquhar R, Hashimoto SA, Hooge J, Kastrukoff LF, Morrison W, Nelson J, Oger J, Paty DW. Depression and multiple sclerosis. Neurology 1996;46:628-632.

52. Schiffer RB, Caine ED, Bamford KA, Levy S. Depressive episodes in patients with multiple sclerosis. Am J Psychiatry 1983;140:1498-1500.

53. Dalton EJ, Heinrichs RW. Depression in multiple sclerosis: a quantitative review of the evidence. Neuropsychology 2005;19:152-158.

54. Siegert RJ, Abernethy DA. Depression in multiple sclerosis: a review. J Neurol Neurosurg Psychiatry 2005;76:469-475.

55. American Psychiatric Association. Diagnostic and Statistical Manual of Mental Disorders - Fourth Edition (DSM-IV) - Text Revision. Washington D.C.: American Psychiatric Association; 2001.

56. Flachenecker P, Kumpfel T, Kallmann B, Gottschalk M, Grauer O, Rieckmann P, Trenkwalder C, Toyka KV. Fatigue in multiple sclerosis: a comparison of different rating scales and correlation to clinical parameters. Mult Scler 2002;8:523-526.

57. Pittion-Vouyovitch S, Debouverie M, Guillemin F, Vandenberghe N, Anxionnat R, Vespignani H. Fatigue in multiple sclerosis is related to disability, depression and quality of life. J Neurol Sci 2006;243:39-45.

58. Benedict RH, Fishman I, McClellan MM, Bakshi R, Weinstock-Guttman B, Munschauer F, Linn R, Miller C, Murphy E, Foley F, Jacobs L. Validity of the Beck Depression Inventory-Fast Screen in multiple sclerosis. Mult Scler 2003;9:393-396.

59. Mohr DC, Goodkin DE, Likosky W, Beutler L, Gatto N, Langan MK. Identification of Beck Depression Inventory items related to multiple sclerosis. J Behav Med 1997;20:407-414.

60. Zigmond AS, Snaith RP. The hospital anxiety and depression scale. Acta Psychiatr Scand 1983;67:361-370.

61. Chwastiak LA, Gibbons LE, Ehde DM, Sullivan M, Bowen JD, Bombardier CH, Kraft GH. Fatigue and psychiatric illness in a large community sample of persons with multiple sclerosis. J Psychosom Res 2005;59:291-298.

62. Fisk JD, Ritvo PG, Ross L, Haase DA, Marrie TJ, Schlech WF. Measuring the functional impact of fatigue: initial validation of the fatigue impact scale. Clin Infect Dis 1994;18:S79-83.

63. Kroencke DC, Lynch SG, Denney DR. Fatigue in multiple sclerosis: relationship to depression, disability, and disease pattern. Mult Scler 2000;6:131-136.

64. Bakshi R, Shaikh ZA, Miletich RS, Czarnecki D, Dmochowski J, Henschel K, Janardhan V, Dubey N, Kinkel PR. Fatigue in multiple sclerosis and its relationship to depression and neurologic disability. Mult Scler 2000;6:181-185.

65. Bakshi R, Czarnecki D, Shaikh ZA, Priore RL, Janardhan V, Kaliszky Z, Kinkel PR. Brain MRI lesions and atrophy are related to depression in multiple sclerosis. Neuroreport 2000;11:1153-1158.

66. Voss WD, Arnett PA, Higginson Cl, Randolph JJ, Campos MD, Dyck DG. Contributing factors to depressed mood in Multiple Sclerosis. Arch Clin Neuropsychol 2002;17:103-115.

67. Strober LB, Arnett PA. An examination of four models predicting fatigue in multiple sclerosis. Arch Clin Neuropsychol 2005;20:631-646.

68. Schreurs KM, de Ridder DT, Bensing JM. Fatigue in multiple sclerosis: reciprocal relationships with physical disabilities and depression. J Psychosom Res 2002;53:775-781.

69. Skerrett TN, Moss-Morris R. Fatigue and social impairment in multiple sclerosis: The role of patients' cognitive and behavioral responses to their symptoms. J Psychosom Res 2006;61:587-593.

70. Iriarte J, Subira ML, Castro P. Modalities of fatigue in multiple sclerosis: correlation with clinical and biological factors. Mult Scler 2000;6:124-130.

71. Moller A, Wiedemann G, Rohde U, Backmund H, Sonntag A. Correlates of cognitive impairment and depressive mood disorder in multiple sclerosis. Acta Psychiatr Scand 1994;89:117-121. 
72. Krupp LB, LaRocca NG, Muir-Nash J, Steinberg AD. The fatigue severity scale. Application to patients with multiple sclerosis and systemic lupus erythematosus. Arch Neurol 1989;46:1121-1123.

73. Clark CM, Fleming JA, Li D, Oger J, Klonoff H, Paty D. Sleep disturbance, depression, and lesion site in patients with multiple sclerosis. Arch Neurol 1992;49:641-643.

74. Fleming WE, Pollak CP. Sleep disorders in multiple sclerosis. Semin Neurol 2005;25:64-68.

75. Lobentanz IS, Asenbaum S, Vass K, Sauter C, Klosch G, Kollegger H, Kristoferitsch W, Zeitlhofer J. Factors influencing quality of life in multiple sclerosis patients: disability, depressive mood, fatigue and sleep quality. Acta Neurol Scand 2004;110:6-13.

76. Stanton BR, Barnes F, Silber E. Sleep and fatigue in multiple sclerosis. Mult Scler 2006;12:481-486.

77. Attarian HP, Brown KM, Duntley SP, Carter JD, Cross AH. The relationship of sleep disturbances and fatigue in multiple sclerosis. Arch Neurol 2004;61:525-528.

78. Taphoorn MJ, van Someren E, Snoek FJ, Strijers RL, Swaab DF, Visscher F, de Waal LP, Polman CH. Fatigue, sleep disturbances and circadian rhythm in multiple sclerosis. J Neurol 1993;240:446-448.

79. Janssens AC, van Doorn PA, de Boer JB, Kalkers NF, van der Meche FG, Passchier J, Hintzen RQ. Anxiety and depression influence the relation between disability status and quality of life in multiple sclerosis. Mult Scler 2003;9:397-403.

80. Zorzon M, de Masi R, Nasuelli D, Ukmar M, Mucelli RP, Cazzato G, Bratina A, Zivadinov R. Depression and anxiety in multiple sclerosis. A clinical and MRI study in 95 subjects. J Neurol 2001;248:416-421.

81. Feinstein A, O'Connor P, Gray $\mathrm{T}$, Feinstein $\mathrm{K}$. The effects of anxiety on psychiatric morbidity in patients with multiple sclerosis. Mult Scler 1999;5:323-326.

82. Trojan D, Arnold D, Collet JP, Shapiro S, Bar-Or A, Robinson A, Le Cruguel JP, Ducruet T, Narayanan S, Arcelin K, Wong A, Tartaglia M, Lapierre Y, Caramanos Z, Da Costa D. Fatigue in multiple sclerosis: association with disease-related, behavioural and psychosocial factors. Mult Scler 2007;13:985-995.

83. MacAllister WS, Krupp LB. Multiple sclerosis-related fatigue. Phys Med Rehabil Clin N Am 2005;16:483502.

84. Fassbender K, Schmidt R, Mossner R, Kischka U, Kuhnen J, Schwartz A, Hennerici M. Mood disorders and dysfunction of the hypothalamic-pituitary-adrenal axis in multiple sclerosis: association with cerebral inflammation. Arch Neurol 1998;55:66-72.

85. Hanley NR, Van de Kar LD. Serotonin and the neuroendocrine regulation of the hypothalamic-pituitaryadrenal axis in health and disease. Vitam Horm 2003;66:189-255.

86. Dantzer R, Kelley KW. Twenty years of research on cytokine-induced sickness behavior. Brain Behav Immun 2007;21:153-160.

87. Arnett PA, Randolph JJ. Longitudinal course of depression symptoms in multiple sclerosis. J Neurol Neurosurg Psychiatry 2006;77:606-610.

88. Gallagher AM, Coldrick AR, Hedge B, Weir WR, White PD. Is the chronic fatigue syndrome an exercise phobia? A case control study. J Psychosom Res 2005;58:367-373.

89. Goeb JL, Even C, Nicolas G, Gohier B, Dubas F, Garre JB. Psychiatric side effects of interferon-beta in multiple sclerosis. Eur Psychiatry 2006;21:186-193.

90. Crawford JD, Mclvor GP. Stress management for multiple sclerosis patients. Psychol Rep 1987;61:423429.

91. Mohr DC, Hart SL, Goldberg A. Effects of treatment for depression on fatigue in multiple sclerosis. Psychosom Med 2003;65:542-547.

92. Brassington JC, Marsh NV. Neuropsychological aspects of multiple sclerosis. Neuropsychol Rev 1998;8:4377.

93. DeSousa EA, Albert RH, Kalman B. Cognitive impairments in multiple sclerosis: a review. Am J Alzheimers Dis Other Demen 2002;17:23-29.

94. Bagert B, Camplair P, Bourdette D. Cognitive dysfunction in multiple sclerosis: natural history, pathophysiology and management. CNS Drugs 2002;16:445-455.

95. Zakzanis KK. Distinct neurocognitive profiles in multiple sclerosis subtypes. Arch Clin Neuropsychol 2000;15 115-136. 
96. Marrie RA, Chelune GJ, Miller DM, Cohen JA, Fisher E, Lee JC, Rudick RA. Subjective cognitive complaints relate to mild impairment of cognition in multiple sclerosis. Mult Scler 2005;11:69-75.

97. Middleton LS, Denney DR, Lynch SG, Parmenter B. The relationship between perceived and objective cognitive functioning in multiple sclerosis. Arch Clin Neuropsychol 2006;21:487-494.

98. Vingerhoets $G$, de Soete $G$, Jannes $C$. Subjective complaints versus neuropsychological test performance after cardiopulmonary bypass. J Psychosom Res 1995;39:843-853.

99. Vermeulen J, Aldenkamp AP, Alpherts WC. Memory complaints in epilepsy: correlations with cognitive performance and neuroticism. Epilepsy Res 1993;15:157-170.

100. Sawrie SM, Martin RC, Kuzniecky R, Faught E, Morawetz R, Jamil F, Viikinsalo M, Gilliam F. Subjective versus objective memory change after temporal lobe epilepsy surgery. Neurology 1999;53:1511-1517.

101. Suhr JA. Neuropsychological impairment in fibromyalgia: relation to depression, fatigue, and pain. J Psychosom Res 2003;55:321-329.

102. Roth RS, Geisser ME, Theisen-Goodvich M, Dixon PJ. Cognitive complaints are associated with depression, fatigue, female sex, and pain catastrophizing in patients with chronic pain. Arch Phys Med Rehabil 2005;86:1147-1154.

103. Stulemeijer M, Vos PE, Bleijenberg G, van der Werf SP. Cognitive complaints after mild traumatic brain injury: Things are not always what they seem. J Psychosom Res 2007;63:637-645.

104. Duits A, Munnecom T, van Heugten C, van Oostenbrugge RJ. Cognitive complaints in the early phase after stroke are not indicative of cognitive impairment. J Neurol Neurosurg Psychiatry 2008;79:143-146.

105. Woods SP, Carey CL, Moran LM, Dawson MS, Letendre SL, Grant I. Frequency and predictors of selfreported prospective memory complaints in individuals infected with HIV. Arch Clin Neuropsychol 2007;22:187-195.

106. Bailey A, Channon S, Beaumont JG. The relationship between subjective fatigue and cognitive fatigue in advanced multiple sclerosis. Mult Scler 2007;13:73-80.

107. Kos D, Kerckhofs E, Nagels G, Geentjens L. Cognitive fatigue in multiple sclerosis: comment on Schwid SR, Tyler CM, Scheid EA, Weinstein A, Goodman AD and McDermott MR. Mult Scler 2004;10:337; author reply 338.

108. Krupp LB, Elkins LE. Fatigue and declines in cognitive functioning in multiple sclerosis. Neurology 2000;55:934-939.

109. Jennekens-Schinkel A, Sanders EA, Lanser JB, Van der Velde EA. Reaction time in ambulant multiple sclerosis patients. Part I. Influence of prolonged cognitive effort. J Neurol Sci 1988;85:173-186.

110. Johnson SK, Lange G, DeLuca J, Korn LR, Natelson BH. The effects of fatigue on neuropsychological performance in patients with chronic fatigue syndrome, multiple sclerosis, and depression. Appl Neuropsychol 1997;4:145-153.

111. Parmenter BA, Denney DR, Lynch SG. The cognitive performance of patients with multiple sclerosis during periods of high and low fatigue. Mult Scler 2003;9:111-118.

112. Paul RH, Beatty WW, Schneider R, Blanco CR, Hames KA. Cognitive and physical fatigue in multiple sclerosis: relations between self-report and objective performance. Appl Neuropsychol 1998;5:143-148.

113. Boksem MA, Meijman TF, Lorist MM. Effects of mental fatigue on attention: An ERP study. Brain Res Cogn Brain Res 2005;25:107-116.

114. Capuron L, Welberg L, Heim C, Wagner D, Solomon L, Papanicolaou DA, Craddock RC, Miller AH, Reeves WC. Cognitive dysfunction relates to subjective report of mental fatigue in patients with chronic fatigue syndrome. Neuropsychopharmacology 2006;31:1777-1784.

115. Cook DB, O'Connor PJ, Lange G, Steffener J. Functional neuroimaging correlates of mental fatigue induced by cognition among chronic fatigue syndrome patients and controls. Neuroimage 2007;36:108122.

116. Petrilli RM, Roach GD, Dawson D, Lamond N. The sleep, subjective fatigue, and sustained attention of commercial airline pilots during an international pattern. Chronobiol Int 2006;23:1357-1362.

117. Van der Linden D, Frese M, Meijman TF. Mental fatigue and the control of cognitive processes: effects on perseveration and planning. Acta Psychol 2003;113:45-65. 
118. Bryant B, Chiaravalloti ND, DeLuca J. Objective Measurement of Cognitive Fatigue in Multiple Sclerosis. Rehab Psychol 2004;49:114-122.

119. Kujala P, Portin R, Revonsuo A, Ruutiainen J. Attention related performance in two cognitively different subgroups of patients with multiple sclerosis. J Neurol Neurosurg Psychiatry 1995;59:77-82.

120. Paul RH, Beatty WW, Schneider R, Blanco C, Hames K. Impairments of attention in individuals with multiple sclerosis. Mult Scler 1998;4:433-439.

121. Schwid SR, Tyler CM, Scheid EA, Weinstein A, Goodman AD, McDermott MP. Cognitive fatigue during a test requiring sustained attention: a pilot study. Mult Scler 2003;9:503-508.

122. Costa PT, Jr., McCrae RR. Somatic complaints in males as a function of age and neuroticism: a longitudinal analysis. J Behav Med 1980;3:245-257.

123. Buckley L, MacHale SM, Cavanagh JT, Sharpe M, Deary IJ, Lawrie SM. Personality dimensions in chronic fatigue syndrome and depression. J Psychosom Res 1999;46:395-400.

124. Johnson SK, DeLuca J, Natelson BH. Personality dimensions in the chronic fatigue syndrome: a comparison with multiple sclerosis and depression. J Psychiatr Res 1996;30:9-20.

125. Magnusson AE, Nias DK, White PD. Is perfectionism associated with fatigue? J Psychosom Res 1996;41:377-383.

126. Pepper CM, Krupp LB, Friedberg F, Doscher C, Coyle PK. A comparison of neuropsychiatric characteristics in chronic fatigue syndrome, multiple sclerosis, and major depression. J Neuropsychiatry Clin Neurosci 1993;5:200-205.

127. Van Geelen SM, Sinnema G, Hermans HJ, Kuis W. Personality and chronic fatigue syndrome: Methodological and conceptual issues. Clin Psychol Rev 2007;27:885-903.

128. Merkelbach S, Konig J, Sittinger H. Personality traits in multiple sclerosis (MS) patients with and without fatigue experience. Acta Neurol Scand 2003;107:195-201.

129. De Ridder D, Fournier M, Bensing J. Does optimism affect symptom report in chronic disease?; What are its consequences for self-care behaviour and physical functioning? J Psychosom Res 2004;56:341-350.

130. Griens AM, Jonker K, Spinhoven P, Blom MB. The influence of depressive state features on trait measurement. J Affect Disord 2002;70:95-99.

131. Benedict RH, Priore RL, Miller C, Munschauer F, Jacobs L. Personality disorder in multiple sclerosis correlates with cognitive impairment. J Neuropsychiatry Clin Neurosci 2001;13:70-76.

132. Benedict RH, Carone DA, Bakshi R. Correlating brain atrophy with cognitive dysfunction, mood disturbances, and personality disorder in multiple sclerosis. J Neuroimaging 2004;14:36S-45S.

133. Taillefer SS, Kirmayer L, Robbins JM, Lasry JC. Psychological correlates of functional status in chronic fatigue syndrome. J Psychosom Res 2002;53:1097-1106.

134. Trigwell $P$, Hatcher $S$, Johnson $M$, Stanley $P$, House A. "Abnormal" illness behaviour in chronic fatigue syndrome and multiple sclerosis. BMJ 1995;311:15-18.

135. Taillefer SS, Kirmayer $\amalg$, Robbins JM, Lasry JC. Correlates of illness worry in chronic fatigue syndrome. J Psychosom Res 2003;54:331-337.

136. Jacobsen PB, Andrykowski MA, Thors CL, Broeckel JA, Horton J, Balducci L, Lyman GH. Relationship of catastrophizing to fatigue among women receiving treatment for breast cancer. J Consult Clin Psychol 2004;72:355-361.

137. Andrea H, Beurskens AJ, Kant I, Davey GC, Field AP, van Schayck CP. The relation between pathological worrying and fatigue in a working population. J Psychosom Res 2004;57:399-407.

138. Jopson NM, Moss-Morris R. The role of illness severity and illness representations in adjusting to multiple sclerosis. J Psychosom Res 2003;54:503-511.

139. Van der Werf SP, Evers A, Jongen PJ, Bleijenberg G. The role of helplessness as mediator between neurological disability, emotional instability, experienced fatigue and depression in patients with multiple sclerosis. Mult Scler 2003;9:89-94.

140. Vlaeyen JWS, Linton SJ. Fear-avoidance and its consequences in chronic musculoskeletal pain: A state of the art. Pain 2000;85:317-332. 
141. Nijs J, De Meirleir K, Duquet W. Kinesiophobia in chronic fatigue syndrome: assessment and associations with disability. Arch Phys Med Rehabil 2004;85:1586-1592.

142. Silver A, Haeney M, Vijayadurai P, Wilks D, Pattrick M, Main CJ. The role of fear of physical movement and activity in chronic fatigue syndrome. J Psychosom Res 2002;52:485-493.

143. Di Fabio RP, Soderberg J, Choi T, Hansen CR, Schapiro RT. Extended outpatient rehabilitation: its influence on symptom frequency, fatigue, and functional status for persons with progressive multiple sclerosis. Arch Phys Med Rehabil 1998;79:141-146.

144. Petajan JH, Gappmaier E, White AT, Spencer MK, Mino L, Hicks RW. Impact of aerobic training on fitness and quality of life in multiple sclerosis. Ann Neurol 1996;39:432-441.

145. Mathiowetz VG, Finlayson ML, Matuska KM, Chen HY, Luo P. Randomized controlled trial of an energy conservation course for persons with multiple sclerosis. Mult Scler 2005;11:592-601.

146. Mostert S, Kesselring J. Effects of a short-term exercise training program on aerobic fitness, fatigue, health perception and activity level of subjects with multiple sclerosis. Mult Scler 2002;8:161-168.

147. Kos D, Duportail M, D’Hooghe M, Nagels G, Kerckhofs E. Multidisciplinary fatigue management programme in multiple sclerosis: a randomized clinical trial. Mult Scler 2007;13:996-1003.

148. Petajan JH, White AT. Recommendations for physical activity in patients with multiple sclerosis. Sports Med 1999;27:179-191.

149. Pucci E, Branas P, D'Amico R, Giuliani G, Solari A, Taus C. Amantadine for fatigue in multiple sclerosis. Cochrane Database Syst Rev 2007;1:CD002818.

150. Solari A, Uitdehaag B, Giuliani G, Pucci E, Taus C. Aminopyridines for symptomatic treatment in multiple sclerosis. Cochrane Database Syst Rev 2003;2:CD001330. 




\section{Abstract}

Objective: To study the impact of physical and mental fatigue on cognitive complaints and cognitive performance in patients with multiple sclerosis (MS).

Design: Cross-sectional study.

Setting: An outpatient neurology clinic.

Subjects: Eighty patients diagnosed with clinically definite MS.

Measures: The subscales physical and mental fatigue of the Multidimensional Fatigue Inventory; the Hospital Anxiety and Depression Scale and the Cognitive Failure Questionnaire. Cognitive performance was assessed by an extensive neuropsychological test battery that included several tasks that required effortful information processing.

Results: Both anxiety and depression and mental fatigue contributed to cognitive complaints, explaining respectively about $9 \%$ and $39 \%$ of the total variance. The contribution of physical fatigue to cognitive complaints was not significant. Both physical and mental fatigue did not significantly contribute to cognitive performance in terms of mental speed, attention, memory and executive functioning.

Conclusions: To refine interventions for those patients with cognitive complaints, we advise adding measurements of anxiety, depression and fatigue to neuropsychological assessment. Fatigue permits extensive neuropsychological assessment, which is needed to detect cognitive impairment in MS patients. 


\section{Introduction}

Multiple sclerosis (MS) is a chronic inflammatory demyelinating disease of the central nervous system (CNS) with an unknown pathogenesis and an unpredictable course [1]. $\mathrm{MS}$ is one of the most common neurological disorders affecting young adults and the clinical picture is diverse, including physical and neuropsychiatric symptoms [2]. Both fatigue and cognitive dysfunction are very common and interfere with the overall quality of life in patients with MS [3-5]. Up to $92 \%$ of patients with MS complain of fatigue and characterize it as one of the most common and troubling problems [4]. While many MS patients report cognitive problems, $45 \%$ to $65 \%$ of patients show measurable cognitive deficits [5], especially impairment of mental speed, cognitive flexibility, sustained attention, and memory retrieval [6]. MS patients frequently report that their cognitive functioning is negatively affected by the experience of fatigue [7-9]. Only two studies have examined the relationship between fatigue and subjective cognitive functioning or cognitive complaints in MS $[10,11]$. Their results showed that fatigue, together with emotional complaints and neurological disability, contributed to cognitive complaints.

More is known about the relationship between fatigue and objective cognitive functioning or cognitive performance, based on neuropsychological assessments. Generally, there is a lack of a relationship between fatigue and cognitive performance in MS [12]. For instance, the level of fatigue in MS is not related to working memory, verbal and non-verbal memory, verbal fluency, executive functioning and attention [8, 9, 1319]. However, these studies do have serious drawbacks, such as small sample sizes that vary from 15 to 45 [8, 13-18], and the use of brief neuropsychological test batteries that require relatively little cognitive effort, such as the Brief Repeatable Battery of Neuropsychological Tests (BRBN) $[9,19]$. The BRBN $[19]$ is the most widely used instrument to assess cognitive functioning in MS patients and includes several short and sensitive tests to detect cognitive impairment in MS. However, such a screening battery might not be appropriate for measuring the effect of fatigue on cognitive performance. Given the evidence in other populations [20-23], a relationship between fatigue and cognitive performance is expected to be based on the rate of effort needed. To expect significance, effortful test such as those for sustained attention and executive control should be included. Such tasks (e.g. the California Verbal Learning Task, the Wisconsin Card Sorting Test and vigilance tasks) are often excluded when testing MS patients because these are time-consuming and supposed to be too enervating for this population [24]. Sustained attention or vigilance is most often assessed with the Paced Auditory Serial Addition Test (PASAT) [25], which is a sensitive cognitive test that takes only a few minutes to administer. However, the PASAT is also a non-specific test that measures information-processing speed, working memory and sustained attention. Performance could easily be negatively affected by mathematical ability and emotional factors, such as 
anxiety and frustration [25]; therefore we should be careful when interpreting low scores as clinically significant.

The aim of the present study was to explore the impact of fatigue on both cognitive complaints and cognitive performance in patients with MS. We hypothesized that 1 ) fatigue, together with anxiety and depression, contribute to cognitive complaints, and that 2) fatigue is related to cognitive performance on neuropsychological tests that require attention and executive functioning.

\section{Methods}

\section{Subjects}

Eighty outpatients (25 males and 55 females) diagnosed with clinically definite MS [26] were recruited from the Department of Neurology of the Maastricht University Medical Centre (MUMC), which has both a local and regional function. Patients were referred for a standardized neuropsychological evaluation, irrespective of whether they had cognitive complaints or not. Their mean age was 43.6 years ( $S D=9.1$, range 24-60). Most of the MS patients $(n=53)$ had a relapsing remitting disease course; 13 patients had a secondary progressive course; and 14 patients a primary progressive course. All of the patients lacked other health problems besides MS; they did not use corticosteroids; they had not experienced an exacerbation during the 4 weeks previous to the evaluation; and they did not have severe visual, verbal, and/or motoric limitations that interfered with (neuro)psychological testing. All of the patients were assessed at the MUMC. Basic demographic information was collected, including age, sex, and level of premorbid intelligence as measured with the Dutch version of the National Adult Reading Test [27]. Medical histories of all the patients (e.g. disease course, disease duration) were collected from the hospital database. The Expanded Disability Status Scale (EDSS) [35], which was assessed by an experienced neurologist familiar with EDSS recording (RH), provided a measure of neurological disability. The medical ethics committee of the MUMC approved the project and all patients gave their written informed consent.

\section{Measures}

Since in clinical practice MS-related fatigue is defined as a subjective experience with both physical and mental aspects [28], we quantified fatigue by using the physical and mental subscales of a multidimensional self-report questionnaire viz. the Multidimensional Fatigue Inventory (MFI) [29]. Both subscales consist of four items with a 5-point response format with scores ranging from 4 to 20 . The statements refer to aspects of fatigue during the past few days. Higher scores indicate more physical or mental fa- 
tigue. The MFI is repeatedly used in the case of patients with chronic (neurological) diseases [30-32], and the Dutch language version has shown good reliability and validity [29].

The Hospital Anxiety and Depression Scale (HADS) [33] was used to assess complaints of anxiety and depression. This instrument has been especially designed to screen physically ill patients for the assessment of anxiety and depression. The HADS does not include somatic symptoms. As such it excludes any overlap with somatic and affective symptoms. Both subscales consist of 7 items with scores ranging from 0 to 21 . Higher scores indicate more complaints. Reliability and validity have been demonstrated for the Dutch population [34].

Cognitive complaints were assessed with the help of the Dutch version of the Cognitive Failure Questionnaire (CFQ), which has good psychometric qualities [36, 37]. The CFQ consists of 25 items covering general daily cognitive mistakes, including failures in memory, attention, action and perception. The total score ranges from 25 to 125 , and higher scores indicate a higher number of cognitive complaints.

To assess cognitive performance, a relatively extensive neuropsychological assessment battery was used including a number of tasks requiring effortful information processing. Eleven psychometric tests were administered to all patients in a fixed order, taking about 120 minutes to complete. The oral version of the Letter Digit Substitution Test (LDST) [38] was administered to assess information-processing speed. The shifting score of the Concept Shifting Test (CST) (CSTc- (CSTa-CSTb)/2) corrected for motor speed [39] was used to measure mental flexibility and divided attention. The 40-item version of the Stroop Color Word Test (SCWT) $[40,41]$ was used to test response inhibition and selective attention. Sustained attention was measured by means of the Dauer Aufmerksamkeit Test (DAUF) of the Vienna Test System, which is a go-no-go computer task that has good psychometric qualities [42]. During this task, which lasts for approximately 25 minutes, 15 series of lines with five triangles are presented on a computer screen and the participant has to press on a button every time two of the five triangles are pointing downwards. Participants are asked to respond as quickly as possible without making mistakes. The test measures reaction time as well as both accuracy (errors, omissions) and stability (standard deviation of the reaction time). The Digit Span subtask of the Wechsler Adult Intelligence Scale (WAIS) was administered to assess working memory [43]. The total reproduction of the five learning trials and the uncued long-term delay of the Dutch version of the California Verbal Learning Task (CVLT) $[44,45]$ were used to evaluate verbal learning and memory. Visual memory was assessed with the help of the multiple choice version of the Benton Visual Retention Test (BVRT) [46]. Fluency tasks were administered to assess language production and strategy-driven retrieval from semantic memory. Semantic and phonemic fluency were respectively measured by means of the semantic fluency task of the Groninger Intelligence Test [47], and the Controlled Oral Word Association Test (COWAT) [24]. The 
computerized version of the Wisconsin Card Sorting Test (WCST) [48] and the Raven's Standard Progressive Matrices (Raven's SPM) [49] were used to measure executive functioning (cognitive flexibility and non-verbal abstract reasoning).

\section{Statistical analyses}

Data were checked for normality, outliers and extremes. Square root and logarithmic transformation were used for not normally distributed variables (skewness $<-1$ or $>1$ ) before parametric testing. To reduce the number of neuropsychological outcome variables, a principal components analysis (PCA) with oblimin rotation (Eigenvalue $>1$ ) was performed. This PCA suggested a four-factor solution accounting for about $70 \%$ of the variance. The four factors were called: 1) mental speed, 2) attention, 3) memory, and 4) executive functioning (See Table 1 for the neuropsychological tests and factor loadings). On the basis of these findings, four compound performance indices were calculated using the mean of the Z-scores of all the variables belonging to a specific factor. The signs of the test scores on all variables of both the "mental speed" and "attention" compound indices, and the variable perseverative errors of the WCST were inverted so that a negative score reflects below average performance and a positive score above average performance for all compound indices.

Pearson correlation coefficients were calculated to examine interrelationships between all independent and dependent variables. Next, hierarchical regression analyses were conducted on both cognitive complaints and cognitive performance (i.e. the four compound performance indices). Age and premorbid intelligence were entered first as control variables. Next, disease severity, anxiety and depression, physical and mental fatigue were entered consecutively to determine the unique contribution of each variable. The assumptions of regression analysis including absence of multicollinearity (Variance Inflation Factors <2), homoscedasticity, normal distribution of the residuals and absence of 'influential cases' (Cook's distance $<1$ ) were checked for all models. P-values $<0.05$ were considered significant. For the regression analyses, the level of significance was set on $\mathrm{p}<0.01$ after Bonferroni correction for multiple testing. Analyses were carried out using the SPSS version 15.0 for Windows.

\section{Results}

The demographic and clinical characteristics of the sample are presented in Table 1. 
Table 1. Demographic and clinical characteristics of the sample $(n=80)$

\begin{tabular}{|c|c|c|c|}
\hline & Mean (SD) & Range & \\
\hline Sex (\% male / \% female) & $31 / 69$ & & \\
\hline Age (in years) & $43.6(9.1)$ & $24-60$ & \\
\hline EDSS & $3.6(2.0)$ & $0-7.5$ & \\
\hline Disease duration (in years) & $5.8(6.4)$ & $0.1-20.5$ & \\
\hline \multirow[t]{2}{*}{ NART IQ } & $102.6(9.4)$ & $76-130$ & \\
\hline & \multicolumn{3}{|r|}{ Internal consistence $(\alpha)$} \\
\hline HADS & $11.7(7.3)$ & $1-29$ & .87 \\
\hline MFI - Physical fatigue & $14.4(3.8)$ & $5-20$ & .80 \\
\hline MFI - Mental fatigue & $12.5(4.5)$ & $4-20$ & .89 \\
\hline CFQ & $39.2(15.9)$ & $8-81$ & .92 \\
\hline \multicolumn{2}{|l|}{ Mental speed-index } & \multicolumn{2}{|r|}{ Factor loadings } \\
\hline LDST (number correct in $60 \mathrm{sec}$.) & $37.0(9.7)$ & $14-71$ & .447 \\
\hline SCWT- Card III (sec.) & $41.6(13.4)$ & 21-101 & -.420 \\
\hline \multicolumn{4}{|l|}{ Verbal fluency: } \\
\hline - animals and professions (total number correct in $60 \mathrm{sec}$.) & $40.7(10.0)$ & $20-66$ & .927 \\
\hline - letters N, K, A ( total number correct in $60 \mathrm{sec}$. ) & $33.1(9.6)$ & $16-60$ & .641 \\
\hline \multicolumn{4}{|l|}{ Attention-index } \\
\hline CST-shifting score (sec.) & $12.1(10.2)$ & $-4-45$ & .771 \\
\hline DAUF - reaction time (sec.) & $0.96(0.17)$ & $0.65-1.51$ & .646 \\
\hline DAUF - stability of reaction time (sec.) & $0.24(0.08)$ & $0.11-0.48$ & .664 \\
\hline \multicolumn{4}{|l|}{ Memory-index } \\
\hline Digit span (number correct) & $14.4(3.4)$ & $8-24$ & .443 \\
\hline BVRT (number correct) & $13.1(1.5)$ & $9-15$ & .591 \\
\hline CVLT - total reproduction trial 1-5 & $52.4(11.6)$ & $24-71$ & .868 \\
\hline CVLT- uncued long term delay & $10.8(3.5)$ & $2-16$ & .981 \\
\hline \multicolumn{4}{|l|}{ Executive functioning-index } \\
\hline WCST (perseverative errors) & $13.0(10.7)$ & $4-62$ & .731 \\
\hline Raven's SPM (number correct) & $45.4(8.0)$ & $25-70$ & -.843 \\
\hline
\end{tabular}

EDSS= Expanded Disability Status Scale; NART IQ= National Adult Reading Test Intelligence Quotient; HADS= Hospital Anxiety and Depression Scale; MFI=Multidimensional Fatigue Inventory; CFQ= Cognitive Failure Questionnaire; LDST= Letter Digit Substitution Test; SCWT= Stroop Color-Word Test; COWAT= Controlled Oral Word Association Test; CST= Concept Shifting Test; DAUF= Dauer Aufmerksamkeit Test; BVRT= Benton Visual Retention Test; CVLT= California Verbal Learning Task; WCST= Wisconsin Card Sorting Test; Raven's SPM= Raven's Standard Progressive Matrices.

Table 2 shows the zero-order correlations between all relevant variables. Anxiety and depression as well as physical and mental fatigue were significantly related to cognitive complaints $(0.367<r<0.721 ; p<0.01)$. With regard to cognitive performance, significance was found for the relationship between physical fatigue and performance on attention 
$(r=-0.310, p<0.01)$ and executive functioning $(r=-0.249, p<0.05)$, respectively. Next, mental fatigue was significantly related to both performance on attention $(r=-0.256$, $p<0.05)$ and memory $(r=-0.285, p<0.05)$.

Table 2. Pearson correlations of independent variables with cognitive complaints and cognitive performance indices $(n=80)$

\begin{tabular}{llllll}
\hline & CFQ & Mental speed & Attention & Memory & $\begin{array}{l}\text { Executive } \\
\text { functioning }\end{array}$ \\
\hline Age & -0.056 & -0.168 & $-0.258^{*}$ & $-0.340^{* *}$ & $-0.255^{*}$ \\
NART IQ & -0.155 & $0.255^{*}$ & 0.195 & $0.478^{* *}$ & $0.278^{*}$ \\
EDSS & -0.013 & -0.132 & $-0.245^{*}$ & $-0.233^{*}$ & $-0.261^{*}$ \\
HADS & $0.501^{* *}$ & -0.047 & -0.169 & -0.086 & $-0.364^{* *}$ \\
MFI-Physical fatigue & $0.367^{* *}$ & -0.001 & $-0.310^{* *}$ & -0.181 & $-0.249^{*}$ \\
MFI-Mental fatigue & $0.721^{* *}$ & -0.101 & $-0.256^{*}$ & $-0.285^{* *}$ & -0.066 \\
\hline
\end{tabular}

CFQ = Cognitive Failure Questionnaire; NART IQ= National Adult Reading Test Intelligence Quotient; EDSS= Expanded Disability Status Scale; HADS= Hospital Anxiety and Depression Scale; MFI= Multidimensional Fatigue Inventory.

${ }^{*} p<0.05 ;{ }^{* *} p<0.01$ (2-tailed)

The results of the final hierarchical regression analyses are presented in Table 3. All the assumptions of regression analysis were fulfilled for each model. Anxiety and depression, as well as mental fatigue significantly contributed to cognitive complaints, explaining about $9 \%$ and $39 \%$ of the total variance respectively. Because the measures of mental fatigue and cognitive complaints were highly correlated $(r=0.72, p<0.01)$ and included some comparable items, (e.g. "When I am doing something, I can keep my thoughts on it", "I can concentrate well"), an additional regression analysis predicting cognitive complaints without the subscale mental fatigue of the MFI was conducted (data not shown). In this way we could ensure that there was no confounding by overlapping constructs. When mental fatigue was not entered in the model, anxiety and depression explained about $16 \%$ of the total variance of cognitive complaints $(\beta=0.414, p<0.01)$. In this model, physical fatigue did not significantly contribute to cognitive complaints $(\beta=0.239, p=0.05)$.

Both physical and mental fatigue did not significantly predict mental speed, attention, memory and executive functioning, after controlling for age, premorbid intelligence, neurological disability, and anxiety and depression. Finally, anxiety and depression significantly contributed to executive functioning, explaining about $14 \%$ of the total variance. 
Table 3. Hierarchical linear regression models for variables predicting cognitive complaints and cognitive performance $(n=80)$

\begin{tabular}{llcccc}
\hline & CFQ & Mental speed & Attention & Memory & $\begin{array}{c}\text { Executive } \\
\text { functioning }\end{array}$ \\
\hline Age & $\beta$ & $\beta$ & $\beta$ & $\beta$ & $\beta$ \\
NART IQ & -0.009 & -0.194 & -0.211 & $-0.357^{*}$ & -0.261 \\
EDSS & 0.016 & 0.272 & 0.139 & $0.465^{*}$ & $0.286^{*}$ \\
HADS & -0.044 & -0.134 & -0.135 & -0.166 & -0.106 \\
MFI-physical fatigue & $0.234^{*}$ & -0.058 & -0.021 & 0.010 & $-0.397^{*}$ \\
MFI-mental fatigue & 0.062 & 0.208 & -0.107 & 0.137 & -0.031 \\
$R^{2}$ & $0.603^{*}$ & -0.110 & -0.195 & -0.261 & 0.125 \\
\hline
\end{tabular}

$\mathrm{CFQ}=$ Cognitive Failure Questionnaire; NART IQ= National Adult Reading Test Intelligence Quotient; EDSS= Expanded Disability Status Scale; HADS= Hospital Anxiety and Depression Scale; MFI= Multidimensional Fatigue Inventory.

${ }^{*} \mathrm{p}<0.01$ (2-tailed)

\section{Discussion}

The present study revealed that mental fatigue, together with anxiety and depression, accounted for a substantial part of the total variance of cognitive complaints. Physical fatigue did not contribute to cognitive complaints. Furthermore, both physical and mental fatigue did not contribute to cognitive performance in terms of mental speed, attention, memory and executive functioning.

The finding that cognitive complaints are determined by fatigue and emotional complaints is in accordance with previous work on both MS patients $[10,11]$ and other clinical populations [50-53]. Despite the definition of fatigue [28] and the recommendation to operationalize it multidimensionally [54], most of these studies used measures of general fatigue only. Our findings suggest that cognitive complaints are related to mental fatigue but not to physical fatigue. Given the overlap in items between mental fatigue and cognitive complaints (e.g. concentration problems), our multidimensional approach reveals a problem of construct validity as is also established by the high correlation found. To adjust for overlapping items, we excluded the mental fatigue subscale in our post-hoc analysis. After that, only anxiety and depression - and not physical fatigue - were contributing to cognitive complaints.

Although we used an extensive neuropsychological battery including effortful tests, both physical and mental fatigue did not contribute to cognitive performance. As such, inclusion of effortful tests did not result in significance and the degree of effort can not explain the absence of a relationship in earlier findings [9, 13, 14, 17, 19, 55]. Although MS patients frequently report that their cognitive functioning is negatively affected by 
the experience of fatigue and it is generally recommended to avoid fatigue during neuropsychological assessment in order to maximize cognitive performance [24], there is a lack of evidence for a major influence of fatigue on cognitive performance in MS patients and several other clinical populations [12]. An explanation for the lack of a relationship between fatigue and cognitive performance might be the different underlying mechanisms. It is likely that cognitive deficits are the result of the neurodegenerative process of MS [5], whereas the experience of fatigue is related to psychological factors [54].

In contrast to studies in clinical samples, findings in healthy participants suggest that fatigue results in a decrease of cognitive performance [20, 22, 23]. This contrast may imply that fatigue in healthy participants is different from that experienced by a clinical population such as MS patients [12]. For instance, healthy participants become only fatigued after physical or mental effort and benefit from rest-breaks and sleep, whereas MS patients experience fatigue even in rest and after sleep.

Several methodological issues have to be considered. Firstly, the cross-sectional design of the study makes it impossible to infer causality from the associations found. To infer causality, at least a randomized experimental or longitudinal design is needed, especially because of the fluctuating nature of the disease and the influence of variations in fatigue and cognitive performance over time [56]. Secondly, although we controlled for neurological disability and we excluded patients with severe motor and visual impairment, visual vigilance tests depend on fine motor and visual function, which can be impaired in MS [24]. This might have influenced the reliability of this outcome variable. Furthermore, we did not control for CNS-active medication, which is often used to treat MS-related symptoms such as spasticity, and is known to influence cognitive performance [57].

Assuming that the present results appear to be stable when the methodology is improved, several implications are apparent for clinical practice. Since anxiety, depression and fatigue have a significant impact on cognitive complaints, it is recommend to add their measures to neuropsychological assessment in patients with MS. In addition, the treatment of cognitive complaints should focus on these complaints rather than on cognition. Because fatigue in MS is not related to cognitive performance, it is permitted to use extensive neuropsychological assessement in fatigued patients with MS. Given the impact of cognitive impairment on daily life, and its heterogeneity in MS, extensive neuropsychological assessment is needed to detect even subtle cognitive dysfunction $[3,6,58]$. 


\section{References}

1. Compston A, Coles A. Multiple sclerosis. Lancet 2008;372:1502-1517.

2. Feinstein A. The clinical neuropsychiatry of multiple sclerosis. Cambridge: University Press; 1999.

3. Benedict RH, Wahlig E, Bakshi R, Fishman I, Munschauer F, Zivadinov R, Weinstock-Guttman, B. Predicting quality of life in multiple sclerosis: accounting for physical disability, fatigue, cognition, mood disorder, personality, and behavior change. J Neurol Sci 2005;231:29-34.

4. Branas P, Jordan R, Fry-Smith A, Burls A, Hyde C. Treatments for fatigue in multiple sclerosis: a rapid and systematic review. Health Technol Assess 2000;4:1-61.

5. DeSousa EA, Albert RH, Kalman B. Cognitive impairments in multiple sclerosis: a review. Am J Alzheimers Dis Other Dem 2002;17:23-29.

6. Zakzanis KK. Distinct neurocognitive profiles in multiple sclerosis subtypes. Arch Clin Neuropsychol 2000;15 115-136.

7. Krupp LB, Alvarez LA, LaRocca NG, Scheinberg LC. Fatigue in multiple sclerosis. Arch Neurol 1988;45:435437.

8. Parmenter BA, Denney DR, Lynch SG. The cognitive performance of patients with multiple sclerosis during periods of high and low fatigue. Mult Scler 2003;9:111-118.

9. Schwartz CE, Coulthard-Morris L, Zeng Q. Psychosocial correlates of fatigue in multiple sclerosis. Arch Phys Med Rehab 1996;77:165-170.

10. Marrie RA, Chelune GJ, Miller DM, Cohen JA, Fisher E, Lee JC, Rudick RA. Subjective cognitive complaints relate to mild impairment of cognition in multiple sclerosis. Mult Scler 2005;11:69-75.

11. Middleton LS, Denney DR, Lynch SG, Parmenter B. The relationship between perceived and objective cognitive functioning in multiple sclerosis. Arch Clin Neuropsychol 2006;21:487-494.

12. DeLuca J. Fatigue, cognition and mental effort. In: Deluca J. (eds). Fatigue as a window to the brain. Cambridge: The MIT press; 2005, p. 37-57.

13. Johnson SK, DeLuca J, Diamond, BJ, Natelson, BH. Memory dysfunction in fatiguing illness: Examining interference and distraction in short-term memory. Cogn Neuropsychiatry 1998;3:269-285.

14. Johnson SK, DeLuca J, Natelson BH. Depression in fatiguing illness: comparing patients with chronic fatigue syndrome, multiple sclerosis and depression. J Affect Disord 1996;39:21-30.

15. Johnson SK, Lange G, DeLuca J, Korn LR, Natelson BH. The effects of fatigue on neuropsychological performance in patients with chronic fatigue syndrome, multiple sclerosis, and depression. Appl Neuropsychol 1997;4:145-153.

16. Geisler MW, Sliwinski M, Coyle PK, Masur DM, Doscher C, Krupp LB. The effects of amantadine and pemoline on cognitive functioning in multiple sclerosis. Arch Neurol 1996;53:185-188.

17. Krupp LB, Elkins LE. Fatigue and declines in cognitive functioning in multiple sclerosis. Neurology 2000;55:934-939.

18. Paul RH, Beatty WW, Schneider R, Blanco CR, Hames KA. Cognitive and physical fatigue in multiple sclerosis: relations between self-report and objective performance. Appl Neuropsychol 1998;5:143-148.

19. Rao SM, Leo GJ, Bernardin L, Unverzagt F. Cognitive dysfunction in multiple sclerosis. I. Frequency, patterns, and prediction. Neurology 1991;41:685-691.

20. Boksem MA, Meijman TF, Lorist MM. Effects of mental fatigue on attention: An ERP study. Brain Res Cogn Brain Res 2005;25:107-116.

21. Capuron L, Welberg L, Heim C, Wagner D, Solomon L, Papanicolaou DA, Craddock RC, Miller AH, Reeves WC. Cognitive dysfunction relates to subjective report of mental fatigue in patients with chronic fatigue syndrome. Neuropsychopharmacology 2006; 31:1777-1784.

22. Petrilli RM, Roach GD, Dawson D, Lamond N. The sleep, subjective fatigue, and sustained attention of commercial airline pilots during an international pattern. Chronobiol Int 2006;23:1357-1362.

23. Van der Linden D, Frese M, Meijman TF. Mental fatigue and the control of cognitive processes: effects on perseveration and planning. Acta Psychol 2003 113:45-65. 
24. Lezak MD, Howieson DB, Loring DW. Neuropsychological assessment. New York/Oxford: Oxford University Press; 2004.

25. Tombaugh TN. A comprehensive review of the Paced Auditory Serial Addition Test (PASAT). Arch Clin Neuropsychol 2006;21:53-76.

26. McDonald WI, Compston A, Edan G, Goodkin D, Hartung HP, Lublin FD, McFarland HF, Paty DW, Polman $\mathrm{CH}$, Reingold SC, Sandberg-Wollheim M, Sibley W, Thompson A, Van den Noort S, Weinshenker BY, Wolinsky JS.et al. Recommended diagnostic criteria for multiple sclerosis: guidelines from the International Panel on the diagnosis of multiple sclerosis. Ann Neurol 2001;50:121-127.

27. Schmand B, Lindeboom J, van Harskamp F. De Nederlandse Leestest voor Volwassenen. Lisse: Swets \& Zeitlinger; 1992.

28. Multiple Sclerosis Council of Clinical Practice Guidelines. Fatigue and multiple sclerosis: evidence-based management strategies for fatigue in multiple sclerosis. Washington D.C.: Paralyzed Veterans of America; 1998.

29. Smets EM, Garssen B, Bonke B, De Haes JC. The Multidimensional Fatigue Inventory (MFI); Psychometric qualities of an instrument to assess fatigue. J Psychosom Res 1995;39:315-325.

30. De Ridder D, Fournier M, Bensing J. Does optimism affect symptom report in chronic disease?; What are its consequences for self-care behaviour and physical functioning? J Psychosom Res 2004;56:341-350.

31. Havlikova E, Rosenberger J, Nagyova I, Middel B, Dubayova T, Gdovinova Z, Groothoff JW, van Dijk, JP. Clinical and psychosocial factors associated with fatigue in patients with Parkinson's disease. Parkinsonism Relat Disord 2008;14:187-192.

32. Minderhoud IM, Oldenburg B, van Dam PS, van Berge Henegouwen GP. High prevalence of fatigue in quiescent inflammatory bowel disease is not related to adrenocortical insufficiency. Am J Gastroenterol 2003 98:1088-1093.

33. Zigmond AS, Snaith RP. The hospital anxiety and depression scale. Acta Psychiatr Scand 1983;67:361-370.

34. Spinhoven P, Ormel J, Sloekers PP, Kempen GI, Speckens AE, Van Hemert AM. A validation study of the Hospital Anxiety and Depression Scale (HADS) in different groups of Dutch subjects. Psychol Med 1997;27:363-370.

35. Kurtzke JF. Rating neurologic impairment in multiple sclerosis: an expanded disability status scale (EDSS). Neurology 1983;33:1444-1452.

36. Broadbent DE, Cooper PF, FitzGerald P, Parkes KR. The Cognitive Failures Questionnaire (CFQ) and its correlates. Br J Clin Psychol 1982;21:1-16.

37. Ponds $\mathrm{R}$, van Boxtel $\mathrm{M}$, Jolles J. De cognitive failure questionnaire. Tijdschrift voor neuropsychologie 2006;1:37-42.

38. Van der Elst W, van Boxtel, MPJ, van Breukelen, GJP, Jolles, J. The Letter Digit Substitution Test: Normative data for 1,858 healthy participants aged 24-81 from the Maastricht Aging Study (MAAS): influence of Age, Education, and Sex. J Clin Exp Neuropsychol 2006;28:998-1009.

39. Van der Elst W, van Boxtel, MPJ, van Breukelen, GJP, Jolles, J. The Concept Shifting Test: Adult normative data. Psychol Assess 2006;18:424-431.

40. Van der Elst W, van Boxtel MP, van Breukelen GJ, Jolles J. The Stroop color-word test: influence of age, sex, and education; and normative data for a large sample across the adult age range. Assessment 2006;13:62-79.

41. Houx PJ, Shepherd J, Blauw GJ, Murphy MB, Ford I, Bollen EL, Buckley B, Stott DJ, Jukema W, Hyland M, Gaw A, Norrie J, Kamper AM, Perry IJ, MacFarlane PW, Meinders AE, Sweeney BJ, Packard CJ, Twomey C, Cobbe SM, Westendorp, RG. Testing cognitive function in elderly populations: the PROSPER study. PROspective Study of Pravastatin in the Elderly at Risk. J Neurol Neurosurg Psychiatry 2002;73:385-389.

42. Schuhfried G. Wiener testsystems. Mödling: dr. G. Schuhfried; 1993.

43. Wechsler D. WAIS III, Dutch Language Version. Lisse: Swets Test Publishers; 2001.

44. Delis DC, Kramer JH, Kaplan E, Ober BA. California Verbal Learning Test: adult version. San Antonio: The Psychological Corporation; 1987. 
45. Mulder JL, Dekker R, Dekker PH. Verbale Leer en Geheugen Test: handleiding. Lisse: Swets Test Publishers; 1996.

46. Benton AL. Revised Visual Retention Test. Clinical and experimental applications. New York: Psychological Corporation; 1974.

47. Luteijn F, van der Ploeg FAE. Groninger Intelligentie Test. Lisse: Swets \& Zeitlinger; 1998.

48. Psychological Assessment Resources. Computerised Wisconsin Card Sorting Task Version 4 (WCST). Odessa: Psychological Assessment Resources; 2003.

49. Raven JC, Court JH, Raven J. Manual for Raven's standard progressive matrices. Oxford: Psychologists Press; 1992.

50. Roth RS, Geisser ME, Theisen-Goodvich M, Dixon PJ. Cognitive complaints are associated with depression, fatigue, female sex, and pain catastrophizing in patients with chronic pain. Arch Phys Med Rehab 2005;86:1147-1154.

51. Stulemeijer M, Vos PE, Bleijenberg G, van der Werf SP. Cognitive complaints after mild traumatic brain injury: Things are not always what they seem. J Psychosom Res 2007;63:637-645.

52. Woods SP, Carey CL, Moran LM, Dawson MS, Letendre SL, Grant I. Frequency and predictors of selfreported prospective memory complaints in individuals infected with HIV. Arch Clin Neuropsychol 2007;22:187-195.

53. Duits A, Munnecom T, van Heugten C, van Oostenbrugge RJ. Cognitive complaints in the early phase after stroke are not indicative of cognitive impairment. J Neurol Neurosurg Psychiatry 2008;79:143-146.

54. Bol Y, Duits AA, Hupperts RM, Vlaeyen JW, Verhey FR. The psychology of fatigue in patients with multiple sclerosis: A review. J Psychosom Res 2009;66:3-11.

55. Paul RH, Cohen RA, Gilchrist JM. Ratings of subjective mental fatigue relate to cognitive performance in patients with myasthenia gravis. J Clin Neurosci 2002;9:243-246.

56. Ytterberg C, Johansson S, Andersson M, Widen Holmqvist L, von Koch L. Variations in functioning and disability in multiple sclerosis. A two-year prospective study. J Neurol 2008;255:967-973.

57. Oken BS, Flegal K, Zajdel D, Kishiyama SS, Lovera J, Bagert B, Bourdette DN. Cognition and fatigue in multiple sclerosis: Potential effects of medications with central nervous system activity. J Rehabil Res Dev 2006;43:83-90.

58. Benedict R, Fischer J, Archibald C, Arnett P, Beatty W, Bobholz J, Chelune G, Fisk J, Langdon D, Caruso L, Foley F, LaRocca N, Vowels L, Weinstein A, DeLuca J, Rao S, Munschauer F. Minimal Neuropsychological Assessment of MS Patients: A Consensus Approach. Clin Neuropsychol 2002;16:381-97. 



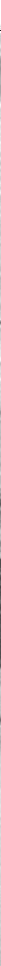

Subjective and objective assessment of mental fatigue in patients with multiple sclerosis

Y Bol, AA Duits, FRJ Verhey, FCH Bakers, E Gorsselink, MJL Romberg-Camps \& RMM Hupperts 


\begin{abstract}
Although mental fatigue is a common and disabling symptom of MS patients, its exact pathogenesis is still unclear. In order to study the disease specificity of mental fatigue in MS we compared a sample of 40 MS patients with 19 healthy controls (HC), and we also included 20 patients with another chronic auto-immune disease (UC) in order to control for non-specific aspects of chronic disease. To better understand MS-related mental fatigue, we used a subjective as wel as an objective measure of fatigue. Besides measurement by self-report, mental fatigue was measured by a decreased performance on a task that required sustained mental effort. We explored the associations between both (subjective and objective) measures of mental fatigue and disease severity in both patient samples. Next, the associations between both measures of mental fatigue on the one hand and both cerebral white matter lesion load measured by MRI (cWML), and depressive complaints on the other hand, were investigated in all three groups. Our findings revealed that MS patients experienced more mental fatigue than both control groups, but the three groups did not differ with regard to the objective measure of mental fatigue. The total amount of $\mathrm{cWML}$ and disease severity did not correlate with the objective measure of mental fatigue. Depressive complaints were only correlated with subjective assessment of mental fatigue in the HC group and not in the MS and UC sample. In conclusion, our distinction between the subjective and objective assessment of mental fatigue did not help us to find an explanation in terms of either disease specificity or significant correlates of MS-related mental fatigue.
\end{abstract}




\section{Introduction}

Fatigue is a common symptom in chronic disease [1], but fatigue in patients with multiple sclerosis (MS) seems to be more severe and disabling than that in other somatic populations [2, 3]. Up to $92 \%$ of patients with MS experience fatigue [4] and although it is one of the most common and most disabling symptoms, its pathogenesis is still poorly understood [5]. Chaurdhuri and Behan [6] proposed that the most common type of fatigue in chronic disease is central fatigue. Central fatigue, in contrast to neuromuscular or peripheral fatigue, represents a failure to complete physical and mental tasks that require self-motivation and internal cues, in the absence of demonstrable cognitive failure or motor weakness. This concept of central fatigue implies a distinction between physical and mental fatigue. Recently increasing attention has been paid to mental fatigue in both healthy and clinical populations, since labour conditions have changed to a large extent from demanding physical effort to demanding mental effort. Hence, mental fatigue can severely affect the ability to perform activities of daily life and is a major reason for unemployment $[7,8]$.

Mental fatigue can be defined and operationalized in two different ways [9]. Firstly, mental fatigue is often defined as a feeling or a subjective experience. Subjective mental fatigue can be measured by self-report questionnaires such as the Multidimensional Fatigue Inventory [10]. Secondly, objective mental fatigue - also known as cognitive fatigue - is defined as a performance decrement and is measured by direct observation of behaviour. There have been several attempts to assess mental fatigue objectively in MS [11]. A recurrent approach is to assess mental fatigue as a decrease in performance on a task that required sustained mental effort [11-15]. For instance, Krupp \& Elkins [13] demonstrated objective mental fatigue by a decline in performance over the course of a sustained working memory task. Compared to the first half of the task, MS patients showed a significant increase in reaction time during the second half of this working memory task, and this difference was significantly higher in patients than in healthy participants. Also Schwid et al. [15] found a decrease in performance during administration of the Paced Auditory Serial Addition Test (PASAT), a task for mental speed, working memory and sustained attention, which was indicative of objective mental fatigue.

There is evidence that subjective and objective measures of mental fatigue have different correlates. In general, subjective fatigue is related to psychosocial factors such as depression [16-18] rather than to disease-related variables, such as disease duration, disease severity as measured by the Expanded Disability Status Scale (EDSS) [16, 19-21], or magnetic resonance imaging (MRI) markers, such as lesion load, gadoliniumenhancing lesion activity and brain atrophy [22-26]. Greim et al. [27] studied both subjective and objective physical and mental fatigue in MS patients and healthy participants and found that depression affects the subjective experience of both physical and 
mental fatigue, but not the objective measures of fatigue. In line with these findings, it is expected that objective mental fatigue, like cognitive impairment [28], is associated with disease-related variables, such as cerebral white matter lesion load (cWML) on $\mathrm{MRI}$, and with disease severity as measured with the EDSS.

In the present study we focused on mental fatigue in MS and its disease specificity by comparing its levels and correlates with those of two control groups. First of all, we included healthy control participants (HC). Secondly, to control for non-specific aspects of chronic disease, we included patients with ulcerative colitis (UC), an inflammatory bowel disease without known underlying cerebral pathology. Both MS and UC are functionally disabling auto-immune diseases, usually starting between the ages of 20 and 40. Like MS, UC is a chronic and intermittent disease, characterized by a lifetime risk of relapses [29]. In contrast to other auto-immune disorders such as rheumatoid arthritis, UC patients are particularly appropriate as controls because pain is not a major symptom in UC during remission.

We tested whether the levels of both subjective and objective fatigue were higher in MS than those in both HC and UC. Next, we explored the associations between both subjective and objective mental fatigue and disease severity in both patient samples. The associations between the fatigue measures and both cWML and depressive complaints were explored in all three groups. We hypothesized that the levels of both subjective and objective mental fatigue are higher in MS patients than those in UC and HC. Furthermore, it was hypothesized that for all participants, depressive complaints are related to subjective mental fatigue, whereas both cWML and disease severity are related to objective mental fatigue.

\section{Methods}

\section{Participants}

Forty MS patients were recruited from the Department of Neurology of the Maastricht University Medical Centre (MUMC), which has both a local and regional function. The neurologist invited consecutive patients who showed up at the outpatients clinic, were aged 18 to 60 years and were diagnosed with clinically definite MS [30] to participate in the study. The Inflammatory Bowel Disease (IBD) - South Limburg database of the Department of Gastroenterology of the MUMC was used to recruit the UC patients. UC patients diagnosed according to the Lennard-Jones criteria [31] were selected from the IBD database and were matched with the MS patients for sex and age. Partners and close family members of $20 \mathrm{MS}$ patients, with no health problems, participated as HC.

To study fatigue in patients in whom the disease was not active and to avoid the effects of corticosteroid use, we excluded patients who had experienced an exacerba- 
tion within the previous 4 weeks. MS Patients with an EDSS $>8$ were excluded, because these patients generally have impaired function of the upper limbs that may interfere with psychological testing. Other exclusion criteria for all participants were: other (neurological) diseases; dementia or severe cognitive dysfunction; visual, verbal and/or motoric limitations interfering with psychological testing.

\section{Measures}

Subjective mental fatigue was assessed by means of the subscale mental fatigue of the Multidimensional Fatigue Inventory (MFI) [10], that consists of four items with a fivepoint response format (range 4-20). Higher scores indicate higher levels of mental fatigue. The MFI is repeatedly used in patients with chronic (neurological) diseases [2, 3234] and the Dutch language version has shown good reliability and validity [10]. In this study Cronbach's alphas were respectively .90 for the MS sample, .85 for the UC sample and finally .86 for the $\mathrm{HC}$ sample.

Objective mental fatigue was measured by means of the Dauer Aufmerksamkeit test (DAUF) of the Vienna Test System [35]. The DAUF takes approximately 25 minutes and it is a computer task designed to assess sustained attention which has good psychometric qualities [35]. During this task 15 series of lines with five triangles are presented on a computer screen and the participant has to press a button every time two of the five triangles are pointing downwards. Participants are asked to respond as quickly as possible without making mistakes. The task measures reaction time as well as both accuracy (errors, omissions) and stability (standard deviation of the reaction time). To ensure understanding of the task and to prevent practice effects, all participants had to complete practice items before starting the task. Objective mental fatigue was calculated by means of subtracting the mean reaction time of the last three series from that of the first three series. A positive outcome indicates mental fatigue. Before this calculation was made, we checked if there was a need to correct for the so-called speedaccuracy trade-off [36]. Trading accuracy for speed results in fast but relatively inaccurate performance, whereas the opposite strategy results in accurate but rather slow performance. In all three groups, correlations between reaction time and the error and omission rate, were significantly positively correlated. These findings suggest that the slowest participants are also the ones that are the least accurate; therefore, accuracy was not used as a covariate.

To measure cerebral white matter lesion load (cWML) all participants underwent a MRI of the brain according to a standardized MS protocol [37]. Because cerebral white matter lesions can appear without some form of cerebral or neurological pathology [38, 39], also the UC patients and HC participants underwent a MRI of the brain. A 1.5 Tesla Phillips Gyroscan, with a dual echo spin-off sequence was used and $5 \mathrm{~mm}$ contiguous axial T1-, T2-weighted and fluid-attenuated inversion-recovery (FLAIR) images of each 
subject were made. All the MRIs were analyzed on the same computer workstation using the semi-automated seed growing software package Show_Images, which has a good intra- and interobserver reliability [40,41]. Lesions were marked and borders were set on each slice by one reader (F.B.) who was blinded to the clinical findings. Afterwards, the total cWML in volumes of $\mathrm{mm}^{3}$ was automatically quantified by the Show_Image software.

In both patient groups a disease-specific measure was used to assess disease severity. In the MS patients the EDSS was used [42]. A slightly modified version of The Colitis Activity Index (CAI) was used to measure disease severity in UC (range 0-18) [43]. This self-report questionnaire includes the number of daily liquid stools, the presence of nocturnal diarrhoea and the percentage of bowel movements with visible blood in the stool. Both the EDSS and the CAI are widely used as outcome measures for monitoring the disease course of respectively MS and UC patients, and higher scores indicate higher disease severity.

The subscale depression of the Hospital Anxiety and Depression Scale (HADS) [44] was used for measuring depressive complaints. This subscale, which consists of 7 items, has been especially designed to screen physically ill patients for depression. Higher scores indicate more complaints of depression (range 0-21). Reliability and validity are adequate for several clinical populations $[45,46]$. In this study Cronbach's alphas were respectively .81 for the MS sample, .82 for the UC sample, and .72 for the HC sample.

\section{Procedure}

All the participants were invited to come to the hospital for MRI scanning and to complete the questionnaires and the computer task. Demographic information (sex and age) was collected and the level of premorbid intelligence was measured with the Dutch version of the National Adult Reading Test [47], in order to describe and compare the three groups of participants. The EDSS was assessed by one experienced neurologist familiar with EDSS recording. Medical histories of the MS and UC patients (disease course, disease duration) were collected from the hospital databases. Disease duration was defined as the interval between the day of the (clinically definite) diagnosis and evaluation. The medical ethics committee of the MUMC approved the project and each participant gave written informed consent.

\section{Data analyses}

All data were checked for missing values, normality, outliers and extremes. One HC was excluded because of an outlier regarding reaction time. Square root transformation was used for abnormally distributed variables before parametric testing. Because of the lack of variance in CWML in both control groups, this variable was not transformed. Because 
of the different ranges of both of the disease severity measures (0-10 versus $0-18)$, the scores of the MS disease severity measure (EDSS) were linearly transformed to the range of the CAI (EDSS-score/10x18) to directly compare their means in both patient samples. Group differences with regard to the participants' characteristics and selfreport measures were analyzed by means of chi-square analyses (sex), one-way ANOVA (comparing three groups), and independent sample Student t-tests (comparing two groups). Non-parametric statistics (Kruskal-Wallis test for the differences between three groups and Mann-Whitney-U tests for two groups) were used for the variable cWML. To compare the levels of fatigue in the three groups, separate general linear model (GLM) univariate ANOVAs were conducted with disease severity and depressive complaints as covariates. The assumption of homogeneity of variance was checked for all ANOVA models. Spearman rank correlations were conducted to examine the relationship between the independent variables (sex, age, premorbid intelligence, disease duration, disease severity, depressive complaints, cWML) and the dependent variables (subjective mental fatigue and objective mental fatigue) for the three groups of participants. P-values $<0.05$ were considered significant. Analyses were carried out using the SPSS version 15.0 for Windows.

\section{Results}

The sample included 40 MS patients, 20 UC patients, and 19 HC participants (see Table 1 for demographic and clinical characteristics). Most of the MS patients (62.5\%) had a relapsing remitting disease course, $22.5 \%$ had secondary progressive MS and $15 \%$ had primary progressive MS. The average EDSS score in the MS sample was 3.6 (SD=1.8, range 0-7.5) and the mean CAI in the UC sample was 3.8 ( $S D=2.2$, range 1-9). The three groups did not differ with regard to sex, age, premorbid intelligence and disease duration, but MS patients showed a higher disease severity than UC patients. MS patients also reported higher levels of depressive complaints than both control groups. Both UC and $\mathrm{HC}$ reported comparable levels of depressive complaints $(t=-0.237, p=0.814)$. MS patients had a higher $c W M L$ than both $U C(Z=-4,854, p=0.000)$ and $H C(Z=-4.818$, $p=0.000)$, whereas the $C W M L$ in the UC and HC group did not differ $(Z=-0.770, p=0.441)$.

MS patients reported higher levels of subjective mental fatigue than both control groups, even after controlling for depression $(F(1,37)=6.261, p=0.003)$. When we controlled for both depression and disease severity, the differences between the two patient groups were still significant $(F(1,58)=11.673, p=0.001)$. Both the UC group and the $\mathrm{HC}$ group reported the same levels of subjective mental fatigue $(t(37)=0.826, p=0.414)$. Although MS patients reacted slower and their deviation in reaction time was higher than that of both control groups, calculated scores of objective mental fatigue did not differ among the three groups of participants. 
Table 1. Demographic and clinical characteristics of the participants (means and standard deviations)

\begin{tabular}{|c|c|c|c|c|}
\hline & $\begin{array}{l}\text { Multiple sclerosis } \\
(n=40)\end{array}$ & $\begin{array}{l}\text { Ulcerative colitis } \\
\qquad(n=20)\end{array}$ & $\begin{array}{l}\text { Healthy controls } \\
(n=19)\end{array}$ & $\begin{array}{l}\text { Significance test } \\
\text { (df) }\end{array}$ \\
\hline Sex (\% men/\% women) & $35 / 65$ & $45 / 55$ & $63 / 37$ & $x^{2}(2)=4.14$ \\
\hline Age (years) & 42.9 (8.9) & $45.6(7.9)$ & $46.1(9.4)$ & $F(2,76)=1.42$ \\
\hline NART IQ & $102.7(7.8)$ & $104.1(9.9)$ & $103.2(7.9)$ & $F(2,76)=0.17$ \\
\hline Disease severity ${ }^{1}$ & $6.4(3.3)$ & $3.8(2.2)$ & - & $t(58)=2.79 *$ \\
\hline Disease duration (years) & $6.2(6.8)$ & $8.5(7.0)$ & - & $t(58)=-1.73$ \\
\hline HADS-Depression & $6.1(4.1)$ & $3.4(2.9)$ & $3.6(3.1)$ & $F(2,76)=5.18^{*}$ \\
\hline $\mathrm{cWML}\left(\mathrm{mm}^{3}\right)$ & $2982.0(3052.1)$ & $122.4(268.0)$ & $179.9(573.9)$ & $X^{2}(2)=36.71^{*}$ \\
\hline MFI-mental fatigue & $12.5(4.5)$ & $8.8(3.4)$ & $8.0(4.1)$ & $F(2,76)=10.14^{*}$ \\
\hline DAUF-reaction time (sec.) & $0.95(0.17)$ & $0.77(0.09)$ & $0.85(0.14)$ & $F(2,76)=11.05^{*}$ \\
\hline DAUF-SD reaction time (sec.) & $0.24(0.07)$ & $0.14(0.04)$ & $0.18(0.06)$ & $F(2,76)=17.92^{*}$ \\
\hline DAUF-objective mental fatigue (sec.) & $0.07(0.25)$ & $0.10(0.18)$ & $0.13(0.18)$ & $F(2,76)=0.52$ \\
\hline
\end{tabular}

NART IQ= National Adult Reading Test Intelligence Quotient; HADS= Hospital Anxiety and Depression Scale; cWML= Cerebral white matter lesion load on MRI; MFI= Multidimensional Fatigue Inventory; DAUF =The Dauer Aufmerksamkeit Test. ${ }^{1}$ Because of the different range of both disease severity measures, the scores of the Expanded Disability Status Scale were linearly transformed into the range of the Colitis Activity Index (0-18) for reasons of comparison (see measures). ${ }^{*} p<0.01$.

Table 2 shows the Spearman rank correlations of all independent variables and both subjective and objective mental fatigue in the three groups. Depression was correlated with subjective mental fatigue only in the case of the $\mathrm{HC}$ group ( $r h o=0.507, p=0.027$ ). No significant correlations were found between $\mathrm{CWML}$ and either fatigue measures.

Table 2. Spearman rank correlations of independent variables and fatigue measures

\begin{tabular}{|c|c|c|c|c|c|c|}
\hline & \multicolumn{2}{|c|}{$\begin{array}{l}\text { Multiple sclerosis } \\
\qquad(n=40)\end{array}$} & \multicolumn{2}{|c|}{$\begin{array}{l}\text { Ulcerative colitis } \\
\qquad(n=20)\end{array}$} & \multicolumn{2}{|c|}{$\begin{array}{l}\text { Healthy controls } \\
\qquad(n=19)\end{array}$} \\
\hline & $\begin{array}{l}\text { Subjective } \\
\text { mental } \\
\text { fatigue }\end{array}$ & $\begin{array}{l}\text { Objective } \\
\text { mental } \\
\text { fatigue }\end{array}$ & $\begin{array}{l}\text { Subjective } \\
\text { mental } \\
\text { fatigue }\end{array}$ & $\begin{array}{l}\text { Objective } \\
\text { mental } \\
\text { fatigue }\end{array}$ & $\begin{array}{l}\text { Subjective } \\
\text { mental } \\
\text { fatigue }\end{array}$ & $\begin{array}{l}\text { Objective } \\
\text { mental } \\
\text { fatigue }\end{array}$ \\
\hline Sex & 0.178 & -0.132 & -0.373 & 0.026 & 0.201 & -0.100 \\
\hline Age & 0.046 & -0.046 & -0.176 & -0.026 & 0.355 & 0.228 \\
\hline Premorbid intelligence & 0.082 & 0.251 & -0.054 & -0.365 & 0.328 & -0.104 \\
\hline Disease duration & 0.095 & -0.179 & 0.158 & $-0.487^{*}$ & - & - \\
\hline Depression & 0.244 & -0.089 & 0.437 & -0.064 & $0.507^{*}$ & -0.284 \\
\hline Disease severity $^{1}$ & -0.301 & -0.245 & -0.156 & -0.440 & - & - \\
\hline $\mathrm{cWML}\left(\mathrm{mm}^{3}\right)^{2}$ & 0.206 & -0.173 & 0.188 & -0.064 & -0.177 & -0.024 \\
\hline
\end{tabular}

${ }^{1}$ Expanded Disability Status Scale in MS and Colitis Activity Index in UC; ${ }^{2}$ cerebral white matter lesion load on MRI. ${ }^{*} p<0.05$. 


\section{Discussion}

To improve our understanding of MS-related fatigue, the present study focused on the concept of mental fatigue. This involved the subjective experience as well as an objective measure representing an increase in reaction time during a cognitive vigilance task. Levels of both subjective and objective mental fatigue were compared to those of patients with another chronic disease viz. UC patients, and to those of a HC sample. We also explored associations between both of the fatigue measures and disease severity, cWML, and depressive complaints respectively.

In line with our first hypothesis, MS patients experienced more mental fatigue than both control groups. Contrary to our expectations, the three groups did not differ with regard to objective mental fatigue. It was also surprising to find that $\mathrm{CWML}$ and disease severity were not associated with objective mental fatigue in either the MS or the UC sample. Furthermore, depressive complaints were related to subjective mental fatigue in the $\mathrm{HC}$ group only and no relationship was found in either the MS or the UC sample.

The present results are in contrast to those of other studies on objective mental fatigue based on measures of information-processing speed and sustained attention $[12,13,15]$. This inconsistency could have several reasons. First of all, we did not assess the overall cognitive status of the participants and in particular the MS patients, which might be related to the performance on the cognitive vigilance task. For instance, Kujala et al. [14] did find evidence for objective mental fatigue with the help of a visual vigilance task that lasted 15 minutes, if MS patients had mild cognitive impairment. Secondly, the use of different tests, varying in duration and effort, could explain the inconsistent findings. The intensity of the task rather than its duration might affect outcomes of objective mental fatigue [48]. It is possible that the sustained attention task selected in the present study, despite its 30-minute duration, required relatively little executive control of behaviour that might be necessary to induce mental fatigue. Bryant et al. [12] showed that the underlying performance strategy during the Paced Auditory Serial Addition Test (PASAT) appeared to be more sensitive to objective mental fatigue than the performance itself. Only the outcome variable that relied on executive functioning revealed a fatigue effect in MS patients compared to healthy controls. Also the finding in healthy participants that working for two hours on cognitively demanding tasks resulted in a reduction of goal-directed attention and decreased performance on executive tasks, such as the Wisconsin Card Sorting Test $[49,50]$, suggests that operationalization of objective mental fatigue should be in terms of executive control.

In accordance with the findings of Greim et al. [27], the present study did not reveal a relationship between depressive complaints and objective mental fatigue. Although an association was found between depressive complaints and subjective mental fatigue in the $\mathrm{HC}$ group, we could not demonstrate significance in either the MS or UC sample. This finding is in contrast to other studies [16-18, 27], which show a positive association be- 
tween depression and subjective mental fatigue in MS patients. Our findings seem to suggest that fatigue in healthy participants is different from that in chronic illness populations. Disease-specific variables may play a role in explaining fatigue in chronic illness, but the present data do not support this conclusion in terms of severity and cWML.

Our study is unique in comparing MS patients with UC patients. Whereas UC patients were selected because they suffer from a chronic auto-immune disease without obvious CNS involvement, recently there has been increasing evidence based on an increased frequency of $\mathrm{CWML}$ compared to age-matched healthy participants that UC may also manifest itself in the central nervous system [51]. Although CWML can appear without some form of cerebral or neurological pathology [38, 39], we cannot exclude CNS involvement in the control groups selected in the present study. Compared to the $\mathrm{HC}$ group, which exhibited $\mathrm{CWML}$ in $15 \%$ of the cases, $30 \%$ of the UC patients exhibited cWML. Nevertheless, the percentage of cWML in MS patients is 88 and this is significantly higher without showing a relationship with objective mental fatigue. As such, CNS involvement based on CWML is not a prerequisite for objective mental fatigue, which might explain the lack of differences in the level of objective mental fatigue between all samples. However, our method to assess CNS involvement, viz. T2-weighted lesion load, may be an underestimation of the complexity of impaired brain functioning. Functional MRI (fMRI) is a relatively new and sensitive measure in detecting the subtle changes in brain functioning during cognitive performance and it has been proved to be a valuable tool to demonstrate mental fatigue in MS [52, 53]. Although fMRI is a sensitive tool, it may be less specific and therefore its use is questionable [54].

In conclusion, the concept of central fatigue and our operationalization of mental fatigue did not help us to find an explanation in terms of significant correlates of MSrelated mental fatigue. This brings us back to the problem of the unknown underlying pathogenesis of fatigue in MS. Although it has been suggested that central fatigue is the major cause of fatigue in chronic disease, it is questionable whether central fatigue explains the experience of fatigue in clinical populations [55]. Perhaps we should focus more on neuromuscular or peripheral fatigue rather than on central fatigue. Furthermore, in line with empirical evidence in other clinical populations, such as patients with chronic fatigue syndrome [56], and cancer survivors [57], future studies should focus on psychological factors, such as personality traits, fatigue-related beliefs and behaviour, rather than on specific disease-related variables. This is not to deny a biological origin of fatigue in MS, but rather a plea for an integrated bio-psychosocial approach that may open more therapeutic options.

Acknowledgments: We thank Prof. dr. F. Barkhof (Image Analysis Centre, VU Medical Centre, the Netherlands) for providing the Show_Images software and Ing. M. Geerlings (Department of Radiology, Maastricht University Medical Centre, the Netherlands) for his technical assistance. 


\section{References}

1. Swain MG. Fatigue in chronic disease. Clin Sci 2000;99:1-8.

2. De Ridder D, Fournier M, Bensing J. Does optimism affect symptom report in chronic disease?; What are its consequences for self-care behaviour and physical functioning? J Psychosom Res 2004;56:341-350.

3. Krupp LB, LaRocca NG, Muir-Nash J, Steinberg AD. The fatigue severity scale. Application to patients with multiple sclerosis and systemic lupus erythematosus. Arch Neurol 1989;46:1121-1123.

4. Branas P, Jordan R, Fry-Smith A, Burls A, Hyde C. Treatments for fatigue in multiple sclerosis: a rapid and systematic review. Health Technol Assess 2000;4:1-61.

5. Kos D, Kerckhofs E, Nagels G, D'Hooghe MB, Ilsbroukx S. Origin of fatigue in multiple sclerosis: review of the literature. Neurorehabil Neural Repair 2008;22:91-100.

6. Chaudhuri A,Behan PO. Fatigue and basal ganglia. J Neurol Sci 2000;179:34-42.

7. Jackson MF, Quaal C, Reeves MA. Effects of multiple sclerosis on occupational and career patterns. Axone 1991;13:16-17, 20-12.

8. Smith MM, Arnett PA. Factors related to employment status changes in individuals with multiple sclerosis. Mult Scler 2005;11:602-609.

9. Christodoulou C. The assessment and measurement of fatigue. In: DeLuca J. (eds): Fatigue as a window to the brain. Cambridge: The MIT press; 2005, p. 19-35.

10. Smets EM, Garssen B, Bonke B,De Haes JC. The Multidimensional Fatigue Inventory (MFI); Psychometric qualities of an instrument to assess fatigue. J Psychosom Res 1995;39:315-325.

11. Deluca J. Fatigue, cognition and mental effort. In: Deluca J. (eds): Fatigue as a window to the brain. Cambridge: The MIT press; 2005, p. 37-57.

12. Bryant B, Chiaravalloti ND, DeLuca J. Objective Measurement of Cognitive Fatigue in Multiple Sclerosis. Rehab Psychol 2004;49:114-122.

13. Krupp LB, Elkins LE. Fatigue and declines in cognitive functioning in multiple sclerosis. Neurology 2000;55:934-939.

14. Kujala P, Portin R, Revonsuo A, Ruutiainen J. Attention related performance in two cognitively different subgroups of patients with multiple sclerosis. J Neurol Neurosurg Psychiatry 1995;59:77-82.

15. Schwid SR, Tyler CM, Scheid EA, Weinstein A, Goodman AD, McDermott MP. Cognitive fatigue during a test requiring sustained attention: a pilot study. Mult Scler 2003;9:503-508.

16. Ford H, Trigwell P, Johnson M. The nature of fatigue in multiple sclerosis. J Psychosom Res 1998;45:3338.

17. Schreurs KM, de Ridder DT, Bensing JM. Fatigue in multiple sclerosis: reciprocal relationships with physical disabilities and depression. J Psychosom Res 2002;53:775-781.

18. Trojan D, Arnold D, Collet JP, Shapiro S, Bar-Or A, Robinson A, Le Cruguel JP, Ducruet T, Narayanan S, Arcelin K, Wong A, Tartaglia M, Lapierre Y, Caramanos Z, Da Costa D. Fatigue in multiple sclerosis: association with disease-related, behavioural and psychosocial factors. Mult Scler 2007;13:985-995.

19. Bakshi R, Shaikh ZA, Miletich RS, Czarnecki D, Dmochowski J, Henschel K, Janardhan V, Dubey N, Kinkel PR. Fatigue in multiple sclerosis and its relationship to depression and neurologic disability. Mult Scler 2000;6:181-185.

20. Fisk JD, Pontefract A, Ritvo PG, Archibald CJ, Murray TJ. The impact of fatigue on patients with multiple sclerosis. Can J Neurol Sci 1994;21:9-14.

21. Krupp LB, Alvarez LA, LaRocca NG, Scheinberg LC. Fatigue in multiple sclerosis. Arch Neurol 1988;45:435437.

22. Bakshi R, Miletich RS, Henschel K, Shaikh ZA, Janardhan V, Wasay M, Stengel LM, Ekes R, Kinkel PR. Fatigue in multiple sclerosis: cross-sectional correlation with brain MRI findings in 71 patients. Neurology 1999;53:1151-1153.

23. Mainero C, Faroni J, Gasperini C, Filippi M, Giugni E, Ciccarelli O, Rovaris M, Bastianello S, Comi G, Pozzilli C. Fatigue and magnetic resonance imaging activity in multiple sclerosis. J Neurol 1999;246:454-458. 
24. Van der Werf SP, Jongen PJ, Lycklama a Nijeholt GJ, Barkhof F, Hommes OR, Bleijenberg G. Fatigue in multiple sclerosis: interrelations between fatigue complaints, cerebral MRI abnormalities and neurological disability. J Neurol Sci 1998;160:164-170.

25. Tartaglia MC, Narayanan S, Francis SJ, Santos AC, De Stefano N, Lapierre Y, Arnold DL. The relationship between diffuse axonal damage and fatigue in multiple sclerosis. Arch Neurol 2004;61:201-207.

26. Codella M, Rocca MA, Colombo B, Martinelli-Boneschi F, Comi G, Filippi M. Cerebral grey matter pathology and fatigue in patients with multiple sclerosis: a preliminary study. J Neurol Sci 2002;194:71-74.

27. Greim B, Benecke R, Zettl UK. Qualitative and quantitative assessment of fatigue in multiple sclerosis (MS). J Neurol 2007;254 Suppl 2:I158-64.

28. Wallin MT, Wilken JA, Kane R. Cognitive dysfunction in multiple sclerosis: Assessment, imaging, and risk factors. J Rehabil Res Dev 2006;43:63-72.

29. Yamada T, Alpers DH, Kaplowitz N, Laine L, Owyang C, Powell DW. Textbook of Gastroenterology. Philadelphia: Lippincott Williams \& Wilkins; 2003.

30. McDonald WI, Compston A, Edan G, Goodkin D, Hartung HP, Lublin FD, McFarland HF, Paty DW, Polman $\mathrm{CH}$, Reingold SC, Sandberg-Wollheim M, Sibley W, Thompson A, van den Noort S, Weinshenker BY, Wolinsky JS. Recommended diagnostic criteria for multiple sclerosis: guidelines from the International Panel on the diagnosis of multiple sclerosis. Ann Neurol 2001;50:121-127.

31. Lennard-Jones JE. Classification of inflammatory bowel disease. Scand J Gastroenterol 1989;170:2-6.

32. Havlikova E, Rosenberger J, Nagyova I, Middel B, Dubayova T, Gdovinova Z, Groothoff J, Van Dijk J. Clinical and psychosocial factors associated with fatigue in patients with Parkinson's disease. Parkinsonism Relat Disord 2007; 14:187-192.

33. Lou JS, Kearns G, Oken B, Sexton G, Nutt J. Exacerbated physical fatigue and mental fatigue in Parkinson's disease. Mov Disord 2001;16:190-196.

34. Minderhoud IM, Oldenburg B, van Dam PS, van Berge Henegouwen GP. High prevalence of fatigue in quiescent inflammatory bowel disease is not related to adrenocortical insufficiency. Am J Gastroenterol 2003;98:1088-1093.

35. Schuhfried G. Wiener test systems. Mödling: dr. G. Schuhfried; 1993.

36. Salthouse TA, Hedden T. Interpreting reaction time measures in between-group comparisons. J Clin Exp Neuropsychol 2002;24:858-872.

37. Filippi M, Rocca MA, Arnold DL, Bakshi R, Barkhof F, De Stefano N, Fazekas F, Frohman E, Wolinsky JS. EFNS guidelines on the use of neuroimaging in the management of multiple sclerosis. Eur J Neurol 2006;13:313-325.

38. De Groot JC, de Leeuw F, Oudkerk M, van Gijn J, Hofman A, Jolles J, Breteler MMB. Cerebral white matter lesions and cognitive function: The Rotterdam scan study. Ann Neurol 2000;47:145-151.

39. Horikoshi T, Yagi S, Fukamachi A. Incidental high-intensity foci in white matter on T2-weighted magnetic resonance imaging. Frequency and clinical significance in symptom-free adults. Neuroradiology 1993;35:151-155.

40. Van Walderveen MA, Barkhof F, Hommes OR, Polman CH, Tobi H, Frequin ST, Valk J. Correlating MRI and clinical disease activity in multiple sclerosis: relevance of hypointense lesions on short-TR/short-TE (T1weighted) spin-echo images. Neurology 1995;45:1684-1690.

41. Van Walderveen MA, Truyen L, van Oosten BW, Castelijns JA, Lycklama a Nijeholt GJ, van Waesberghe JH, Polman C, Barkhof F. Development of hypointense lesions on T1-weighted spin-echo magnetic resonance images in multiple sclerosis: relation to inflammatory activity. Arch Neurol 1999;56:345-351.

42. Kurtzke JF. Rating neurologic impairment in multiple sclerosis: an expanded disability status scale (EDSS). Neurology 1983;33:1444-1452.

43. Lichtiger S, Present DH, Kornbluth A, Gelernt I, Bauer J, Galler G, Michelassi F, Hanauer S. Cyclosporine in severe ulcerative colitis refractory to steroid therapy. N Engl J Med 1994;330:1841-1845.

44. Zigmond AS, Snaith RP. The hospital anxiety and depression scale. Acta Psychiatr Scand 1983;67:361-370. 
45. Spinhoven P, Ormel J, Sloekers PP, Kempen GI, Speckens AE, Van Hemert AM. A validation study of the Hospital Anxiety and Depression Scale (HADS) in different groups of Dutch subjects. Psychol Med 1997;27:363-370.

46. Bjelland I, Dahl AA, Haug TT, Neckelmann D. The validity of the Hospital Anxiety and Depression Scale. An updated literature review. J Psychosom Res 2002;52:69-77.

47. Schmand B, Lindeboom J, van Harskamp, F. De Nederlandse Leestest voor Volwassenen. Lisse: Swets \& Zeitlinger; 1992.

48. Meijman TF. Mental fatigue and the efficiency of information processing in relation to work times. Int J Ind Ergon 1997;20:31-38.

49. Boksem MA, Meijman TF, Lorist MM. Effects of mental fatigue on attention: An ERP study. Brain Res. Cogn Brain Res 2005;25:107-116.

50. Van der Linden D, Frese M, Meijman TF. Mental fatigue and the control of cognitive processes: effects on perseveration and planning. Acta Psychol 2003;113:45-65.

51. Gupta G, Gelfand JM, Lewis JD. Increased risk for demyelinating diseases in patients with inflammatory bowel disease. Gastroenterology 2005;129:819-826.

52. DeLuca J, Genova HM, Hillary FG, Wylie G. Neural correlates of cognitive fatigue in multiple sclerosis using functional MRI. J Neurol Sci 2008;270:28-39.

53. Filippi M, Rocca MA, Colombo B, Falini A, Codella M, Scotti G, Comi G. Functional magnetic resonance imaging correlates of fatigue in multiple sclerosis. Neuroimage 2002;15:559-567.

54. Logothetis NK. What we can do and what we cannot do with fMRI. Nature 2008;453:869-878.

55. DeLuca J. Fatigue, its definition, its study and its future. In: Deluca J. (eds): Fatigue as a window to the brain. Cambridge: The MIT press;2005, p. 319-325.

56. Deary V, Chalder T, Sharpe M. The cognitive behavioural model of medically unexplained symptoms: a theoretical and empirical review. Clin Psychol Rev 2007;27:781-797.

57. Donovan KA, Small BJ, Andrykowski MA, Munster P, Jacobsen PB. Utility of a cognitive-behavioral model to predict fatigue following breast cancer treatment. Health Psychol 2007;26:464-472. 



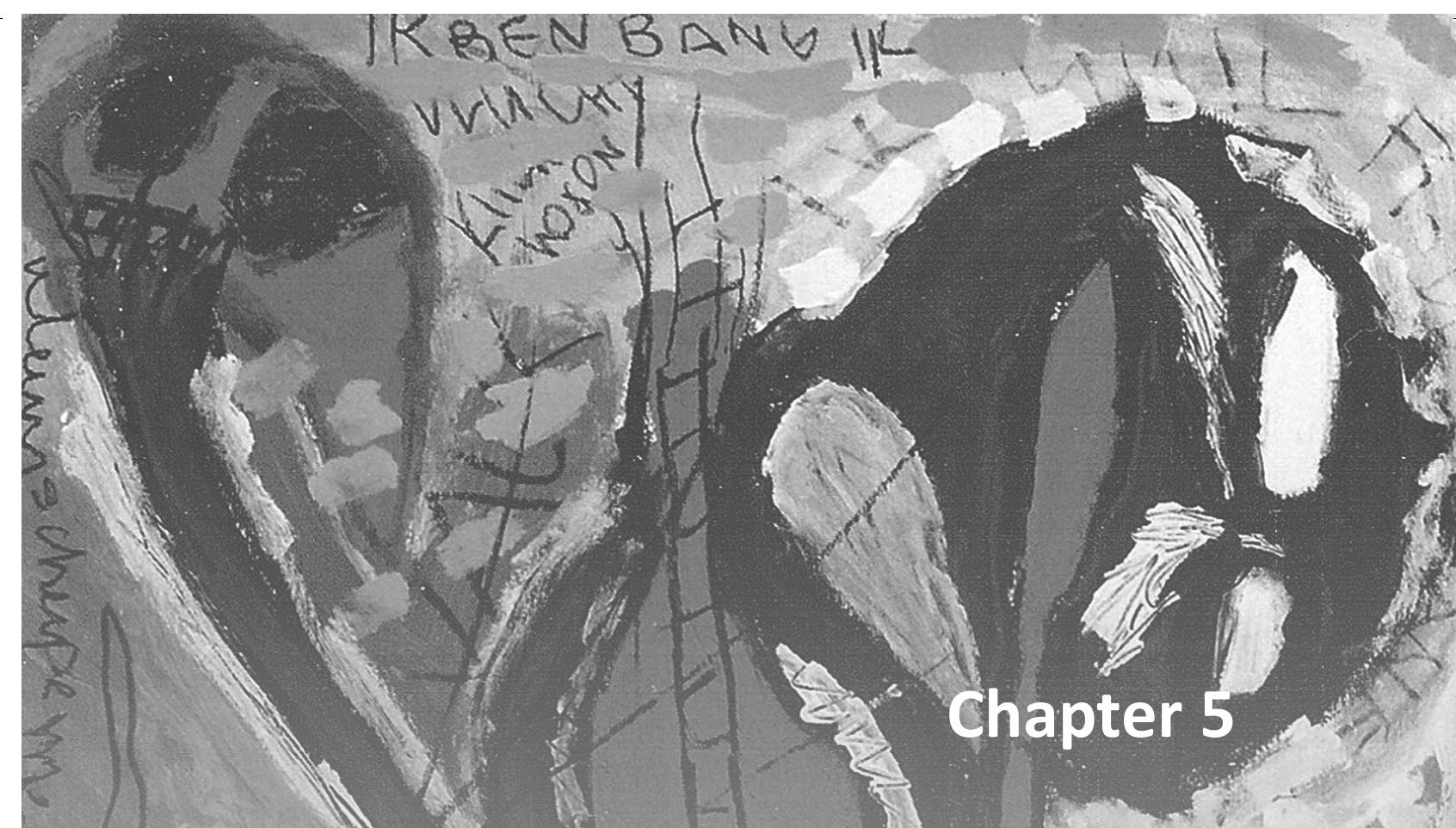

The contribution of disease severity, depression and negative affectivity to fatigue in multiple sclerosis: A comparison with ulcerative colitis

Y Bol, AA Duits, CER Vertommen-Mertens, RMM Hupperts, MJL Romberg-Camps, FRJ Verhey \& JWS Vlaeyen

Accepted for publication in Journal of Psychosomatic Research 


\section{Abstract}

Background: Fatigue is one of the most common and troubling symptoms of multiple sclerosis (MS) and more severe and disabling than fatigue in other somatic populations. Although fatigue seems MS specific, its pathogenesis is still poorly understood.

Objective: To study the disease specificity of fatigue in MS by comparing its level, its physical and psychological correlates to those of patients with ulcerative colitis (UC), a peripheral chronic auto-immune disease. We focused on the relative contribution of disease severity, depression and negative affectivity to fatigue in both patient samples.

Methods: A total of $88 \mathrm{MS}$ and 76 UC patients were included in this cross-sectional study. Fatigue, depression and negative affectivity were assessed respectively with the physical and mental fatigue subscales of the Multidimensional Fatigue Inventory; the depression subscale of the Hospital Anxiety and Depression Scale; and the neuroticism subscale of the Dutch NEO Five-Factor Inventory. The Expanded Disability Status Scale and the Colitis Activity Index were used to measure disease severity in MS and UC patients respectively.

Results: While levels of both physical and mental fatigue were significantly higher in MS patients than in UC patients, there were no group differences in the contribution of disease severity, depression and negative affectivity to both physical and mental fatigue.

Conclusion: Although levels of fatigue are higher for MS patients when compared with UC patients, the correlates of fatigue do not indicate MS specificity. As such our results support a trans-diagnostic approach to fatigue in MS. 


\section{Introduction}

Fatigue is one of the most common and disabling symptoms of multiple sclerosis (MS), but its aetiology is still poorly understood $[1,2]$. Up to $92 \%$ of the patients with MS complain of fatigue and over two-thirds of patients characterize it as the most troubling symptom [3]. Fatigue in MS is more severe and disabling compared to fatigue in healthy controls and several other somatic populations [4-9]. Usually, fatigue in MS presents as a chronic symptom, but it may also precede or accompany exacerbations [10-12]. Fatigue is frequently the presenting symptom at the time of diagnosis [5], and it is even reported as the only symptom of an acute relapse [13]. These findings suggest that fatigue is intrinsic to MS, but even though there is increasing evidence for the role of disease-related pathophysiological mechanisms in MS-related fatigue, these mechanisms can only explain a small part of the variance [1, 2].

Since fatigue in MS is defined as a subjective experience [14], psychological variables are expected also to contribute to MS-related fatigue. Moreover, fatigue in a chronic illness often co-occurs with negative affect [15]. Compared to other chronic illnesses, depression is more common in MS, and MS patients are especially at risk for fatigue [16-18]. There is also evidence that the personality trait negative affectivity, also called neuroticism or emotional instability, plays an important role in the experience of chronic symptoms, including fatigue [19]. A few studies [4, 7, 20, 21] have examined the impact of negative affectivity on fatigue in MS, and in two of these studies significant associations between negative affectivity and fatigue have been found [4, 20]. In the study by Penner et al. [7] the relationship between negative affectivity and fatigue disappeared after controlling for depression in both groups, which suggests that the effect of negative affectivity on fatigue is mediated by depression.

Fatigue is a common symptom in chronic diseases and it is a multidimensional phenomenon that may be caused by many non-specific disease-related factors [15]. While there have been many efforts to study fatigue in MS and the factors affecting it, most of the studies have focused on comparison with healthy controls or they did not even use a control group. In contrast, the present study compared fatigue in MS to that in patients with ulcerative colitis (UC), which was taken as an example of another chronic auto-immune disease. UC is an inflammatory bowel disease without obvious CNS involvement, but like MS it is a chronic, intermittent, and disabling disease, characterized by a lifetime risk of relapses, that starts between the ages of 20 and 40 [22].

To study the specificity of fatigue in MS, we first compared the levels of fatigue in both patient groups. Next, we explored the relative contribution of disease severity, depression and negative affectivity to fatigue in MS patients compared to UC patients. Besides overall relevance in both samples, we expected that both disease severity and depression contribute more to fatigue in MS patients than in UC patients; whereas we 
expected negative affectivity to contribute less to fatigue levels in MS patients than in UC patients.

\section{Methods}

\section{Patient samples}

Eighty-eight MS patients and 76 UC patients were included in this cross-sectional study, which was conducted in the period from July 2004 to December 2006. The MS patients were recruited from the Department of Neurology of the Maastricht University Medical Centre (MUMC, Maastricht, the Netherlands), which performs both a local and regional function. Consecutively referred patients who showed up at the outpatients clinic, were aged 18 to 60 years, and were diagnosed with clinically definite MS [23], were asked to participate in the study. The UC patients were selected with the help of the Inflammatory Bowel Disease (IBD) South Limburg database of the Department of Gastroenterology at the MUMC. UC patients who had been diagnosed using the Lennard-Jones criteria [24] were selected from the IBD database and matched with the MS patients on the basis of sex and age.

In order to study fatigue in patients in whom the disease was not active, we excluded patients who had had an exacerbation within the past 4 weeks. In the case of MS patients an exacerbation was defined as a sudden onset or increase within 24 hours of a symptom that resolves fully or partially over the course of weeks and for which a neurologist was consulted. An exacerbation of UC was defined as a score of 10 or more on the Colitis Activity Index [25] (see measurements). MS patients with a Kurtzke Expanded Disability Status Scale (EDSS) score >8 [26] were also excluded, because patients in this range of scores generally have impaired function of the upper limbs, which may interfere with psychological testing. Other exclusion criteria were: use of corticosteroids, somatic co-morbidity, dementia, or severe cognitive dysfunction and visual, verbal and/or motoric limitations that interfere with psychological testing.

\section{Measurements}

We used a multidimensional assessment approach, based on the physical and mental fatigue subscales of the Multidimensional Fatigue Inventory (MFI) [27]. Both of these subscales consist of four items with a 5-point response format with scores ranging from 4 to 20. The statements refer to aspects of fatigue during the past few days. Higher scores indicate more physical or mental fatigue. The MFI is generally used in the case of patients with chronic (neurological) diseases [4, 28, 29], and the Dutch language version has shown good reliability and validity [27]. In this study Cronbach's alphas of both 
subscales were respectively .80 and .89 for the MS sample and .90 and .89 for the UC sample.

The Expanded Disability Status Scale (EDSS) [26], assessed by the patient's own neurologist $(\mathrm{RH})$, who is an experienced MS neurologist familiar with EDSS recording, provided a measure of disease severity in MS patients. The EDSS is divided into 8 functioning systems (pyramidal, cerebellar, brainstem, mental, bowel and bladder, visualoptic, sensory, and other). Impairment in each system is graded separately by means of neurological examination. EDSS-scores range from 0 to 10, with 0 being normal neurological examination and 10 being death due to MS. The Colitis Activity Index (CAI) was used to measure disease severity in the case of UC patients [25]. For practical reasons, one item of the CAI (i.e. abdominal tenderness assessed by a clinician) was not included. We did use the other 7 items of the CAl, including the number of daily liquid stools; presence of nocturnal diarrhoea; occurrence of faecal incontinence; severity of abdominal pain; percentage of bowel movements with visible blood in the stool; perceived general well being; and the use of anti-diarrhoeal medication. The total score of this version of the CAI ranges from 0 to 18 . Both the EDSS and CAI are widely used as an outcome measure for monitoring the disease course. Higher scores on both measures indicate a higher level of disease severity.

The depression subscale of the Hospital Anxiety and Depression Scale (HADS) [30] was used to assess depressive complaints. This instrument has been especially designed to screen physically ill patients for the assessment of anxiety and depression; it does not include somatic symptoms. By making use of this instrument, we could ensure that fatigue and depression were measured as separate entities. The subscale depression consists of 7 items (scores ranging from 0 to 21). Higher scores indicate more complaints of depression. Reliability and validity are adequate for the Dutch population [31]. In this study Cronbach's alphas were respectively .85 for the MS sample and .82 for the UC sample.

Negative affectivity was assessed with the neuroticism subscale of the Dutch NEO Five-Factor Inventory (P-NEO-FFI), which is a reliable and valid personality questionnaire [32]. This subscale consists of 12 statements, rated on a 5-point scale and resulting in total dimension scores ranging from 12 to 70 . Higher scores indicate higher levels of neuroticism. Internal consistency of the neuroticism subscale in this study was high with Cronbach's alphas of .86 in the MS sample and .88 in the UC sample.

\section{Procedure}

All the participants were evaluated at the Department of Psychology of the MUMC, where they completed the questionnaires. General information necessary for the description and comparison of the two patient groups was collected. This included sex and age, as well as the level of premorbid intelligence, which was measured with the Dutch 
version of the National Adult Reading Test [33]. Medical histories of the MS and UC patients (disease course, disease duration) were collected from the hospital databases. Disease duration was defined as the interval between the day of the (clinically definite) diagnosis and evaluation. UC patients completed the CAI at inclusion. For the MS patients, EDSS-scores were collected from the hospital database. If there was no recent (>3 months before inclusion) EDSS-score available, the treating neurologist was consulted for reassessment. The medical ethics committee of the MUMC approved the project and each participant gave informed consent.

\section{Data analyses}

Based on the significant results obtained from a sample of $80 \mathrm{MS}$ patients in a comparable study [20], we assumed that the number of patients included in the present study was sufficient. Data were checked for missing values, normality, outliers and extremes. Square root transformation was used for abnormally distributed variables before parametric testing. Differences in characteristics between the MS and UC group and selfreport measures were analyzed by means of independent sample Student t-tests and chi-square analyses. Because of the different ranges of both of the disease severity measures (0-10 versus $0-18$ ), the scores of the MS disease severity measure (EDSS) were linearly transformed to the range of the CAI (EDSS-score/10x18) in order to be able to directly compare the mean of disease severity in both patient samples.

Furthermore, Pearson correlation coefficients were calculated for both groups in order to examine interrelationships between independent variables (age, sex, disease duration, disease severity, depression, negative affectivity) and dependent variables (physical and mental fatigue). Fatigue levels in both patient groups were compared with the help of multiple-regression analyses that were conducted in the total sample using a forced entry method with physical and mental fatigue as outcome measures and age, sex, disease duration, disease severity, depression, negative affectivity and disease as independent variables. In order to assess the contribution of disease severity, depression and negative affectivity to fatigue in both patient groups, we conducted multiple regression analyses in the MS and UC sample separately.

Next, we tested the impact of disease as a moderator between respectively disease severity, depression and negative affectivity on the one hand, and physical and mental fatigue on the other. In line with the procedure specified by Baron and Kenny [34] interaction terms were calculated (disease severity $x$ disease, depression $x$ disease, and negative affectivity $x$ disease) and entered in a second step. Before computing the interaction terms, all independent variables were centred (dichotomic variables) or transformed into standardized values (continuous variables) to avoid artificially induced multicollinearity. Because of the disease specific measurement of disease severity, we calculated standardized scores for both patient groups separately. The assumptions of 
regression analysis (absence of multicollinearity, homoscedasticy, normal distribution of the residuals, and absence of 'influential cases') were checked for all models. P-values $<0.05$ were considered significant. Analyses were carried out using the SPSS version 15.0 for Windows.

\section{Results}

\section{Demographic and clinical characteristics}

Table 1 shows the demographic and clinical characteristics of both patient groups. Most of the MS patients (66\%) had a relapsing remitting disease course, $18 \%$ had secondary progressive MS, and $16 \%$ primary progressive MS. The average EDSS score was 3.5 ( $S D=1.9$, range 0-7.5). In the UC sample, the mean CAI was 3.5 ( $S D=2.1$, range 0-9). Compared to the UC group, the MS had higher ratings on disease severity, but shorter disease duration. On average, the MS patients had higher scores on physical fatigue, mental fatigue, and depression than the UC patients. Levels of negative affectivity were equal in both patient groups.

Table 1. Demographic and clinical characteristics (mean, (SD)) of both patient groups

\begin{tabular}{lcc}
\hline & $\begin{array}{c}\text { Multiple sclerosis } \\
(\mathbf{n = 8 8})\end{array}$ & $\begin{array}{c}\text { Ulcerative colitis } \\
(\mathbf{n}=\mathbf{7 6})\end{array}$ \\
\hline Sex (\% male / \% female) & $30 / 70$ & $32 / 68$ \\
Age in years & $43.6(9.0)$ & $45.3(8.8)$ \\
Premorbid intelligence & $102.0(9.4)$ & $103.1(9.8)$ \\
Disease severity ${ }^{1}$ & $6.4(3.5)$ & $3.5(2.1)^{*}$ \\
Disease duration & $5.7(6.2)$ & $10.1(7.0)^{*}$ \\
Physical fatigue & $14.4(3.7)$ & $11.1(4.8)^{*}$ \\
Mental fatigue & $12.3(4.6)$ & $9.7(4.6)^{*}$ \\
Depression & $5.6(4.0)$ & $4.0(3.6)^{*}$ \\
Negative affectivity & $32.0(8.6)$ & $31.0(9.0)$ \\
\hline
\end{tabular}

${ }^{1}$ Because of the different range of both disease severity measures, the scores of the MS disease severity measure (EDSS) were linearly transformed into the range of the CAI (0-18) for reasons of comparison. $*_{p}<0.01$ (2-tailed)

\section{Zero-order relationships between all measures and fatigue}

The correlations between all independent variables and physical and mental fatigue in both patient groups are presented in Table 2 . In both groups, disease severity was significantly related to physical fatigue (MS: $r=0.387 ; p<0.01$, UC: $r=0.641 ; p<0.01$ ). Furthermore, in the case of both MS and UC patients, negative affectivity was significantly 
related to both physical (MS: $r=0.350, p<0.01$, UC: $r=0.522 ; p<0.01$ ) and mental fatigue (MS: $r=0.422 ; p<0.01$, UC: $r=0.569 ; p<0.01$ ). Also depression was significantly related to both physical (MS: $r=0.507, p<0.01$, UC: $r=0.521 ; p<0.01$ ) and mental fatigue (MS: $r=0.521 ; p<0.01, U C: r=0.554 ; p<0.01$ ) in both patient groups.

Table 2. Pearson correlations of all measures with fatigue in both patient groups

\begin{tabular}{|c|c|c|c|c|}
\hline & \multicolumn{2}{|c|}{$\begin{array}{l}\text { Multiple sclerosis } \\
\qquad(n=88)\end{array}$} & \multicolumn{2}{|c|}{$\begin{array}{l}\text { Ulcerative colitis } \\
\qquad(n=76)\end{array}$} \\
\hline & Physical fatigue & Mental fatigue & Physical fatigue & Mental fatigue \\
\hline Sex & -0.024 & 0.138 & 0.075 & 0.127 \\
\hline Age & 0.193 & -0.019 & 0.151 & 0.018 \\
\hline Disease duration & $0.267^{*}$ & 0.078 & $0.231^{*}$ & 0.154 \\
\hline Disease severity ${ }^{1}$ & $0.387 * *$ & -0.039 & $0.641 * *$ & 0.199 \\
\hline Depression & $0.507^{* *}$ & $0.368^{* *}$ & $0.521 * *$ & $0.554^{* *}$ \\
\hline Negative affectivity & $0.350 * *$ & $0.422 * *$ & $0.522 * *$ & $0.569 * *$ \\
\hline
\end{tabular}

${ }^{1}$ Expanded Disability Status Scale in MS and Colitis Activity Index in UC ${ }^{*} \mathrm{p}<0.05 ;{ }^{* *} \mathrm{p}<0.01$ (2-tailed)

\section{Multiple-regression analyses predicting physical and mental fatigue}

As shown in Table 3, disease independently contributed to both physical fatigue $(\beta=-0.326 ; p<0.01)$ and mental fatigue $(\beta=-0.196 ; p<0.01)$. This supported our first hypothesis that MS patients report significantly higher levels of both physical and mental fatigue compared to UC patients, also after controlling for negative affectivity, depression, disease severity, disease duration, sex, and age.

Table 3. Multiple-regression models predicting physical and mental fatigue in the total sample $(n=164)$

\begin{tabular}{lcc}
\hline & Physical fatigue & Mental fatigue \\
\hline Sex & $\beta$ & B \\
Age & 0.029 & 0.129 \\
Disease duration & 0.027 & 0.032 \\
Disease severity & 0.081 & 0.039 \\
Depression & $0.332^{* *}$ & 0.111 \\
Negative affectivity $^{1}$ & $0.279^{* *}$ & $0.307^{* *}$ \\
Disease $^{1}$ & $0.166^{*}$ & $0.321^{* *}$ \\
$R^{2}$ & $-0.326^{* *}$ & $-0.196^{* *}$ \\
\hline
\end{tabular}

${ }^{1}$ multiple sclerosis $=-1$, ulcerative colitis $=1$

${ }^{*} p<0.05 ;{ }^{* *} p<0.01$ (2-tailed) 
The contribution of disease severity, depression and negative affectivity to fatigue in both samples is shown in Table 4. In both the MS and UC sample, disease severity contributed to physical fatigue, but not to mental fatigue, explaining respectively about $6 \%$ and $26 \%$ of the variance. Depression was the largest independent contributor to physical fatigue in the MS group, accounting for about $14 \%$ of the variance, whereas depression accounted for about $9 \%$ of the variance of mental fatigue. In the UC sample, depression explained about $7 \%$ and $10 \%$ of the variance of respectively physical and mental fatigue. In both the MS and UC patient groups, negative affectivity only contributed to mental fatigue and not to physical fatigue, explaining respectively about $7 \%$ and $12 \%$ of the variance.

To test whether the factor disease would have a moderating effect on the relationships between disease severity, depression and negative affectivity on the one hand, and fatigue on the other hand, interaction terms were calculated and added to the second step (data not shown). The addition of these three interaction effects did not result in a significant increment of $R^{2}$ above that associated with the main effect model for both physical and mental fatigue (F-change $=2.319, p=0.078$; F-change $=0.337$, $p=0.799$ ). These results mean that the contribution of disease severity, depression and negative affectivity to fatigue does not significantly differ between the patient groups.

Table 4. Multiple-regression models predicting physical and mental fatigue in both patient groups

\begin{tabular}{lcccc}
\hline & \multicolumn{2}{c}{$\begin{array}{c}\text { Multiple sclerosis } \\
\text { (n=88) }\end{array}$} & \multicolumn{2}{c}{$\begin{array}{c}\text { Ulcerative colitis } \\
\text { (n=76) }\end{array}$} \\
& Physical fatigue & Mental fatigue & Physical fatigue & Mental fatigue \\
& $\beta$ & $\beta$ & $\beta$ & $\beta$ \\
\hline Sex & 0.098 & $0.234^{*}$ & -0.056 & 0.009 \\
Age & 0.024 & -0.024 & 0.024 & -0.073 \\
Disease duration & 0.144 & 0.060 & 0.072 & 0.036 \\
Disease severity & $0.215^{*}$ & -0.158 & $0.624^{* *}$ & $0.481^{* *}$ \\
Depression & $0.407^{* *}$ & $0.345^{* *}$ & $0.252^{*}$ & $0.338^{* *}$ \\
Negative affectivity & 0.116 & $0.272^{*}$ & 0.176 & $0.393^{* *}$ \\
$R^{2}$ & $0.371^{* *}$ & $0.285^{* *}$ & $0.519^{* *}$ & $0.399^{* *}$ \\
\hline
\end{tabular}

${ }^{1}$ Expanded Disability Status Scale in MS and Colitis Activity Index in UC ${ }^{*} \mathrm{p}<0.05 ; *{ }^{*} \mathrm{p}<0.01$ (2-tailed)

\section{Discussion}

The aim of the present study was to improve the understanding of fatigue in MS by comparing its level and correlates to those of UC patients, a comparable but peripheral auto-immune disease. The correlates referred to the relative contribution of disease 
severity, depression and negative affectivity to both physical and mental fatigue. The levels of both physical and mental fatigue were significantly higher in MS than in UC, suggesting MS specificity. The correlates, however, did not differ between both samples, suggesting a lack of MS specificity.

Although several previous studies did not find any association between disease severity, as measured with the EDSS, and fatigue [35-38], our study revealed that disease severity was an independent contributor to physical fatigue only, which is in line with other findings [7]. Contrary to our expectations, the groups did not differ when it came to the contribution of disease severity to fatigue. Hence, both MS and UC patients experienced more fatigue with increasing disease severity. In line with related studies in MS, which also used the so-called exclusive approach of measuring depression [38, 39], depression explained a moderate amount of the variance of both physical and mental fatigue in both patient samples. Given the problem that fatigue is a symptom of depression, we used the HADS, which excludes somatic items to ensure that fatigue and depression were measured as separate entities. This is often not the case in related studies [7, 40-42].

Whereas it became clear that depression contributed to both physical and mental fatigue in both patient samples, negative affectivity contributed to only mental fatigue. Although we did find significant correlations between negative affectivity and both physical and mental fatigue, the associations with physical fatigue disappeared after controlling for sex, age, disease duration, disease severity and depression. Our findings are in contrast to the results of Penner et al. [7], who did not find a relationship between negative affectivity and either physical or mental fatigue after controlling for disease severity, as measured with the EDSS, and depression. Several factors can explain these contradictory results, including the use of different instruments to assess fatigue and depression. Penner et al. [7] revealed that MS patients had elevated levels of negative affectivity compared to the healthy controls, and assumed that the increase of negative affectivity is related to the MS disease itself. In our study, levels of negative affectivity were equal in both patient groups. This is in accordance with other results [4] suggesting that elevated levels of negative affectivity are a feature of chronic illness and as such are not specific for MS. Our results support the need for a multidimensional assessment of fatigue, at least in a physical and mental dimension, as well as the importance of controlling for depression as a confounder.

Comparison of the independent contributors of physical and mental fatigue in both MS and UC patients revealed that there were no significant differences between these two patient groups. Given the fact that both MS and UC are auto-immune diseases, these findings could lead to a new hypothesis that immune system dysregulation is related to fatigue. However, attempts to correlate MS-related fatigue with immune system activation, assessed by circulating levels of cytokines, have so far led to inconsistent results $[43,44]$. To examine the hypothesis that MS-related fatigue is caused by 
ongoing inflammation, future studies should focus on fatigue during exacerbations instead of on chronic fatigue.

Several methodological limitations to this study need to be mentioned. Firstly, the representativeness and comparability of both patient samples can be a point of discussion. The recruitment procedure of both patient samples was different and as a result there might be a selection bias interfering with the present results. Secondly, the crosssectional design of our study makes it impossible to infer causality from the associations found. To infer causality an experimental longitudinal design would be needed. Thirdly, it is possible that strong associations between self-reported variables, such as depression, negative affectivity and fatigue are the result of similar methods of measurement. Fourthly, the measurement of disease severity in both patient groups merits further consideration. Although both the EDSS and the CAI are widely used as outcome scales for monitoring the disease course of respectively MS and UC patients, both of these scales are partly subjective. An overall biomarker of disease activity may enhance comparability across groups, but as yet no such valid and reliable biomarker is available.

Our study is unique in comparing MS patients with patients with UC, i.e. an autoimmune disease without obvious CNS involvement. Although the ideal control group is always a point of discussion, UC patients are especially appropriate as controls, because $\mathrm{UC}$ is also a chronic, intermittent, and disabling disease, that most often starts between the ages of 20 and 40 [22]. Furthermore, fatigue and depression are common symptoms in both MS and UC $[29,45,46]$, and UC is not characterized by chronic pain such as rheumatoid arthritis.

To disentangle the complex aetiology of MS-related fatigue, future research may focus on comparison with other clinical samples that have fatigue as a symptom. If there is additional evidence for non-specificity of fatigue in MS, we should use a transdiagnostic approach to fatigue. Such an approach may help to develop specific interventions and to improve the overall management of fatigue in MS patients.

Acknowledgments: We thank Prof. dr. R.J. Brummer (Department of Internal Medicine, Maastricht University Medical Centre, the Netherlands and School of Health and Medical Sciences, Örebro University, Sweden) for his advice during the planning of the project and E.G.W. Schouten (Department of Clinical Psychological Science, Faculty of Psychology and Neuroscience, Maastricht University, the Netherlands) for his statistical assistance. 


\section{References}

1. Bol Y, Duits AA, Hupperts RM, Vlaeyen JW, Verhey FR. The psychology of fatigue in patients with multiple sclerosis: A review. J Psychosom Res 2009;66:3-11.

2. Kos D, Kerckhofs E, Nagels G, D'Hooghe MB, Ilsbroukx S. Origin of fatigue in multiple sclerosis: review of the literature. Neurorehabil Neural Repair 2008;22:91-100.

3. Branas P, Jordan R, Fry-Smith A, Burls A, Hyde C. Treatments for fatigue in multiple sclerosis: a rapid and systematic review. Health Technol Assess 2000;4:1-61.

4. De Ridder D, Fournier M, Bensing J. Does optimism affect symptom report in chronic disease?; What are its consequences for self-care behaviour and physical functioning? J Psychosom Res 2004;56:341-350.

5. Krupp LB, Alvarez LA, LaRocca NG, Scheinberg LC. Fatigue in multiple sclerosis. Arch Neurol 1988;45:435-437.

6. Krupp LB, LaRocca NG, Muir-Nash J, Steinberg AD. The fatigue severity scale. Application to patients with multiple sclerosis and systemic lupus erythematosus. Arch Neurol 1989;46:1121-1123.

7. Penner IK, Bechtel N, Raselli C, Stocklin M, Opwis K, Kappos L, Calabrese P. Fatigue in multiple sclerosis: relation to depression, physical impairment, personality and action control. Mult Scler 2007;13:1161-1167.

8. Krupp L. Fatigue is intrinsic to multiple sclerosis (MS) and is the most commonly reported symptom of the disease. Mult Scler 2006;12:367-368.

9. Trojan D, Arnold D, Collet JP, Shapiro S, Bar-Or A, Robinson A, Le Cruguel JP, Ducruet T, Narayanan S, Arcelin K, Wong A, Tartaglia M, Lapierre Y, Caramanos Z, Da Costa D. Fatigue in multiple sclerosis: association with disease-related, behavioural and psychosocial factors. Mult Scler 2007;13:985-995.

10. Comi G, Leocani L, Rossi P, Colombo B. Physiopathology and treatment of fatigue in multiple sclerosis. J Neurol 2001;248:174-179.

11. Freal JE, Kraft GH, Coryell JK. Symptomatic fatigue in multiple sclerosis. Arch Phys Med Rehabil 1984;65:135-138.

12. Krupp LB, Christodoulou C. Fatigue in multiple sclerosis. Curr Neurol Neurosci Rep 2001;1:294-298.

13. Flachenecker $\mathbf{P}$, Meissner $\mathrm{H}$. Fatigue in multiple sclerosis presenting as acute relapse: subjective and objective assessment. Mult Scler 2008;14:274-277.

14. Multiple Sclerosis Council of Clinical Practice Guidelines. Fatigue and multiple sclerosis: evidence-based management strategies for fatigue in multiple sclerosis. Washington D.C.: Paralyzed Veterans of America; 1998.

15. Swain MG. Fatigue in chronic disease. Clin Sci 2000;99:1-8.

16. Schubert DS, Foliart RH. Increased depression in multiple sclerosis patients. A meta-analysis. Psychosomatics 1993;34:124-130.

17. Siegert RJ, Abernethy DA. Depression in multiple sclerosis: a review. J Neurol Neurosurg Psychiatry 2005;76:469-475.

18. Arnett PA, Barwick FH, Beeney JE. Depression in multiple sclerosis: review and theoretical proposal. J Int Neuropsychol Soc 2008;14:691-724.

19. Turk Charles S, Gatz M, Kato K, Pedersen NL. Physical health 25 years later: the predictive ability of neuroticism. Health Psychol 2008;27:369-378.

20. Merkelbach S, Konig J, Sittinger H. Personality traits in multiple sclerosis (MS) patients with and without fatigue experience. Acta Neurol Scand 2003;107:195-201.

21. Van der Werf SP, Evers A, Jongen PJ, Bleijenberg G. The role of helplessness as mediator between neurological disability, emotional instability, experienced fatigue and depression in patients with multiple sclerosis. Mult Scler 2003;9:89-94.

22. Yamada T, Alpers DH, Kaplowitz N, Laine L, Owyang C, Powell DW. Textbook of Gastroenterology. Philadelphia: Lippincott Williams \& Wilkins; 2003.

23. McDonald WI, Compston A, Edan G, Goodkin D, Hartung HP, Lublin FD, McFarland HF, Paty DW, Polman $\mathrm{CH}$, Reingold SC, Sandberg-Wollheim M, Sibley W, Thompson A, Van den Noort S, Weinshenker BY, Wolinsky JS. Recommended diagnostic criteria for multiple sclerosis: guidelines from the International Panel on the diagnosis of multiple sclerosis. Ann Neurol 2001;50:121-127. 
24. Lennard-Jones JE. Classification of inflammatory bowel disease. Scand J Gastroenterol 1989;170:2-6.

25. Lichtiger S, Present DH, Kornbluth A, Gelernt I, Bauer J, Galler G, Michelassi F, Hanauer S. Cyclosporine in severe ulcerative colitis refractory to steroid therapy. N Engl J Med 1994; 330:1841-1845.

26. Kurtzke JF. Rating neurologic impairment in multiple sclerosis: an expanded disability status scale (EDSS). Neurology 1983;33:1444-1452.

27. Smets EM, Garssen B, Bonke B, De Haes JC. The Multidimensional Fatigue Inventory (MFI); Psychometric qualities of an instrument to assess fatigue. J Psychosom Res 1995;39:315-325.

28. Havlikova E, Rosenberger J, Nagyova I, Middel B, Dubayova T, Gdovinova Z, Groothoff J, Van Dijk J. Clinical and psychosocial factors associated with fatigue in patients with Parkinson's disease. Parkinsonism Relat Disord 2007;14:187-192.

29. Minderhoud IM, Oldenburg B, van Dam PS, Van Berge Henegouwen GP. High prevalence of fatigue in quiescent inflammatory bowel disease is not related to adrenocortical insufficiency. Am J Gastroenterol 2003;98:1088-1093.

30. Zigmond AS, Snaith RP. The hospital anxiety and depression scale. Acta Psychiatr Scand 1983; 67:361-370.

31. Spinhoven P, Ormel J, Sloekers PP, Kempen GI, Speckens AE, Van Hemert AM. A validation study of the Hospital Anxiety and Depression Scale (HADS) in different groups of Dutch subjects. Psychol Med 1997;27:363-370.

32. Costa PT, McCrae RR. The NEO Personality Inventory Manual. Odessa: Psychological Assessment Resources; 1985.

33. Schmand B, Lindeboom J, van Harskamp, F. De Nederlandse Leestest voor Volwassenen. Lisse: Swets \& Zeitlinger; 1992.

34. Baron RM, Kenny DA. The moderator-mediator variable disctinction in social psychological research: conceptual, strategic and statistical considerations. J Pers Soc Psychol 1986;51:1173-1182.

35. Bakshi R, Shaikh ZA, Miletich RS, Czarnecki D, Dmochowski J, Henschel K, Janardhan V, Dubey N, Kinkel PR. Fatigue in multiple sclerosis and its relationship to depression and neurologic disability. Mult Scler 2000;6:181-185.

36. Fisk JD, Pontefract A, Ritvo PG, Archibald CJ, Murray TJ. The impact of fatigue on patients with multiple sclerosis. Can J Neurol Sci 1994;21:9-14.

37. Ford H, Trigwell P, Johnson M. The nature of fatigue in multiple sclerosis. J Psychosom Res 1998;45:33-38.

38. Skerrett TN, Moss-Morris R. Fatigue and social impairment in multiple sclerosis: The role of patients' cognitive and behavioral responses to their symptoms. J Psychosom Res 2006;61:587-593.

39. Chwastiak LA, Gibbons LE, Ehde DM, Sullivan M, Bowen JD, Bombardier CH, Kraft GH. Fatigue and psychiatric illness in a large community sample of persons with multiple sclerosis. J Psychosom Res 2005;59:291-298.

40. Flachenecker P, Kumpfel T, Kallmann B, Gottschalk M, Grauer O, Rieckmann P, Trenkwalder C, Toyka KV. Fatigue in multiple sclerosis: a comparison of different rating scales and correlation to clinical parameters. Mult Scler 2002;8:523-526.

41. Lerdal A, Celius EG, Krupp L, Dahl AA. A prospective study of patterns of fatigue in multiple sclerosis. Eur J Neurol 2007;14:1338-1343.

42. Pittion-Vouyovitch S, Debouverie M, Guillemin F, Vandenberghe N, Anxionnat R, Vespignani H. Fatigue in multiple sclerosis is related to disability, depression and quality of life. J Neurol Sci 2006;243:39-45.

43. Heesen C, Nawrath L, Reich C, Bauer N, Schulz KH, Gold SM. Fatigue in multiple sclerosis: an example of cytokine mediated sickness behaviour? J Neurol Neurosurg Psychiatry 2006;77:34-39.

44. Giovannoni G, Thompson AJ, Miller DH, Thompson EJ. Fatigue is not associated with raised inflammatory markers in multiple sclerosis. Neurology 2001;57:676-681.

45. Fuller-Thomson E, Sulman J. Depression and inflammatory bowel disease: findings from two nationally representative Canadian surveys. Inflamm Bowel Dis 2006;12:697-707.

46. Tanaka M, Kazuma K. Ulcerative colitis: factors affecting difficulties of life and psychological well being of patients in remission. J Clin Nurs 2005;14:65-73. 



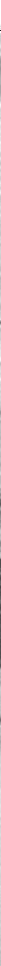

Fatigue and physical disability in patients with multiple sclerosis: A structural equation modelling approach

Y Bol, AA Duits, R Lousberg, RMM Hupperts, MHP Lacroix, FRJ Verhey \& JWS Vlaeyen Revised version submitted to Journal of Behavioral Medicine 


\begin{abstract}
Background: Although fatigue is one of the most common and disabling symptoms in patients with multiple sclerosis (MS), its pathogenesis is still poorly understood. In a biomedical approach, MS-related fatigue is assumed to be directly related to the severity of the disease; whereas in a cognitive behavioural approach it is assumed that fatigue is worsened or perpetuated not by the severity of the disease or its associated symptoms, but by the interpretation of these symptoms. The aim of the current study was to compare the assumptions of a biomedical model with those of a cognitive behavioural one.
\end{abstract}

Methods: A sample of 262 MS patients completed a battery of questionnaires assessing physical fatigue; catastrophizing about fatigue; fatigue-related fear and avoidance behaviour; depression; and physical disability. Disease severity was assessed by a neurologist using the Expanded Disability Status Scale. Structural equation modelling was applied to test both models.

Results: Neither of the models showed adequate fit of our data, and the modification indices supported an integrated cognitive behavioural model, in which catastrophizing about fatigue was a key factor that mediated the relationship between fatigue and fatigue-related fear and avoidance behaviour. Disease severity did indirectly contribute to fatigue, through fatigue-related fear and avoidance behaviour as well as physical disability. Depression appeared to be a negative consequence of physical disability, and contributed directly to both fatigue as well as to the catastrophizing about fatigue.

Conclusion: Although we did not perform cross-validation of the final model, it is clear that there are a number of relevant factors besides the severity of symptoms to be considered when trying to explain fatigue and physical disability in MS patients, viz.: catastrophizing about fatigue, and fatigue-related fear and avoidance behaviour, in combination with depression, also play an important role. Hence, the modification of catastrophic thoughts about fatigue may be a promising intervention method to help MS patients achieve their daily life goals. 


\section{Introduction}

Multiple sclerosis (MS) is a chronic inflammatory demyelinating disease of the central nervous system with an unknown pathogenesis and an unpredictable course. MS is considered to be one of the most common neurological disorders affecting young adults [1]. The clinical picture of MS is diverse, including physical and neuropsychiatric symptoms [2]. Up to $90 \%$ of patients with MS complain of fatigue [3]. Although fatigue is one of the most common and disabling symptoms in MS patients, its pathogenesis is still poorly understood $[4,5]$.

From a traditional biomedical perspective, MS-related fatigue is considered to be a primary symptom of MS that is directly related to the severity of the disease. Although there is some evidence for underlying pathophysiological mechanisms, including inflammation, demyelinisation, axonal loss and neuroendocrine dysregulation, these variables appear to explain only a small part of the variance of both MS-related fatigue and its disability $[4,5]$. More recently, a cognitive behavioural approach has been proposed which suggests that fatigue is not perpetuated or worsened by the severity of the disease or associated symptoms, but by the individual's interpretation of these symptoms $[6,7]$. Empirical evidence for such an approach has been found in cases of chronic fatigue syndrome [8-10], cancer survivors [11], and chronic pain [12, 13].

One of the key variables in recent cognitive behavioural approaches of symptom reporting is the way information is interpreted. For example, catastrophic interpretations are characterized by exaggerated negative rumination, amplification of the symptoms, and helplessness $[13,14]$; they have furthermore been shown to be associated with negative emotions. In particular, catastrophizing is associated with specific, symptom-related, fear which in turn incites avoidance behaviour and in the long term contributes to disability $[9,10,15,16]$. Also in MS there is evidence that patients who catastrophize about their fatigue and who attribute their fatigue to their illness are more likely to focus their attention on signs of fatigue and to interpret the consequences of fatigue as a sign of physical damage [6].

The aim of the current study was to compare the assumptions of a biomedical model with a cognitive behavioural conceptualization of fatigue and physical disability in MS patients. The hypothesis based on the cognitive behavioural model was that patients who catastrophically interpret their fatigue also report more fatigue-related fear and avoidance behaviour, and hence are more physically disabled and depressed $[6,7]$. In contrast, the biomedical model assigns a more prominent role to disease severity in the case of fatigue as well as depression [17-19]. Hence, it considers catastrophizing about fatigue, and fatigue-related fear and avoidance behaviour, as consequences rather than precursors of physical disability.

By applying structural equation modelling (SEM), we tested whether structural relationships between substantively meaningful variables showed a better fit with ei- 
ther of the theoretical models. In line with evidence in other populations [8-11, 13], we expected to find that the overall test of the cognitive behavioural model would show a better fit than that of the traditional biomedical model. A comparison of cognitive behavioural and biomedical models of fatigue is not merely of theoretical importance; it also has potential clinical implications, as effective treatments for fatigue in patients with MS are scarce.

\section{Methods}

\section{Participants}

Participants were recruited from the hospital databases of the Departments of Neurology of the Maastricht University Medical Centre and Atrium Medical Centre Parkstad Heerlen. A total of 404 patients aged 18 years and older and diagnosed with clinically definite MS [20], were eligible for inclusion. To preserve patient confidentiality, the initial letters were sent to these $404 \mathrm{MS}$ patients by their treating neurologist. In total 294 patients were willing to participate and contacted the researchers (73\% response rate) and all these 294 patients were screened by telephone to verify eligibility. Four patients were excluded because they had problems understanding the questionnaires. Furthermore, ten patients who had suffered from a (recent) exacerbation and were taking corticosteroids were included 4 weeks later when their condition was stabilized. A total of 290 patients were sent a patient information letter, a consent form and questionnaires. Only 20 patients failed to return these forms, leaving the total sample at 270 (93\% response rate). The medical ethics committee of both the Maastricht University Medical Centre and Atrium Medical Centre Parkstad Heerlen approved the project and each patient gave their informed consent.

\section{Measures}

The use of psychopharmaca and demographic information, including sex, age, level of education, marital status, and employment status was obtained by a demographic inventory filled out by the MS patients. The level of education was assessed by classifying formal schooling in three groups: those with at most primary education (low level of education); those with junior vocational training (average level of education); and those with senior vocational or academic training (high level of education). Medical data, including disease severity, disease course, disease duration, and disease modifying drugs were collected from the hospital databases.

The Expanded Disability Status Scale (EDSS) [21], assessed by an experienced neurologist familiar with EDSS recording $(\mathrm{RH})$, provided a measure of disease severity. The 
EDSS is divided into 8 functioning systems (pyramidal, cerebellar, brainstem, mental, bowel and bladder, visual-optic, sensory, and other). Impairment in each system is graded separately by means of neurological examination. EDSS scores range from 0 to 10 , with 0 being normal neurological examination and 10 being death due to MS. If there was no recent ( $>3$ months) EDSS score available, the treating neurologist was consulted for a new assessment.

All participants completed a battery of questionnaires assessing the following variables.

The Abbreviated Fatigue Questionnaire (AFQ) [22] was used to measure physical fatigue. The AFQ is a reliable and easily used instrument, consisting of four items ('I feel tired', 'I tire easily', 'I feel fit' and 'I feel physically exhausted'), which are rated on a 7point Likert scale with scoring alternatives ranging from "yes, that is true" to "no, that is not true". After inverting the items 1, 2 and 4, a total score was calculated (range 4-28), with higher scores indicating a higher severity of physical fatigue.

Catastrophizing about fatigue was measured with the Fatigue Catastrophizing Scale (FCS), which is an adjusted version of the Dutch version of the Pain Catastrophizing Scale (PCS) $[14,23]$. The PCS is a 13-item questionnaire that measures the frequency of catastrophizing thoughts displayed by patients about the pain they experience. Psychometric properties of the PCS appeared adequate $[24,25]$. We adapted the PCS by replacing the word 'pain' by the word 'fatigue' in all items. Scoring alternatives ranged from 'strongly disagree' to 'strongly agree'. Three MS-related items were added ("When I am tired, this is a signal there is something wrong in my brain", "When I am tired, this is a warning for physical decline", "When I am tired, this is a sign that my MS is getting worse"). The FCS consists of 16 items, with scores ranging from 0-64 and with higher scores indicating higher intensity.

The fatigue version of the Tampa Scale for Kinesiophobia (TSK-F) [10] was used to measure fatigue-related fear and avoidance behaviour. The TSK-F is an adapted version of the original 17-item TSK for chronic pain $[26,27]$, and measures the extent to which patients believe that fatigue associated with physical activity is a sign of body damage, and the extent to which they avoid physical activity because of these beliefs. To make this questionnaire adequate for fatigue the word 'pain' was replaced by the word 'fatigue' and the former item was adjusted, e.g. "I am afraid that I might make my symptoms worse if I exercise", instead of "I'm afraid that I might injure myself if I exercise". Each item is provided with a 4-point Likert scale with scoring alternatives ranging from 'not at all' to 'all the time' (with scores ranging from 17-68).

Depression was measured with the subscale depression of the Hospital Anxiety and Depression Scale (HADS) [28]. The HADS is specially designed to screen physically ill patients for anxiety and depression and does not include somatic symptoms. The depression scale consists of 7 items, with depression scores ranging from 0-21 and with 
higher scores indicating higher intensity. Scores over 7 indicate that patients are likely to be depressed. Reliability and validity are adequate for several clinical populations $[29,30]$.

The physical dimension of the Dutch version of the Short Form Health Survey (SF36) [31] was used to measure physical disability. The physical dimension includes four subscales, viz.: physical functioning, role limitations due to physical health problems, bodily pain and general health. The standardized scores (ranging from 0 to 100) of each subscale were added to lower scores indicating more physical disability. The SF-36 was found to have adequate psychometric properties [31].

\section{Analysis}

Data analysis was performed using the SPSS 15.0 version for Windows. Data were checked for missing values, normality and outliers. Of the 270 returned questionnaires, 8 cases were excluded because too many values were missing ( $\geq 25 \%$ of items of questionnaire missing or $\geq 50 \%$ if a questionnaire consisted of 4 items). For all other cases $(\mathrm{N}=26)$ all missing values were random and imputed by inserting the mean of the remaining non-missing items of the subscale. Any variables that were significantly skewed (skewness $<-1$ or $>1$ ) were transformed appropriately before parametric testing. Descriptive statistics were used to describe the sample. Cronbach's alpha was used to test reliability of all questionnaires. Pearson correlations were used to analyze relations between all variables. The models were tested and modified with the help of the computer program AMOS 16.0.1. [32]. We tested a measurement model with directly observed variables in which the error terms associated with the observed variables were left free to be estimated and also were assumed to be uncorrelated with each other. In line with the recommendations of Byrne [33], model fit was assessed using several fit indices, respectively chi-square statistic $\left(\mathrm{Chi}^{2}\right)$, goodness-of-fit index (GFI), adjusted goodness-of-fit index (AGFI), root mean square error of approximation (RMSEA), comparative fit index (CFI) and the consistent akaike information criteria (CAIC). According to guidelines for SEM, the data were considered to fit the model if the $\mathrm{Chi}^{2}$, a statistical test of lack of fit resulting from overidentifying restrictions placed in a model, was not significant. $\mathrm{Chi}^{2}$ is the most frequently used goodness-of-fit index. A statistically significant $\mathrm{Chi}^{2}$ indicates that a significant amount of observed covariance between items remains unexplained by the model, while a non-significant $\mathrm{Chi}^{2}$ implies a good fit of the model to the data. However, this index is sensitive to sample size, which is a disadvantage [34]. In a small sample, a poor fit may result in a non-significant $\mathrm{Chi}^{2}$, indicating a good fit. In a large sample, a good fit may result in a significant $\mathrm{Chi}^{2}$ indicating a poor fit. Values of the GFI and the AGFI assessing the extent to which a model provides a better fit compared to no model at all, should be high, respectively above 0.95 and 0.85 . The RMSEA was taken into account as a measure of discrepancy per degree of freedom. 
RMSEA estimates lack of fit in a model compared to a perfect model, and should therefore be small. RMSEA values up to 0.05 indicate a close fit, whereas values ranging between 0.08 and 0.10 indicate a mediocre fit and those greater than 0.10 indicate a poor fit. The CFI represents the proportionate improvement in model fit by comparing the target model with a baseline model, usually a null model in which all the observed variables are uncorrelated; CFI values larger than 0.95 indicate an adequate fit. The CAIC is used in the comparison of two or more not-nested models, with smaller values representing a better fit.

\section{Results}

\section{Patient sample}

A total of 262 outpatients (69 male, 193 female) were included. Their mean age was 47.6 years $(S D=11.7$, range $21-80)$. Most of them $(n=136)$ had a relapsing remitting disease course, while 67 patients had a secondary progressive, and 59 patients a primary progressive course. The average EDSS score was $4.0(S D=2.2$, range $0-8)$, reflecting a moderate disease severity. See table 1 for a summary of all patient characteristics.

Table 1. Patient characteristics $(n=262)$

\begin{tabular}{|c|c|c|}
\hline Sex (\% male / \% female) & $26 / 74$ & \\
\hline Age in years (mean, (SD)) & $47.6(11.7)$ & range $21.1-79.9$ \\
\hline Disease duration in years (mean, (SD)) & $8.6(7.9)$ & range $0.1-53.7$ \\
\hline Disease course (\% RR / \% SP / \% PP) & $52 / 26 / 22$ & \\
\hline EDSS (mean, (SD)) & $4.0(2.2)$ & range $0-8$ \\
\hline HADS-depression $(\%<8 / \% \geq 8)$ & $68 / 32$ & \\
\hline Use of disease modifying drugs ( $\%$ yes / $\%$ no) & $43.5 / 56.5$ & \\
\hline Use of psychopharmaca (\% yes / \% no) & $26 / 74$ & \\
\hline Level of education (\% low / \% average/ \% high) & $28 / 36 / 36$ & \\
\hline Marital status (\% partner / \% no partner) & $78 / 22$ & \\
\hline Employment status (\% working / \% not working) & $30 / 70$ & \\
\hline
\end{tabular}

$\mathrm{RR}=$ relapsing remitting; $\mathrm{SP}=$ secondary progressive; $\mathrm{PP}=$ primary progressive; $\mathrm{EDSS}=$ Expanded Disability Status Scale; HADS= Hospital Anxiety and Depression Scale.

Table 2 presents means, standard deviations, ranges, Cronbach's alphas for all variables under study, as well as their intercorrelations (Pearson). All questionnaires had excellent internal consistency as measured by Cronbach's alpha, ranging from 0.82 to 0.91 . Although all intercorrelations were statistically significant $(p<0.01)$, the strongest association was found between catastrophizing about fatigue and fatigue-related fear and 
avoidance behaviour. Higher levels of catastrophizing about fatigue were related to higher levels of fatigue-related fear and avoidance behaviour $(r=0.64, p<0.001)$. The lowest association was found between disease severity and catastrophizing about fatigue $(r=0.17, p<0.01)$.

Table 2. Means, standard deviations (SD), ranges, Cronbach's alphas ( $\alpha$ ) and Pearson-correlations of all measures

\begin{tabular}{lcccccccc}
\hline & Mean (SD) & Range & $\mathbf{\alpha}$ & $\mathbf{2}$ & $\mathbf{3}$ & $\mathbf{4}$ & $\mathbf{5}$ & $\mathbf{6}$ \\
\hline 1. Disease severity (EDSS) & $4.0(2.2)$ & $0-8$ & - & $-.27^{* *}$ & $.17^{*}$ & $.25^{* *}$ & $.26^{* *}$ & $-.58^{* *}$ \\
2. Physical fatigue (AFQ) & $19.8(6.6)$ & $4-28$ & .91 & - & $.56^{* *}$ & $.37^{* *}$ & $.49^{* *}$ & $-.60^{* *}$ \\
3. Catastrophizing about fatigue (FCS) & $20.4(15.1)$ & $0-64$ & .91 & - & - & $.64^{* *}$ & $.57^{* *}$ & $-.57^{* *}$ \\
4. Fatigue-related fear and avoidance (TSK-F) & $37.9(9.4)$ & $17-61.82$ & - & - & - & $.50^{* *}$ & $-.56^{* *}$ \\
5. Depression (HADS-D) & $6.0(4.2)$ & $0-21.83$ & - & - & - & - & $-.57^{* *}$ \\
6. Physical disability (SF-36) & $246.3(87.0)$ & $15-390.91$ & - & - & - & - & - \\
\hline
\end{tabular}

EDSS= Expanded Disability Status Scale; $A F Q=$ Abbreviated Fatigue Questionnaire; FCS= Fatigue Catastrophizing Scale; TSK-F= Fatigue version of the Tampa Scale for Kinesiophobia; HADS= Hospital Anxiety and Depression Scale; SF-36= Short Form Health Survey. ${ }^{*} p<0.01 ;{ }^{* *} p<0.001$.

\section{Structural equation modelling analyses}

An overview of all goodness-of-fit indices is displayed in Table 3. Figure 1 depicts the SEM results for the cognitive behavioural model (model 1). None of the goodness-of-fit indices satisfied the a priori criteria for a good model fit. Although all hypothesized relationships of the biomedical model (model 2, figure 2) were statistically significant, SEM analyses of this model also revealed an unacceptable fit. As such, neither of the initial models that were designed a priori fit our data.

Although SEM is generally used to test pre-specified conceptual models, it is often also applied in an exploratory way [32]. Since there is empirical support for both cognitive behavioural and biomedical factors in explaining MS-related fatigue, it was anticipated that the exploratory use of SEM, including factors of both models, would improve the overall understanding of fatigue and physical disability in MS. To explore whether a better fitting model existed, we adapted the cognitive behavioural model by adding relationships suggested by the modification indices (MI) provided by the AMOS program [33, 34]. A MI represents the value that $\mathrm{Chi}^{2}$ is expected to decrease if such a relationship would be included. In this way new causal relationships can be identified that improve the model. Because SEM is a theoretically driven technique we only added theoretically meaningful modifications. We subsequently added the relationships between disease severity and physical disability ( $\mathrm{Ml}=80.10)$; physical disability and depression ( $\mathrm{Ml}=33.77)$; depression and catastrophizing about fatigue ( $\mathrm{Ml}=12.97)$; and disease severity and fatigue-related fear and avoidance behaviour ( $\mathrm{Ml}=10.56$ ). Finally, we successively deleted non-significant relationships in order to explain as much variance as 
possible with a minimum of variables (principle of maximum parsimony). We deleted two non-significant relationships, respectively the path from disease severity to fatigue and from fatigue-related fear and avoidance behaviour to depression and subsequently refitted each model. The final model (see Table 3 and Figure 3) had acceptable GFI, AGFI, RMSEA and CFI values, and also produced the lowest CAIC value, indicating the best fit of all the models proposed.

Table 3. Goodness-of-fit summary for the models tested $(n=262)$

\begin{tabular}{|c|c|c|c|c|c|c|}
\hline & $\mathrm{Chi}^{2}$ (df) & RMSEA & GFI & AGFI & CFI & CAIC \\
\hline Model 1. Cognitive behavioural model & $202.77(8)^{* *}$ & 0.305 & 0.814 & 0.512 & 0.709 & 288.16 \\
\hline Model 2. Biomedical model & $107.76(7)^{* *}$ & 0.235 & 0.902 & 0.706 & 0.850 & 199.71 \\
\hline \multicolumn{7}{|l|}{ Model 1a: added: } \\
\hline Disease severity to physical disability & $102.15(7)^{* *}$ & 0.228 & 0.886 & 0.659 & 0.858 & 194.11 \\
\hline \multicolumn{7}{|l|}{ Model 1b: added: } \\
\hline Physical disability to depression & $52.54(6)^{* *}$ & 0.172 & 0.940 & 0.789 & 0.931 & 151.06 \\
\hline \multicolumn{7}{|l|}{ Model 1c: added: } \\
\hline Depression to catastrophizing & $25.93(5)^{* *}$ & 0.127 & 0.969 & 0.870 & 0.969 & 131.02 \\
\hline \multicolumn{7}{|l|}{ Model 1d: added: } \\
\hline Disease severity to fear-avoidance & $14.86(4)^{*}$ & 0.102 & 0.982 & 0.905 & 0.984 & 126.52 \\
\hline \multicolumn{7}{|l|}{ Final model (model 3): deleted: } \\
\hline Non significant paths & $17.44(6)^{*}$ & 0.085 & 0.979 & 0.925 & 0.983 & 115.96 \\
\hline
\end{tabular}

GFI= goodness-of-fit index; $\mathrm{AGFI}=$ adjusted goodness-of-fit index; RMSEA= root mean square error of approximation; $\mathrm{CFI}=$ comparative fit index; $\mathrm{CAIC}=$ consistent akaike information criteria.

Catastrophizing= catastrophizing about fatigue; Fear-Avoidance= Fatigue-related fear and avoidance behaviour ${ }^{*} \mathrm{p}<0.01 ;{ }^{* *} \mathrm{p}<0.001$.

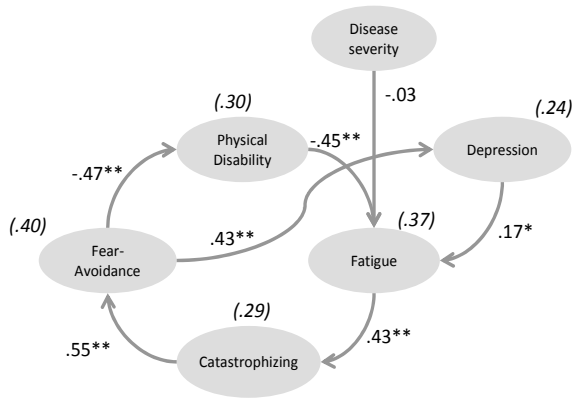

Figure 1. Cognitive behavioural model

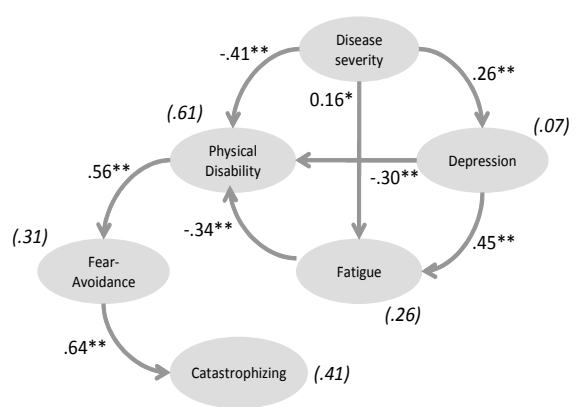

Figure 2. Biomedical model

Fear-Avoidance $=$ Fatigue-related fear and avoidance behaviour; Catastrophizing $=$ catastrophizing about fatigue. Values shown are standardized regression coefficients. Explained variances are provided in parentheses. ${ }^{*} p<0.01 ;{ }^{* *} p<0.001$. 


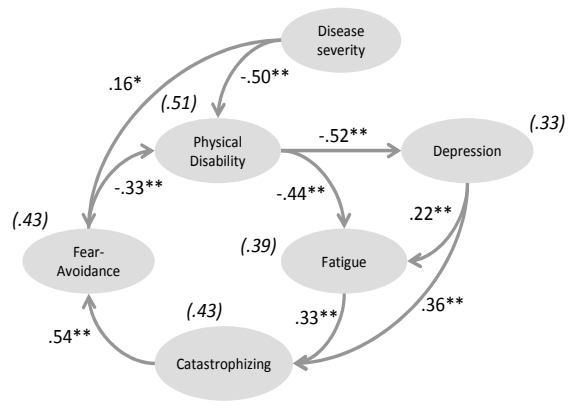

Figure 3. Final model

Fear-Avoidance $=$ Fatigue-related fear and avoidance behaviour; Catastrophizing = catastrophizing about fatigue. Values shown are standardized regression coefficients. Explained variances are provided in parentheses. ${ }^{*} \mathrm{p}<0.01 ;{ }^{*} \mathrm{p}<.0 .001$

\section{Discussion}

The aim of the current study was to compare the assumptions of a traditional biomedical model with those of a cognitive behavioural model. In particular, we tested and explored the role of catastrophic (mis)interpretations on MS-related fatigue and physical disability. In contrast to the biomedical model, the cognitive behavioural model's main assumption is that fatigue is not perpetuated or worsened by disease severity or associated symptoms, but by the interpretation of these symptoms by the patient.

SEM revealed that neither of the initial models showed adequate fit of our data. By using the modification indices, the cognitive behavioural model was modified by adding several theoretically meaningful relationships and deleting non-significant relationships. The final model met all the preset fit criteria, and was generally in line with the fearavoidance model of chronic pain [13]. Catastrophic interpretations of fatigue such as "When I am tired, this is a signal there is something wrong in my brain" and "When I am tired, this is a sign that my MS is getting worse", seemed to be a key factor and mediated the relationship between fatigue and fatigue-related fear and avoidance behaviour. Hence, catastrophizing is an important target for cognitive behavioural interventions during which dysfunctional fatigue-related thoughts can be challenged [35]. In this kind of a cognitive treatment, patients are given the opportunity to test the credibility of their beliefs in catastrophic outcomes, and to correct these accordingly.

Furthermore, depression appeared to play an important role in our model. Depression was a negative consequence of increased disability, and directly contributed to fatigue and catastrophizing about fatigue. Depression is known to be the most common psychiatric disorder in MS, with an estimated prevalence ranging between $27 \%$ and $54 \%$ 
[36-39]. Therefore, we recommend the screening of fatigued MS patients for depression and the treatment of this psychiatric co-morbidity.

In contrast to the fear-avoidance model in chronic pain, disease severity played a prominent role in the adjusted cognitive behavioural model of fatigue in MS. Disease severity indirectly contributed to fatigue, through fatigue-related fear, avoidance behaviour, and physical disability. MS patients with higher levels of disease severity seem to experience more fear-related cognitions, and hence more physical disability. It is possible that information about the disease heightens the fear of fatigue, which may lead to a decrease in physical activity, that in turn may cause an increase in fatigue levels.

Our results are in line with the findings of the first randomized clinical trial of cognitive behavioural therapy (CBT) for fatigue in MS patients [40]. In this study, eight weekly sessions of CBT appeared to be more effective in reducing self-reported fatigue than relaxation therapy. Not only fatigue, but also fatigue-related disability and depression showed a significant decrease. The intervention in this study was a general one that included only one session focused on changing negative thoughts. The effectivity of interventions might be increased by challenging cognitive misinterpretations of MSrelated fatigue more systematically.

\section{Limitations}

There are several limitations to this study, which should be taken into account when interpreting the results and which may be addressed in future studies. First of all, the design is cross-sectional, making it impossible to draw firm conclusions about causal relationships between variables. Prospective and longitudinal studies are needed to infer causality. Secondly, because of our relatively small sample size, we were not able to split our sample in order to cross-validate our final model. Thirdly, we used a postal questionnaire to collect our data. Although we had a favourable response rate for a postal questionnaire, we were not able to examine the differences between responders and non-responders. As a result, a potential selection bias interfering with the present results cannot be excluded. Fourthly, our measures for catastrophizing about fatigue (FCS), and fatigue-related fear and avoidance behaviour (TSK-F) are quite new. Although both questionnaires are adaptations of valid instruments and show excellent internal consistency, their reliability and validity need to be established further. Finally, all data, including those on physical disability, were self-reported and therefore amenable to retrospective bias and social desirability effects. Furthermore, it is possible that strong associations between self-reported variables are the result of shared-method variance [41]. Future studies should also include more objective measures such as an accelerometer, which is a reliable and valid measure of daily activity levels $[42,43]$. 


\section{Conclusions}

Despite the limitations described above, this study shows that there are a number of relevant factors besides the severity of disease symptoms to be considered when trying to explain fatigue and physical disability in MS patients, viz.: catastrophizing about fatigue, and fatigue-related fear and avoidance behaviour, in combination with depression, are also relevant factors. Assuming that the final model is stable, the present results may not only contribute to a better understanding of fatigue and physical disability in MS patients, but also suggest (additional) psychological interventions that will help MS patients to achieve their daily life goals. 


\section{References}

1. Compston A, Coles, A. Multiple sclerosis. Lancet 2008;372:1502-1517.

2. Feinstein A. The clinical neuropsychiatry of multiple sclerosis. Cambridge: University Press;1999.

3. Branas P, Jordan R, Fry-Smith A, Burls A, Hyde C. Treatments for fatigue in multiple sclerosis: a rapid and systematic review. Health Technol Assess 2000; 4:1-61.

4. Bol Y, Duits AA, Hupperts RM, Vlaeyen JW, Verhey FR. The psychology of fatigue in patients with multiple sclerosis: A review. J Psychosom Res 2009;66:3-11.

5. Kos D, Kerckhofs E, Nagels G, D'Hooghe MB, Ilsbroukx S. Origin of fatigue in multiple sclerosis: review of the literature. Neurorehabil Neural Repair 2008;22:91-100.

6. Skerrett TN, Moss-Morris R. Fatigue and social impairment in multiple sclerosis: The role of patients' cognitive and behavioural responses to their symptoms. J Psychosom Res 2006;61:587-593.

7. Van Kessel K, Moss-Morris R. Understanding multiple sclerosis fatigue: a synthesis of biological and psychological factors. J Psychosom Res 2006;61:583-585.

8. Deary V, Chalder T, Sharpe $M$. The cognitive behavioural model of medically unexplained symptoms: a theoretical and empirical review. Clin Psychol Rev 2007; 27:781-797.

9. Nijs J, De Meirleir K, Duquet W. Kinesiophobia in chronic fatigue syndrome: assessment and associations with disability. Arch Phys Med Rehabil 2004; 85:1586-1592.

10. Silver A, Haeney M, Vijayadurai P, Wilks D, Pattrick M, Main CJ. The role of fear of physical movement and activity in chronic fatigue syndrome. J Psychosom Res 2002;52:485-493.

11. Donovan KA, Small BJ, Andrykowski MA, Munster P, Jacobsen PB. Utility of a cognitive-behavioral model to predict fatigue following breast cancer treatment. Health Psychol 2007;26:464-472.

12. Arntz A, Claassens L. The meaning of pain influences its experienced intensity. Pain 2004;109:20-25.

13. Leeuw M, Goossens ME, Linton SJ, Crombez G, Boersma K, Vlaeyen JW. The fear-avoidance model of musculoskeletal pain: current state of scientific evidence. J Behav Med 2007;30:77-94.

14. Sullivan MJ, Bishop SR, Pivik J. The Pain Catastrophizing Scale: Development and validation. Psychol Assess 1995; 7:524-532.

15. Jacobsen PB, Andrykowski MA, Thors CL, Broeckel JA, Horton J, Balducci L, Lyman GH. Relationship of catastrophizing to fatigue among women receiving treatment for breast cancer. J Consult Clin Psychol 2004;72:355-361.

16. Andrea H, Beurskens AJ, Kant I, Davey GC, Field AP, van Schayck CP. The relation between pathological worrying and fatigue in a working population. J Psychosom Res 2004;57:399-407.

17. Merkelbach $\mathrm{S}$, Sittinger $\mathrm{H}$, Koenig $\mathrm{J}$. Is there a differential impact of fatigue and physical disability on quality of life in multiple sclerosis? J Nerv Ment Dis 2002;190:388-393.

18. Amato MP, Ponziani G, Rossi F, Liedl CL, Stefanile C, Rossi L. Quality of life in multiple sclerosis: the impact of depression, fatigue and disability. Mult Scler 2001;7:340-344.

19. Janardhan V, Bakshi R. Quality of life in patients with multiple sclerosis. The impact of fatigue and depression. J Neurol Sci, 2002;205:51-58.

20. McDonald WI, Compston A, Edan G, Goodkin D, Hartung HP, Lublin FD, McFarland HF, Paty DW, Polman CH, Reingold SC, Sandberg-Wollheim M, Sibley W, Thompson A, van den Noort S, Weinshenker BY, Wolinsky JS. Recommended diagnostic criteria for multiple sclerosis: guidelines from the International Panel on the diagnosis of multiple sclerosis. Ann Neurol 2001;50:121-127.

21. Kurtzke JF. Rating neurologic impairment in multiple sclerosis: an expanded disability status scale (EDSS). Neurology, 1983;33:1444-1452.

22. Alberts M, Smets EM, Vercoulen JH, Garssen B, Bleijenberg G. ['Abbreviated fatigue questionnaire': a practical tool in the classification of fatigue]. Ned Tijdschr Geneeskd 1997;141:1526-1530.

23. Crombez G, Vlaeyen JWS. The Pain Catastrophizing Scale. Unpublished Dutch/Flemish translation; 1996.

24. Van Damme S, Crombez G, Vlaeyen JWS, Goubet L, v.d Broeck A, Van Houdenhove B. De Pain Catastrophizing Scale: psychometrische karakteristieken en normering. Gedragstherapie 2000;33:209-220. 
25. Crombez G, Vervaet L, Lysens R, Baeyens F, Eelen P. Avoidance and confrontation of painful, backstraining movements in chronic back pain patients. Behav Modif 1998;22:62-77.

26. Miller RP, Kori SH, Todd DD. The Tampa Scale. Unpublished Report; 1991.

27. Vlaeyen JWS, Kole-Snijders AMJ, Rotteveel AM, Ruesink R. The role of fear of movement/(re)injury in pain disability. J Occup Rehabil 1995; 5:235-252.

28. Zigmond AS, Snaith RP. The hospital anxiety and depression scale. Acta Psychiatr Scand 1983;67:361-70.

29. Spinhoven P, Ormel J, Sloekers PP, Kempen GI, Speckens AE, Van Hemert AM. A validation study of the Hospital Anxiety and Depression Scale (HADS) in different groups of Dutch subjects. Psychol Med 1997;27:363-370.

30. Bjelland I, Dahl AA, Haug TT, Neckelmann D. The validity of the Hospital Anxiety and Depression Scale. An updated literature review. J Psychosom Res 2002;52:69-77.

31. Aaronson NK, Muller M, Cohen PD, Essink-Bot ML, Fekkes M, Sanderman R, Sprangers MA, te Velde A, Verrips E. Translation, validation, and norming of the Dutch language version of the SF-36 Health Survey in community and chronic disease populations. J Clin Epidemiol 1998;51:1055-1068.

32. Arbuckle JL. Amos 16.0 User's Guide. Spring House: Amos Development Corporation; 2007.

33. Byrne BM. Structural Equation Modeling with AMOS. Basis concepts, applications and programming. New Jersey: Lawrence Erlbaum Associates; 2001.

34. Schumacker RE, Lomax RG. A beginner's guide to structural equation modeling. New Jersey: Lawrence Erlbaum Associates; 2004.

35. Swain MG. Fatigue in chronic disease. Clin Sci 2000;99:1-8.

36. Minden SL, Orav J, Reich P. Depression in multiple sclerosis. Gen Hosp Psychiatry 1987;9:426-434.

37. Sadovnick AD, Remick RA, Allen J, Swartz E, Yee IM, Eisen K, Farquhar R, Hashimoto SA, Hooge J, Kastrukoff LF, Morrison W, Nelson J, Oger J, Paty DW. Depression and multiple sclerosis. Neurology 1996;46:628-632.

38. Schiffer RB, Caine ED, Bamford KA, Levy S. Depressive episodes in patients with multiple sclerosis. Am J Psychiatry 1983;140:1498-1500.

39. Minden SL, Schiffer RB. Affective disorders in multiple sclerosis. Review and recommendations for clinical research. Arch Neurol 1990;47:98-104.

40. Van Kessel K, Moss-Morris R, Willoughby E, Chalder T, Johnson MH, Robinson E. A Randomized Controlled Trial of Cognitive Behavior Therapy for Multiple Sclerosis Fatigue. Psychosom Med 2008;70:205213.

41. Podsakoff PM, MacKenzie SB, Lee JY, Podsakoff NP. Common method biases in behavioral research: a critical review of the literature and recommended remedies. J Appl Psychol 2003;88:879-903.

42. Bassett DR, Jr. Validity and reliability issues in objective monitoring of physical activity. Res Q Exerc Sport 2000;71:S30-S36.

43. Ng AV, Kent-Braun JA. Quantitation of lower physical activity in persons with multiple sclerosis. Med Sci Sports Exerc 1997;29:517-523. 


\section{Introduction}

Fatigue is a frequent and disabling symptom in patients with multiple sclerosis (MS), and although it has been studied for over 25 years, its pathogenesis is still poorly understood. The evidence for explanatory biological factors is at best conflicting and a psychological approach may be helpful to further explain and treat fatigue in MS. Therefore the general aim of this thesis was to better understand the concept of MSrelated fatigue from a psychological perspective. As such the focus was on identifying relevant psychological factors in explaining MS-related fatigue and their added value to biological factors such as disease severity and cerebral white matter lesions.

The specific questions were:

- What is MS-related fatigue and is it related to psychological factors?

- Is cognitive functioning negatively affected by fatigue?

- How disease specific is fatigue in MS? Is fatigue associated with disease-related factors and is the contribution of disease severity and psychological factors in MS different from that in patients with a non-neurological chronic auto-immune disease?

- $\quad$ Are negative affectivity and depression risk factors for fatigue in MS?

- Does worrying about fatigue increase MS-related fatigue and physical disability?

In order to answer the first question we reviewed the literature to define MS-related fatigue and to select relevant psychological factors (Chapter 2). Next, we examined two data samples in order to answer the remaining questions, which address the relationship between fatigue and the respective psychological factors, and more specifically, the relationship of fatigue to cognition (Chapter 3), its disease specificity, and the extent to which it can be explained by depression, negative affectivity (Chapter 4 and 5), and cognitive behavioural factors (Chapter 6 ). In this concluding chapter the main findings are summarized and related topics are discussed. Furthermore, we consider some methodological issues, make recommendations for future research and discuss clinical implications.

\section{Main findings}

- MS-related fatigue is defined as a subjective experience that has both physical and mental aspects (Chapter 2).

- When studying the relationship between mental fatigue and cognition in MS, construct validity is an area of concern (Chapter 2 and 3 ). 
- Mental fatigue, together with anxiety and depression, accounts for a substantial part of the total variance of cognitive complaints (Chapter 3 ).

- Subjective fatigue does not contribute to cognitive performance (Chapter 3).

- MS patients experience higher levels of fatigue than healthy participants and than patients with ulcerative colitis (UC), a non-neurological auto-immune disease (Chapter 4 and 5).

- Levels of objective mental fatigue, defined as a decrease in performance during a vigilance task, do not differ between MS patients, UC patients and healthy participants (Chapter 4).

- Cerebral white matter lesion load is not related to mental fatigue (Chapter 4).

- Disease severity is an independent contributor to physical fatigue, but not to mental fatigue in both MS and UC patients (Chapter 4 and 5).

- Depression is related to both physical and mental fatigue, whereas negative affectivity is only related to mental fatigue, in both MS and UC patients (Chapter 5).

- The contribution of disease severity, depression, and negative affectivity to fatigue is equal in both MS and UC patients and is not MS-specific (Chapter 5).

- Disease severity contributes indirectly to physical fatigue, through fatigue-related fear and avoidance behaviour, and physical disability (Chapter 6).

- Depression appears to be a negative consequence of physical disability and it contributes directly to both fatigue and catastrophizing about fatigue (Chapter 6).

- Not just the severity of MS symptoms, but catastrophizing about fatigue and fatigue-related fear and avoidance behaviour, in combination with depression, are significant determinants of fatigue and physical disability levels in MS patients (Chapter 6).

\section{The concept of fatigue in MS: definition and assessment}

As described in Chapter 2, the consensus definition of MS-related fatigue [1] implies that fatigue has both physical and mental aspects and therefore should be assessed multidimensionally. The findings described in this thesis demonstrate the importance of such a multidimensional assessment and support the idea that physical and mental fatigue have different correlates. For instance, as described in Chapter 5, both in the case of MS and UC patients disease severity was an independent contributor to physical fatigue, but not to mental fatigue. In contrast, in both these patients groups negative affectivity was related to mental fatigue only. This multidimensional nature has also been recognized in other studies in the case of MS [2-5] as well as other chronic diseases $[6,7]$, which supports the differentiation between physical and mental fatigue. 
MS-related fatigue is not only defined as a multidimensional symptom, but also as a subjective experience; therefore the patient's report is actually the only information available with which to rate fatigue severity [8]. Nevertheless, several attempts have been made to assess fatigue objectively in order to overcome the limitations of selfreport questionnaires, such as retrospective bias. A recurrent approach is to operationalize mental fatigue in terms of a decrease in performance during a task that requires sustained mental effort [9]. In the study described in Chapter 4, we used such an approach. Our results showed that MS patients experienced more mental fatigue than healthy participants and UC patients, but that there were no differences in mental fatigue between all groups when fatigue was objectively measured by using a performance task. Although the latter finding is in contrast to other findings in MS patients [10, 11], numerous investigations of various clinical populations exist which show that there is no change in mental task performance relative to controls [12].

As already suggested by DeLuca [13], the experience of fatigue does not imply diminished performance. Although self-reported fatigue and diminished task performance are both methods with which to assess fatigue, a strong relationship between these two assessments is not obvious. Indeed, there is no significant relationship between both assessments and this conclusion is also supported by evidence in various clinical populations [9]. This is similar to the lack of an association between cognitive complaints and cognitive performance, based on neuropsychological assessment [1420].

While there is little overlap between the subjective and objective assessment of fatigue, the objective method of fatigue assessment does share a component with that of cognition in terms of performance, which leads to a problem of construct validity. Given the method used to objectify mental fatigue, a decrease in performance is equal to a decrease in cognitive performance, which may reduce the usefulness of objective measures of fatigue in research and clinical practice that is related to both fatigue and cognition. Hence, even if we do find sensitive measures with which to assess mental fatigue objectively in MS patients, the experience of fatigue and related complaints must be the starting point in daily practice [21]. As such, a subjective assessment would be sufficient for assessing both mental and physical fatigue.

\section{The impact of fatigue on cognitive functioning in MS}

While the previous paragraph ended with a plea for subjective assessment only, which was based on the relevance of the experience and the problem of construct validity of the so-called objective assessment method, our findings in Chapter 3 indicate the same problem of construct validity for the subjective assessment method. Besides fatigue, cognitive complaints are very common in patients with MS [22-24]; yet both subjective 
mental fatigue and cognitive complaints are generally measured by using questionnaires with comparable items (e.g. concentration problems), and therefore measuring mainly the same construct. This problem of construct validity has also been established by the high correlation found between subjective mental fatigue and cognitive complaints (Chapter 3).

In Chapter 3, we investigated the contribution of physical and mental fatigue to both cognitive complaints and cognitive performance respectively. Our study revealed that mental fatigue, together with anxiety and depression, accounted for a substantial part of the total variance of cognitive complaints. This result is in accordance with other findings both in MS and in other populations, which showed that cognitive complaints are often determined by such non-cognitive factors [14-16, 25-30].

Since cognitive complaints do not necessarily predict deficits in cognitive performance [14-16], it is not surprising that we failed to find a relationship between fatigue as a subjective experience and cognitive performance measures (Chapter 3 ). While one would expect, as we also did, fatigue to be related to cognitive performance in neuropsychological tests that require attention and executive functioning, neither physical nor mental fatigue appeared to be related to mental speed, attention, memory or executive functioning. Our findings are in line with recent work by Morrow et al. [31], who concluded, based on both cross-sectional and longitudinal findings, that there is little empirical support for a relationship between subjective fatigue and cognitive performance.

These results might question the clinical assumption that neuropsychological performance is adversely affected by fatigue [32]. The present findings argue against the suggestion that test sessions should be shortened. In order to ensure the valid assessment of cognitive performance in fatigued patients one does not need to reduce the number of tests. On the contrary, given the impact of cognitive impairment on daily life, and its heterogeneity in MS, both routine and extensive neuropsychological assessment is recommended to detect cognitive impairment [22, 33, 34]. In addition, and also supported by the present findings, we conclude that one cannot rely on MS patients' selfreports to obtain a reliable estimate of cognitive functioning.

\section{The specificity of fatigue in MS}

The focus of the studies described in Chapter 4 and 5 was on the disease specificity of fatigue in MS. Because fatigue is a common symptom in chronic diseases that might be caused by many non-specific disease-related factors [35], we compared levels of fatigue in MS not only to those in healthy control participants (Chapter 4), but also to levels of fatigue in patients with a comparable non-neurological auto-immune disease (Chapter 4 and 5). Ulcerative colitis (UC), an inflammatory bowel disease, was taken as an example 
of a chronic auto-immune disease without obvious CNS involvement. UC resembles MS: it is chronic, intermittent, and disabling; and it is characterized by a lifetime risk of relapses that start between the ages of 20 and 40 [36]. As shown in the study described in Chapter 4, MS patients experienced significantly higher levels of mental fatigue than both healthy control participants and UC patients. Furthermore, the study described in Chapter 5 revealed that the levels of both physical and mental fatigue were significantly higher in MS patients than those in UC patients. Our results are in line with the findings of other studies that compared fatigue in MS to that in healthy controls and to several other somatic populations $[2,4,8,37-39]$. This suggests that fatigue is specifically related to MS, and not just an non-specific consequence of disease and handicap. However, as described in Chapter 5, its correlates are not MS specific. That is, there are no differences in the contribution of disease severity, depression and negative affectivity to both physical and mental fatigue in the different patients groups.

So far, there is no evidence that pathophysiological mechanisms play a major role in contributing to fatigue in MS, which also questions the MS specificity of fatigue. For instance, the total amount of cerebral white matter lesions is not related to mental fatigue (Chapter 4). Although the existence of white matter lesions is part of the clinical diagnosis of MS [40], using structural imaging is of course an underestimation of the complexity of the CNS mechanisms in MS. Recent views propose that MS no longer primarily be considered a white matter disease, but rather a neurodegenerative disease, in which acute inflammatory demyelination and both axonal and grey matter damage are involved [41]. Several recent imaging studies show that fatigue in MS is related to both subcortical and cortical grey matter atrophy, especially in the frontal areas [42-44]. Using positron emission tomography, Roelcke et al. [45] demonstrated that fatigue is associated with reduced cerebral glucose metabolism in frontal areas and basal ganglia. These findings suggest that fatigue is associated with a disruption of brain networks involved in cognitive functioning, especially attentional and executive processing.

Recently, there has been increased interest in the use of functional MRI (fMRI), which measures the hemodynamic response related to neural activity in the CNS and offers a sensitive measure of changes in brain functioning [46]. Using fMRI, MS patients showed an increased activation in the basal ganglia and frontal regions during cognitive performance measured by a modified Symbol Digit Modalities Task (mSDMT) [13], which was interpreted as a correlate of mental fatigue in terms of a compensatory mechanism to complete the mSDMT. Like patients with traumatic brain injury, there is evidence that MS patients require much more cerebral activation to compensate for processing deficits while undertaking effortful and sustained cognitive tasks than healthy controls $[47,48]$. The additional cerebral activation that is required to perform what was previously a more automatic cerebral routine, is hypothetically a plausible mechanism underlying central fatigue [13]. 


\section{Central fatigue}

In Chapter 2, we mentioned the distinction between central and peripheral fatigue, as suggested by Chaurdhuri and Behan [6]. Central fatigue, in contrast to neuromuscular or peripheral fatigue, is defined as the failure to initiate and/or sustain attentional tasks (mental fatigue) and physical activities (physical fatigue) that require self-motivation. Although it has been suggested that central fatigue is the major cause of fatigue in chronic disease, including MS [49], it is questionable whether central fatigue explains the experience of fatigue in clinical populations. From a theoretical point of view, the distinction between central and peripheral fatigue seems a clear one, but in general practice this distinction is difficult. For instance, physical fatigue can be the result of muscle fatigue (peripheral processes) or of brain control over the muscle (central processes) [12]. Fatigue is influenced by a complex interaction between peripheral and central factors and the degree to which peripheral and/or central processes are involved is often difficult to determine, as their contribution may vary between activities and even within the same activity.

The findings of several studies described above [13] correspond to the hypothesis of Chaudhuri and Behan [49] that damage to the basal ganglia and their circuitry predisposes one to symptoms of central fatigue. However, there is no direct evidence that this mechanism is relevant. Although fMRI studies seem promising, this technique is less specific and therefore its use is questionable [46].

In sum, even though the literature regarding pathophysiological mechanisms in the explanation of MS-related fatigue is increasing, the suggested mechanisms are mainly hypothetical; even if evidence does exist, it has to be kept in mind that disease-related variables can only explain a small part of the variance. In conclusion, despite some circumstantial evidence, there is no definite proof for a disease-specific origin of fatigue in MS. Therefore our findings support a trans-diagnostic approach to fatigue.

\section{Fatigue in MS explained by negative affectivity and depression}

In Chapter 5 we studied the relationship between fatigue and respectively negative affectivity and depression. This study revealed that whereas negative affectivity contributed only to mental fatigue, depression contributed to both physical and mental fatigue. In our integrated model, which is described in Chapter 6, depression was also directly related to physical fatigue.

However, because our studies were cross-sectional, we cannot definitely answer the question whether depression and negative affectivity are risk factors for fatigue in MS. To the best of our knowledge, no longitudinal studies that focus on the relationship between negative affectivity and fatigue in MS have been conducted. However, there is 
major evidence that negative affectivity predicts several physical conditions, as has been shown in a large longitudinal cohort twin study [50]. With regard to depression, our findings are in line with two available intervention studies that suggest that fatigue is caused by depression [51, 52]. Also recent longitudinal findings ( $n=2768)$ support this relationship between fatigue and depression in MS [53]. Baseline levels of fatigue, depression, and pain accounted for about $35 \%$ of the variance in one-year follow-up fatigue scores.

There is evidence that these three symptoms, i.e. fatigue, depression, and pain form a symptom cluster in MS patients [54] and other chronic populations, including patients with rheumatoid arthritis [55] and cancer survivors [56]. A symptom cluster is defined as a stable group of two or more concurrent symptoms that are related to one another and independent of other symptoms or symptom clusters [57]. It has been suggested that symptoms in a cluster could share covariance, have a common aetiology, or have a common influence on patient outcomes. The existence of a symptom cluster in MS may provide evidence for shared common mechanisms, such as decreased activity of dopaminergic, serotonergic and noradrenergic systems [58], or increased levels of pro-inflammatory cytokines $[59,60]$. Also psychological variables, such as negative affectivity, can contribute to such a symptom cluster [50]. Furthermore, these symptoms might predict physical activity, while MS patients who are physically active report lower levels of depression, fatigue, and pain than those who are less physically active [54].

\section{Why fatigue in MS can become chronic: a model of perpetuation}

In Chapter 6, we investigated the role of catastrophic (mis)interpretations of fatigue on both fatigue and physical disability in MS patients. We compared a cognitive behavioural model with a traditional biomedical model with the help of structural equation modelling (SEM). We found evidence in favour of an integrated cognitive behavioural model, in which catastrophizing about fatigue was a key factor that mediated the relationship between fatigue and fatigue-related fear and avoidance behaviour. In contrast to the fear-avoidance model in chronic pain [61], disease severity played a prominent role in the adjusted cognitive behavioural model of fatigue in MS. Disease severity indirectly contributed to fatigue, through fatigue-related fear and avoidance behaviour as well as physical disability. Depression appeared to be a negative consequence of physical disability, and contributed directly to both fatigue as well as to catastrophizing about fatigue. The findings of Chapter 6 show, in line with evidence in MS $[62,63]$ and cancer survivors $[64,65]$, that patients who catastrophize about fatigue are prone to maintain their fatigue symptoms. Because MS is an unpredictable and incurable disabling disease, patients run the risk of negative thinking [66]. Furthermore, as our 
model shows, those patients who are depressed are especially liable to catastrophize about fatigue. In sum, our study revealed that physical fatigue is not just a consequence of disease severity, but that catastrophizing about fatigue, and fatigue-related fear and avoidance behaviour, in combination with depression, were significant determinants of fatigue and physical disability levels in MS patients.

Our model is in line with the model of predisposing, precipitating and perpetuating factors that was developed to better understand fatigue and medically unexplained symptoms in general [67-69]. Predisposing factors are characteristics of a patient that increase the chance to develop fatigue as soon as a precipitating factor is present. Examples of such predisposing factors are a genetic predisposition, negative affectivity, physical inactivity, and female sex $[67,70]$. The last may be an influencing factor in MS, because the majority of MS patients are female. However, most studies did not find a relationship between sex and fatigue in MS [71, 72]. Precipitating factors trigger the onset of fatigue in MS patients and include acute manifestations of illness or psychological stressors. It is known that fatigue often accompanies exacerbations and infections [73-75], but also life-events and stress [4]. Factors that may perpetuate fatigue once fatigue has been developed include specific cognitive and behavioural responses to fatigue and the physiological changes that may accompany these responses. These perpetuating factors, such as catastrophizing about the symptoms, symptom focusing, and the avoidance of physical activity, can maintain the fatigue symptoms over time. Also depression [52] and sleep disorders might be important perpetuating factors in MS-related fatigue [76].

The approach based on the idea of perpetuation can be useful in explaining why acute fatigue in MS patients can become chronic and it has been proven fruitful in the case of other populations [67-69]. Like the model of perpetuation, our model can be used trans-diagnostically and it differs from a more generic bio-psychosocial model by proposing a unique interaction of cognitive, behavioural, and physiological factors in the case of each individual.

\section{Methodological considerations}

In the next section we will mention the strengths and limitations of the studies described in this thesis.

\section{Strengths}

Our study is unique in comparing MS patients with patients with UC, i.e. an autoimmune disease without obvious CNS involvement. UC patients are especially appropriate as controls, because they also suffer from a chronic, intermittent, and disabling 
disease that most often starts between the ages of 20 and 40. Furthermore, fatigue and depression are common symptoms in both MS and UC, and like MS patients, UC patients are not characterized by chronic pain such as rheumatoid arthritis.

Overall, both the MS and UC patient samples are representative for clinical settings. Our studies were conducted on MS patients at the Department of Neurology of the Maastricht University Medical Centre (Chapter 3, 4, 5 and 6), which combines a regional and academic function, and at the general district hospital in Heerlen (Atrium Medical Centre Parkstad) (Chapter 6). UC patients were found by using the Inflammatory Bowel Disease (IBD) - South Limburg database of the Department of Gastroenterology of the MUMC, in which the UC patients are registered of all the three hospitals in South Limburg, i.e. the MUMC, the general district hospital in Heerlen (Atrium Medical Centre Parkstad), and the general district hospital in Sittard (Orbis Medical Centre).

Other strengths are: the adequate sample sizes (Chapter 3, 5 and 6); the multidimensional assessment of fatigue; and the integration of biological and psychological factors. Finally, in contrast to several other studies, we were able to ensure that fatigue and depression were measured as separate entities, as the Hospital Anxiety and Depression Scale was selected to assess depression.

\section{Limitations}

Evaluation of our work from a methodological viewpoint brings limitations as well as strengths to light. For example, questions about the design of the studies, patient recruitment, data collection and the assessment of the included variables.

The design we used in all studies was cross-sectional, which makes it impossible to draw firm conclusions about causal relationships between variables. Longitudinal studies with repeated measures and randomized clinical trials are needed to infer causality.

The comparability of the MS and UC samples (Chapter 4 and 5) is a point of discussion. Overall, our patient samples are representative for clinical settings, but their recruitment was different. Furthermore, we were not able to compare responders and non-responders and as a result there might be a selection bias interfering with the present results.

Most of the variables, such as fatigue, depression and physical disability, were selfreported and therefore amenable to retrospective bias and social desirability effects. Furthermore, it is possible that strong associations between self-reported variables are the result of common-method variance [77]. To adjust for common-method variance one should obtain the measures of variables from different sources. For instance, future studies should include more than one self-report instrument in order to measure symptoms such as fatigue, and more objective tools for measuring daily activity levels, such as an accelerometer $[78,79]$. 
Next, it is important to realize that we used a depression questionnaire to measure depressive symptoms and did not use a DSM-IV diagnosis of a depressive disorder [80]. To answer the question whether a depressive disorder contributes to fatigue in MS, future studies should use semi-structured clinical interviews conducted by a psychologist or psychiatrist. Furthermore, two questionnaires we used in the study described in Chapter 6, the Fatigue Catastrophizing Scale and the fatigue version of the Tampa Scale for Kinesiophobia are adaptations of valid instruments and show excellent internal consistency. However, their reliability and validity need to be established further.

Finally, the measurement of disease severity in both patient groups merits consideration. Although both the Expanded Disability Status Scale and the Colitis Activity Index are widely used as outcome scales for monitoring the disease course of respectively MS and UC patients, both scales are partly subjective. An overall biomarker of disease activity may enhance comparability across groups and would make it possible to study trans-diagnostic mechanisms such as cytokine-induced sickness behaviour. Unfortunately, no such valid and reliable biomarker is available as yet.

\section{Future research directions}

In future research, fatigue should be multidimensionally assessed, as we suggest before, and the assessment should include not only its severity but also the patient's perception and appraisal of fatigue. Instruments such as the Fatigue Catastrophizing Scale (Chapter 6) or the Fatigue Quality List [81] might be applicable. Using such a qualitative approach might also enhance our understanding of the disease specificity of fatigue in chronic illness. Furthermore, other possible relevant variables, including pain, sleep disturbances, and medication use should be included.

Besides the need to deal with the above-mentioned limitations of our integrated cognitive behavioural model it should be replicated and its stability should be tested by cross-validation. Subsequently, single case design studies need to be conducted on highly fatigued MS patients who exhibit high levels of catastrophizing about fatigue and fatigue-related fear and avoidance behaviour. Catastrophic thoughts about fatigue should be detected and adjusted by the use of behavioural experiments. Finally, assuming that our model appears to be stable and the results of the case studies are promising, the effectiveness of (cognitive) behavioural interventions should be tested in randomized clinical trials. Given the evidence in chronic fatigue syndrome [68] and cancer survivors [82, 83], graded exercise therapy and cognitive behavioural therapy could also prove to be promising in MS. The positive findings of the first randomized clinical trial of cognitive behavioural therapy for fatigue in MS patients [84] already supported this conclusion. 


\section{Implications for clinical practice}

If our findings appear to be stable in future research, they may provide a useful framework for identifying and treating MS patients at risk for chronic fatigue. With no current effective pharmacological therapy available $[85,86]$, the treatment possibilities for fatigued MS patients should focus on potentially modifiable variables with a high impact on fatigue. Depression is the most common psychiatric disorder (27-54\%) in MS and approximately $50 \%$ of the MS patients suffers from a depressive disorder during their disease course [87]. As such, and given its impact in the integrated model, depression is a relevant modifiable factor. It is important to mention that although depression is very common in MS, it is often undertreated [88, 89]. Furthermore, physical activity is an important modifiable factor to highlight, because MS is associated with reduced physical activity when compared with non-disease populations [90]. Furthermore, for many years, patients with MS have been advised to avoid exercise in order to minimize the risk of exacerbations and symptoms of fatigue [91-93]. Such advice is detrimental as it may contribute to the persistence of fatigue. The benefits of physical activity have been well documented in both healthy and somatic populations, and the potential for reducing mental and physical symptoms is substantial. Also there is evidence that exercise therapy can be beneficial and improve the quality of life of MS patients [94, 95].

What should we advise Ms. A. and Mrs. B., the two MS patients described in the introduction of this thesis? First of all, assuming that underlying somatic causes for fatigue such as a urinal infection are excluded, both patients should be screened for depression. If Ms. A. and Mrs. B. appear to be clinically depressed, they should be treated by cognitive behavioural therapy [96] and/or anti-depressive medication [97, 98]. Secondly, if both patients, after adequate treatment of their depression, still report disabling fatigue, both could benefit from cognitive behavioural interventions [84]. Such an intervention should start with a comprehensive clinical evaluation of fatigue, including all possible influencing psychological variables, such as sleep disorder, pain, catastrophizing about fatigue, fatigue-related fear and avoidance behaviour. Also a neuropsychological assessment could be included while both patients experience cognitive complaints. Neuropsychological assessment, including the additional assessment of anxiety, depression and fatigue will be needed to clearly indicate whether their experience is due to cognitive dysfunctioning, or due to mood problems and fatigue $[99,100]$. After that, both patients, and in case of Mrs. B. also her husband, should be informed that the way patients perceive and think about their fatigue could influence fatigue and physical disability. Negative thoughts about fatigue and physical activity should be detected and adjusted and physical activity should be encouraged in general. Finally, both patients could benefit from energy conserving strategies to cope with their fatigue and to optimize the use of available energy by modifying their daily activities, incorporating rest and restarting activities [101-103]. These cognitive behavioural interventions 
should be integrated in a multidisciplinary rehabilitation programme, including occupational therapy and physiotherapy to improve their overall quality of life [94, 104].

\section{Conclusion}

In the present thesis, we enhanced our knowledge and understanding of MS-related fatigue and provided insight into its psychological correlates. Of course, not all of the potential contributing factors to MS-related fatigue have been investigated in this thesis; and we acknowledge that biological factors can contribute to fatigue. Nevertheless, a psychological approach to the understanding and treatment of fatigue seems promising. Moreover, this conclusion is in line with the modern, integrated, approach in medicine. It sends out a positive message that opens new ways to treatment options for MS patients who suffer from fatigue. 


\section{References}

1. Multiple Sclerosis Council of Clinical Practice Guidelines. Fatigue and multiple sclerosis: evidence-based management strategies for fatigue in multiple sclerosis. Washington D.C.: Paralyzed Veterans of America; 1998.

2. Penner IK, Bechtel N, Raselli C, Stocklin M, Opwis K, Kappos L, Calabrese P. Fatigue in multiple sclerosis: relation to depression, physical impairment, personality and action control. Mult Scler 2007;13:11611167.

3. Pittion-Vouyovitch S, Debouverie M, Guillemin F, Vandenberghe N, Anxionnat R, Vespignani H. Fatigue in multiple sclerosis is related to disability, depression and quality of life. J Neurol Sci 2006;243:39-45.

4. Trojan D, Arnold D, Collet JP, Shapiro S, Bar-Or A, Robinson A, Le Cruguel JP, Ducruet T, Narayanan S, Arcelin K, Wong A, Tartaglia M, Lapierre Y, Caramanos Z, Da Costa D. Fatigue in multiple sclerosis: association with disease-related, behavioural and psychosocial factors. Mult Scler 2007;13:985-995.

5. Ford H, Trigwell P, Johnson M. The nature of fatigue in multiple sclerosis. J Psychosom Res 1998;45:3338.

6. Barendregt PJ, Visser MR, Smets EM, Tulen JH, van den Meiracker AH, Boomsma F, Markusse HM. Fatigue in primary Sjogren's syndrome. Ann Rheum Dis 1998;57:291-295.

7. Kalaitzakis E, Carlsson E, Josefsson A, Bosaeus I. Quality of life in short-bowel syndrome: impact of fatigue and gastrointestinal symptoms. Scand J Gastroenterol 2008;43:1057-1065.

8. Krupp L. Fatigue is intrinsic to multiple sclerosis (MS) and is the most commonly reported symptom of the disease. Mult Scler 2006;12:367-368.

9. DeLuca J. Fatigue, cognition and mental effort. In: Deluca J. (eds). Fatigue as a window to the brain. Cambridge: The MIT press; 2005, p. 37-57.

10. Krupp LB, Elkins LE. Fatigue and declines in cognitive functioning in multiple sclerosis. Neurology 2000;55:934-939.

11. Schwid SR, Tyler CM, Scheid EA, Weinstein A, Goodman AD, McDermott MP. Cognitive fatigue during a test requiring sustained attention: a pilot study. Mult Scler 2003;9:503-508.

12. DeLuca J. Fatigue, its definition, its study and its future. In: Deluca J. (eds). Fatigue as a window to the brain. Cambridge: The MIT press; 2005, p. 319-325.

13. DeLuca J, Genova HM, Hillary FG, Wylie G. Neural correlates of cognitive fatigue in multiple sclerosis using functional MRI. J Neurol Sci 2008;270:28-39.

14. Maor $\mathrm{Y}$, Olmer L, Mozes B. The relation between objective and subjective impairment in cognitive function among multiple sclerosis patients--the role of depression. Multi Scler 2001;7:131-135.

15. Middleton LS, Denney DR, Lynch SG, Parmenter B. The relationship between perceived and objective cognitive functioning in multiple sclerosis. Arch Clin Neuropsychol 2006;21:487-494.

16. Julian L, Merluzzi NM, Mohr DC. The relationship among depression, subjective cognitive impairment, and neuropsychological performance in multiple sclerosis. Mult Scler 2007;13:81-86.

17. Vingerhoets $G$, de Soete $G$, Jannes $C$. Subjective complaints versus neuropsychological test performance after cardiopulmonary bypass. J Psychosom Res 1995;39:843-853.

18. Vermeulen J, Aldenkamp AP, Alpherts WC. Memory complaints in epilepsy: correlations with cognitive performance and neuroticism. Epilepsy Res 1993;15:157-170.

19. Sawrie SM, Martin RC, Kuzniecky R, Faught E, Morawetz R, Jamil F, Viikinsalo M, Gilliam F. Subjective versus objective memory change after temporal lobe epilepsy surgery. Neurology 1999;53:1511-1517.

20. Duits A, Munnecom T, van Heugten C, van Oostenbrugge RJ. Cognitive complaints in the early phase after stroke are not indicative of cognitive impairment. J Neurol Neurosurg Psychiatry 2008;79:143-146.

21. Zwarts MJ, Bleijenberg G, van Engelen BG. Clinical neurophysiology of fatigue. Clin Neurophysiol 2008;119:2-10.

22. Benedict RH, Wahlig E, Bakshi R, Fishman I, Munschauer F, Zivadinov R, Weinstock-Guttman B. Predicting quality of life in multiple sclerosis: accounting for physical disability, fatigue, cognition, mood disorder, personality, and behavior change. J Neurol Sci 2005;231:29-34. 
23. Branas P, Jordan R, Fry-Smith A, Burls A, Hyde C. Treatments for fatigue in multiple sclerosis: a rapid and systematic review. Health Technol Assess 2000;4:1-61.

24. DeSousa EA, Albert RH, Kalman B. Cognitive impairments in multiple sclerosis: a review. Am J Alzheimers Dis Other Dem 2002;17:23-29.

25. Benedict RH, Munschauer F, Linn R, Miller C, Murphy E, Foley F, Jacobs L. Screening for multiple sclerosis cognitive impairment using a self-administered 15-item questionnaire. Mult Scler 2003;9:95-101.

26. Gold SM, Schulz H, Monch A, Schulz KH, Heesen C. Cognitive impairment in multiple sclerosis does not affect reliability and validity of self-report health measures. Mult Scler 2003;9:404-410.

27. Lester K, Stepleman L, Hughes M. The association of illness severity, self-reported cognitive impairment, and perceived illness management with depression and anxiety in a multiple sclerosis clinic population. J Behav Med 2007;30:177-186.

28. Woods SP, Carey CL, Moran LM, Dawson MS, Letendre SL, Grant I. Frequency and predictors of selfreported prospective memory complaints in individuals infected with HIV. Arch Clin Neuropsychol 2007;22:187-195.

29. Roth RS, Geisser ME, Theisen-Goodvich M, Dixon PJ. Cognitive complaints are associated with depression, fatigue, female sex, and pain catastrophizing in patients with chronic pain. Arch Phys Med Rehab 2005;86:1147-1154.

30. Suhr JA. Neuropsychological impairment in fibromyalgia: relation to depression, fatigue, and pain. J Psychosom Res 2003;55:321-329.

31. Morrow S, Weinstock-Guttman B, Munschauer F, Hojnacki D, Benedict R. Subjective fatigue is not associated with cognitive impairment in multiple sclerosis: cross-sectional and longitudinal analysis. Mult Scler 2009;15:998-1005.

32. Lezak MD, Howieson DB, Loring DW. Neuropsychological assessment. New York/Oxford: Oxford University Press; 2004.

33. Benedict R, Fischer J, Archibald C, Arnett P, Beatty W, Bobholz J, Chelune G, Fisk J, Langdon D, Caruso L, Foley F, LaRocca N, Vowels L, Weinstein A, DeLuca J, Rao S, Munschauer F. Minimal Neuropsychological Assessment of MS Patients: A Consensus Approach. Clin Neuropsychol 2002;16:381-397.

34. Zakzanis KK. Distinct neurocognitive profiles in multiple sclerosis subtypes. Arch Clin Neuropsychol 2000;15;115-136.

35. Swain MG. Fatigue in chronic disease. Clin Sci 2000;99:1-8.

36. Yamada T, Alpers DH, Kaplowitz N, Laine L, Owyang C, Powell DW. Textbook of Gastroenterology. Philadelphia: Lippincott Williams \& Wilkins; 2003.

37. De Ridder D, Fournier M, Bensing J. Does optimism affect symptom report in chronic disease?; What are its consequences for self-care behaviour and physical functioning? J Psychosom Res 2004;56:341-350.

38. Krupp LB, Alvarez LA, LaRocca NG, Scheinberg LC. Fatigue in multiple sclerosis. Arch Neurol 1988;45:435437.

39. Krupp LB, LaRocca NG, Muir-Nash J, Steinberg AD. The fatigue severity scale. Application to patients with multiple sclerosis and systemic lupus erythematosus. Arch Neurol 1989;46:1121-1123.

40. McDonald WI, Compston A, Edan G, Goodkin D, Hartung HP, Lublin FD, McFarland HF, Paty DW, Polman $\mathrm{CH}$, Reingold SC, Sandberg-Wollheim M, Sibley W, Thompson A, van den Noort S, Weinshenker BY, Wolinsky JS. Recommended diagnostic criteria for multiple sclerosis: guidelines from the International Panel on the diagnosis of multiple sclerosis. Ann Neurol 2001;50:121-127.

41. Compston A, Coles A. Multiple sclerosis. Lancet 2008;372:1502-1517.

42. Niepel G, Tench Ch R, Morgan PS, Evangelou N, Auer DP, Constantinescu CS. Deep gray matter and fatigue in MS: a T1 relaxation time study. J Neurol 2006;253:896-902.

43. Sepulcre J, Masdeu J, Goni J, Arrondo G, Velez de Mendizabal N, Bejarano B, Villoslada P. Fatigue in multiple sclerosis is associated with the disruption of frontal and parietal pathways. Mult Scler 2009;15:337-344. 
44. Tedeschi G, Dinacci D, Lavorgna L, Prinster A, Savettieri G, Quattrone A, Livrea P, Messina C, Reggio A, Servillo G, Bresciamorra V, Orefice G, Paciello M, Brunetti A, Paolillo A, Coniglio G, Bonavita S, Di Costanzo A, Bellacosa A, Valentino P, Quarantelli M, Patti F, Salemi G, Cammarata E, Simone I, Salvatore M, Bonavita $\mathrm{V}$, Alfano B. Correlation between fatigue and brain atrophy and lesion load in multiple sclerosis patients independent of disability. J Neurol Sci 2007;263:15-19.

45. Roelcke U, Kappos L, Lechner-Scott J, Brunnschweiler H, Huber S, Ammann W, Plohmann A, Dellas S, Maguire RP, Missimer J, Radu EW, Steck A, Leenders KL. Reduced glucose metabolism in the frontal cortex and basal ganglia of multiple sclerosis patients with fatigue: a 18F-fluorodeoxyglucose positron emission tomography study. Neurology 1997;48:1566-1571.

46. Logothetis NK. What we can do and what we cannot do with fMRI. Nature 2008;453:869-878.

47. Chiaravalloti N, Hillary F, Ricker J, Christodoulou C, Kalnin A, Liu WC, Steffener J, DeLuca J. Cerebral activation patterns during working memory performance in multiple sclerosis using FMRI. J Clin Exp Neuropsychol 2005;27:33-54.

48. Staffen W, Mair A, Zauner H, Unterrainer J, Niederhofer H, Kutzelnigg A, Ritter S, Golaszewski S, Iglseder $B$, Ladurner $\mathrm{G}$. Cognitive function and $\mathrm{fMRI}$ in patients with multiple sclerosis: evidence for compensatory cortical activation during an attention task. Brain 2002;125:1275-1282.

49. Chaudhuri A, Behan PO. Fatigue and basal ganglia. J Neurol Sci 2000;179:34-42.

50. Turk Charles S, Gatz M, Kato K, Pedersen NL. Physical health 25 years later: the predictive ability of neuroticism. Health Psychol 2008;27:369-378.

51. Crawford JD, Mclvor GP. Stress management for multiple sclerosis patients. Psychol Rep 1987;61:423429.

52. Mohr DC, Hart SL, Goldberg A. Effects of treatment for depression on fatigue in multiple sclerosis. Psychosom Med 2003;65:542-547.

53. Patrick E, Christodoulou C, Krupp L. Longitudinal correlates of fatigue in multiple sclerosis. Mult Scler 2009;15:258-261.

54. Motl RW, McAuley E. Symptom Cluster as a Predictor of Physical Activity in Multiple Sclerosis: Preliminary Evidence. J Pain Symptom Manage 2009;38:270-280.

55. Belza BL. Comparison of self-reported fatigue in rheumatoid arthritis and controls. J Rheumatol 1995;22:639-643.

56. Barsevick AM. The elusive concept of the symptom cluster. Oncol Nurs Forum 2007;34:971-980.

57. Kim HJ, McGuire DB, Tulman L, Barsevick AM. Symptom clusters: concept analysis and clinical implications for cancer nursing. Cancer Nurs 2005;28:270-282; quiz 283-274.

58. MacAllister WS, Krupp LB. Multiple sclerosis-related fatigue. Phys Med Rehabil Clin N Am 2005;16:483502.

59. Fassbender K, Schmidt R, Mossner R, Kischka U, Kuhnen J, Schwartz A, Hennerici M. Mood disorders and dysfunction of the hypothalamic-pituitary-adrenal axis in multiple sclerosis: association with cerebral inflammation. Arch Neurol 1998;55:66-72.

60. Dantzer R, Kelley KW. Twenty years of research on cytokine-induced sickness behavior. Brain Behav Immun 2007;21:153-160.

61. Leeuw M, Goossens ME, Linton SJ, Crombez G, Boersma K, Vlaeyen JW. The fear-avoidance model of musculoskeletal pain: current state of scientific evidence. J Behav Med 2007;30:77-94.

62. Jopson NM, Moss-Morris R. The role of illness severity and illness representations in adjusting to multiple sclerosis. J Psychosom Res 2003;54:503-511.

63. Skerrett TN, Moss-Morris R. Fatigue and social impairment in multiple sclerosis: The role of patients' cognitive and behavioral responses to their symptoms. J Psychosom Res 2006;61:587-593.

64. Donovan KA, Small BJ, Andrykowski MA, Munster P, Jacobsen PB. Utility of a cognitive-behavioral model to predict fatigue following breast cancer treatment. Health Psychol 2007;26:464-472.

65. Young KE, White CA. The prevalence and moderators of fatigue in people who have been successfully treated for cancer. J Psychosom Res 2006;60:29-38. 
66. Bruce JM, Arnett P. Clinical correlates of generalized worry in multiple sclerosis. J Clin Exp Neuropsychol 2008; 31:698-705.

67. Deary $\mathrm{V}$, Chalder $\mathrm{T}$, Sharpe $\mathrm{M}$. The cognitive behavioural model of medically unexplained symptoms: a theoretical and empirical review. Clin Psychol Rev 2007;27:781-797.

68. Prins JB, van der Meer JW, Bleijenberg G. Chronic fatigue syndrome. Lancet 2006;367:346-355.

69. Wessely S, Hotopf, M, Sharpe M. Chronic fatigue and its syndromes. Oxford: Oxford University Press; 1998.

70. Van Wijk CM, Kolk AM. Sex differences in physical symptoms: the contribution of symptom perception theory. Soc Sci Med 1997;45:231-246.

71. Kos D, Kerckhofs E, Nagels G, D'Hooghe M B, llsbroukx S. Origin of fatigue in multiple sclerosis: review of the literature. Neurorehabil Neural Repair 2008;22:91-100.

72. Krupp LB. Fatigue in Multiple Sclerosis. A Guide to Diagnosis and Management. New York: Demos Medical Publishing; 2004.

73. Comi G, Leocani L, Rossi P, Colombo B. Physiopathology and treatment of fatigue in multiple sclerosis. J Neurol 2001;248:174-179.

74. Freal JE, Kraft GH, Coryell JK. Symptomatic fatigue in multiple sclerosis. Arch Phys Med Rehabil 1984;65:135-138.

75. Krupp LB, Christodoulou C. Fatigue in multiple sclerosis. Curr Neurol Neurosci Rep 2001;1:294-298.

76. Strober LB, Arnett PA. An examination of four models predicting fatigue in multiple sclerosis. Arch Clin Neuropsychol 2005;20:631-646.

77. Podsakoff PM, MacKenzie SB, Lee JY, Podsakoff NP. Common method biases in behavioral research: a critical review of the literature and recommended remedies. J Appl Psychol 2003;88:879-903.

78. Bassett DR, Jr. Validity and reliability issues in objective monitoring of physical activity. Res Q Exerc Sport 2000;71:S30-36.

79. Ng AV, Kent-Braun JA. Quantitation of lower physical activity in persons with multiple sclerosis. Med Sci Sports Exerc 1997;29:517-523.

80. American Psychiatric Association. Diagnostic and Statistical Manual of Mental Disorders - Fourth Edition (DSM-IV) - Text Revision. Washington D.C.: American Psychiatric Association; 2001.

81. Gielissen MF, Knoop H, Servaes P, Kalkman JS, Huibers MJ, Verhagen S, Bleijenberg G. Differences in the experience of fatigue in patients and healthy controls: patients' descriptions. Health Qual Life Outcomes 2007;5:36.

82. Gielissen MF, Verhagen CA, Bleijenberg G. Cognitive behaviour therapy for fatigued cancer survivors: long-term follow-up. Br J Cancer 2007;97:612-618.

83. Gielissen MF, Verhagen S, Witjes F, Bleijenberg G. Effects of cognitive behavior therapy in severely fatigued disease-free cancer patients compared with patients waiting for cognitive behavior therapy: a randomized controlled trial. J Clin Oncol 2006;24:4882-4887.

84. Van Kessel K, Moss-Morris R, Willoughby E, Chalder T, Johnson MH, Robinson E. A Randomized Controlled Trial of Cognitive Behavior Therapy for Multiple Sclerosis Fatigue. Psychosom Med 2008;70:205213.

85. Pucci E, Branas P, D'Amico R, Giuliani G, Solari A, Taus C. Amantadine for fatigue in multiple sclerosis. Cochrane Database Syst Rev 2007:CD002818.

86. Solari A, Uitdehaag B, Giuliani G, Pucci E, Taus C. Aminopyridines for symptomatic treatment in multiple sclerosis. Cochrane Database Syst Rev 2003:CD001330.

87. Siegert RJ, Abernethy DA. Depression in multiple sclerosis: a review. J Neurol Neurosurg Psychiatry 2005;76:469-475.

88. Mohr DC, Hart SL, Fonareva I, Tasch ES. Treatment of depression for patients with multiple sclerosis in neurology clinics. Mult Scler 2006;12:204-208.

89. Cetin K, Johnson KL, Ehde DM, Kuehn CM, Amtmann D, Kraft GH. Antidepressant use in multiple sclerosis: epidemiologic study of a large community sample. Mult Scler 2007;13:1046-1053. 
90. Motl RW, McAuley E, Snook EM. Physical activity and multiple sclerosis: a meta-analysis. Mult Scler 2005;11:459-463.

91. Petajan JH, Gappmaier E, White AT, Spencer MK, Mino L, Hicks RW. Impact of aerobic training on fitness and quality of life in multiple sclerosis. Ann Neurol 1996;39:432-441.

92. Petajan JH, White AT. Recommendations for physical activity in patients with multiple sclerosis. Sports Med 1999;27:179-191.

93. Sutherland G, Andersen MB. Exercise and multiple sclerosis: physiological, psychological, and quality of life issues. J Sports Med Phys Fitness 2001;41:421-432.

94. Rietberg MB, Brooks D, Uitdehaag BM, Kwakkel G. Exercise therapy for multiple sclerosis. Cochrane Database Syst Rev 2005:CD003980.

95. Motl RW, Gosney JL. Effect of exercise training on quality of life in multiple sclerosis: a meta-analysis. Mult Scler 2008;14:129-135.

96. Thomas PW, Thomas S, Hillier C, Galvin K, Baker R. Psychological interventions for multiple sclerosis. Cochrane Database Syst Rev 2006:CD004431.

97. Mohr DC, Boudewyn AC, Goodkin DE, Bostrom A, Epstein L. Comparative outcomes for individual cognitive-behavior therapy, supportive-expressive group psychotherapy, and sertraline for the treatment of depression in multiple sclerosis. J Consult Clin Psychol 2001;69:942-949.

98. Mohr DC, Hart SL, Goldberg A. Effects of treatment for depression on fatigue in multiple sclerosis. Psychosom Med 2003;65:542-547.

99. Benedict R, Cookfair DL, Gavett R. Validity of the minimal assesment of cognitive function in multiple sclerosis (MACFIMS). J Int Neuropsychol Soc 2006;12:549-558.

100. Benedict RH, Fischer JS, Archibald CJ, Arnett PA, Beatty WW, Bobholz J, Chelune GJ, Fisk JD, Langdon DW, Caruso L, Foley F, LaRocca NG, Vowels L, Weinstein A, DeLuca J, Rao SM, Munschauer F. Minimal neuropsychological assessment of MS patients: a consensus approach. Clin Neuropsychol 2002;16:381-397.

101. Mathiowetz V, Matuska KM, Murphy ME. Efficacy of an energy conservation course for persons with multiple sclerosis. Arch Phys Med Rehabil 2001;82:449-456.

102. Mathiowetz VG, Finlayson ML, Matuska KM, Chen HY, Luo P. Randomized controlled trial of an energy conservation course for persons with multiple sclerosis. Mult Scler 2005;11:592-601.

103. Sauter C, Zebenholzer K, Hisakawa J, Zeitlhofer J, Vass K. A longitudinal study on effects of a six-week course for energy conservation for multiple sclerosis patients. Mult Scler 2008;14:500-505.

104. Khan F, Turner-Stokes L, Ng L, Kilpatrick T. Multidisciplinary rehabilitation for adults with multiple sclerosis. Cochrane Database Syst Rev 2007:CD006036. 
Multiple sclerosis (MS) is a chronic inflammatory demyelinating disease of the central nervous system and the most common neurological disorders affecting young adults. The clinical picture of MS is diverse, including both physical and neuropsychiatric symptoms. Fatigue is one of the most common and disabling symptoms of MS, but its aetiology is still poorly understood and treatment options are limited. Fatigue cannot fully be explained by biological factors and a psychological approach may be helpful to further explain and treat fatigue in MS. Therefore, the general aim of this thesis was to better understand the concept of MS-related fatigue from a psychological perspective. As such the focus was on identifying relevant psychological factors in explaining MS-related fatigue and their added value to biological factors, such as disease severity and cerebral white matter lesions. More specifically, we studied the impact of fatigue on cognition, the disease specificity of MS-related fatigue, and the extent to which it can be explained by depression, negative affectivity, and cognitive behavioural factors.

Chapter 1 is a general introduction into the clinical diagnosis of multiple sclerosis: its epidemiology, aetiology, pathophysiology and symptoms, including fatigue. Two case reports are presented to illustrate the clinical presentation of fatigue and its impact on daily life. Finally, the aim, the research questions, and the outline of this thesis are presented.

Chapter 2 presents a critical review of the existing literature on MS-related fatigue and its psychological correlates. We started by defining fatigue in MS and discussed its measurement. Next, we focused on conceptual issues including the relationships between MS-related fatigue and mood, anxiety, and cognitive impairment, and the impact of both personality and cognitive behavioural factors on MS-related fatigue. Implications for clinical practice and research are presented.

In Chapter 3 we investigated the contribution of physical and mental fatigue to both cognitive complaints and cognitive performance in $80 \mathrm{MS}$ patients. A relatively extensive neuropsychological assessment battery was used which included a number of tasks that required effortful information processing. Our study revealed that mental fatigue together with anxiety and depression accounted for a substantial part of the total variance of cognitive complaints. The contribution of physical fatigue to cognitive complaints was not significant. Neither physical, nor mental fatigue was related to mental speed, attention, memory and executive functioning. To refine interventions for those patients with cognitive complaints, we advise adding measurements of anxiety, depression and fatigue to their neuropsychological assessment. Because fatigue in MS patients is not related to cognitive performance, it is permitted to use extensive neuropsychological assessment in fatigued patients with MS. Given the impact of cognitive im- 
pairment on daily life, and its heterogeneity in MS, extensive neuropsychological assessment is needed to detect even subtle cognitive dysfunction.

In Chapter 4 we focused on mental fatigue in $40 \mathrm{MS}$ patients and its disease specificity by comparing its levels and correlates with those of 19 healthy control participants (HC) and 20 patients with ulcerative colitis (UC), which is a non-neurological, chronic, and intermittent, auto-immune disease. To better understand MS-related mental fatigue, we used a subjective and objective measure of fatigue. Besides measurement by selfreport, mental fatigue was also measured by a decreased performance on a task that required sustained mental effort. We explored the associations between both (subjective and objective) measures of mental fatigue and disease severity in both patient samples. Next, the associations between both measures of mental fatigue on the one hand and both cerebral white matter lesion load measured by magnetic resonance imaging, and depressive complaints on the other hand, were investigated in all three groups. Our findings revealed that MS patients experienced more mental fatigue than both control groups, but the three groups did not differ with regard to the objective measurement of mental fatigue. The total amount of cerebral white matter leasion load and disease severity did not correlate with both measures of mental fatigue. Depressive complaints were only correlated with subjective assessment of mental fatigue in the HC group and not in the MS and UC sample. In conclusion, our distinction between subjective and objective assessment of mental fatigue did not help us to find an explanation in terms of either disease specificity or significant correlates of MS-related mental fatigue.

In Chapter 5 we again examined the disease specificity of fatigue in MS. We compared MS patients with UC patients, but now we focused on the impact of disease severity, depression and negative affectivity on subjective measures of both physical and mental fatigue. A total of $88 \mathrm{MS}$ and 76 UC patients were included in this cross-sectional study. While levels of both physical and mental fatigue were significantly higher in MS patients than in UC patients, there were no group differences in the contribution of disease severity, depression and negative affectivity to both physical and mental fatigue. Our study revealed that disease severity was an independent contributor to physical fatigue, but not to mental fatigue, while the opposite was the case for negative affectivity. Depression contributed to both physical and mental fatigue. Although levels of fatigue were higher for MS patients when compared with UC patients, their correlates do not indicate MS specificity. As such our results support a trans-diagnostic approach to fatigue in MS.

In Chapter 6 we investigated the role of catastrophic (mis)interpretations of fatigue on fatigue and physical disability in a sample of $262 \mathrm{MS}$ patients. We compared a cognitive behavioural model with a traditional biomedical model using structural equation mod- 
elling (SEM). The explorative use of SEM resulted in an integrated cognitive behavioural model, in which catastrophizing about fatigue was a key factor that mediated the relationship between fatigue and fatigue-related fear and avoidance behaviour. Disease severity did indirectly contribute to fatigue, through fatigue-related fear and avoidance behaviour as well as physical disability. Depression appeared to be a negative consequence of physical disability, and contributed directly to both fatigue as well as to catastrophizing about fatigue. Our study revealed that not just the severity of symptoms, but catastrophizing about fatigue, and fatigue-related fear and avoidance behaviour, in combination with depression, were significant determinants of fatigue and physical disability levels in MS patients. Our results suggest that the modification of catastrophic thoughts about fatigue may be a promising intervention method to help MS patients achieve their daily life goals.

Finally, in Chapter 7, the main findings of this thesis are summarized, discussed, and placed into perspective within the context of this thesis and the recent literature. Methodological issues with regard to the studies conducted are discussed and recommendations for future research and clinical practice are presented. By considering the methodological limitations of the studies we conducted, the present work has enhanced our knowledge and understanding of MS-related fatigue and provided insight into its psychological correlates. The findings of this thesis support the conclusion that a psychological approach of MS-related fatigue is promising and that this approach can be used for the development of new interventions to reduce fatigue and improve the quality of life of patients with MS. 


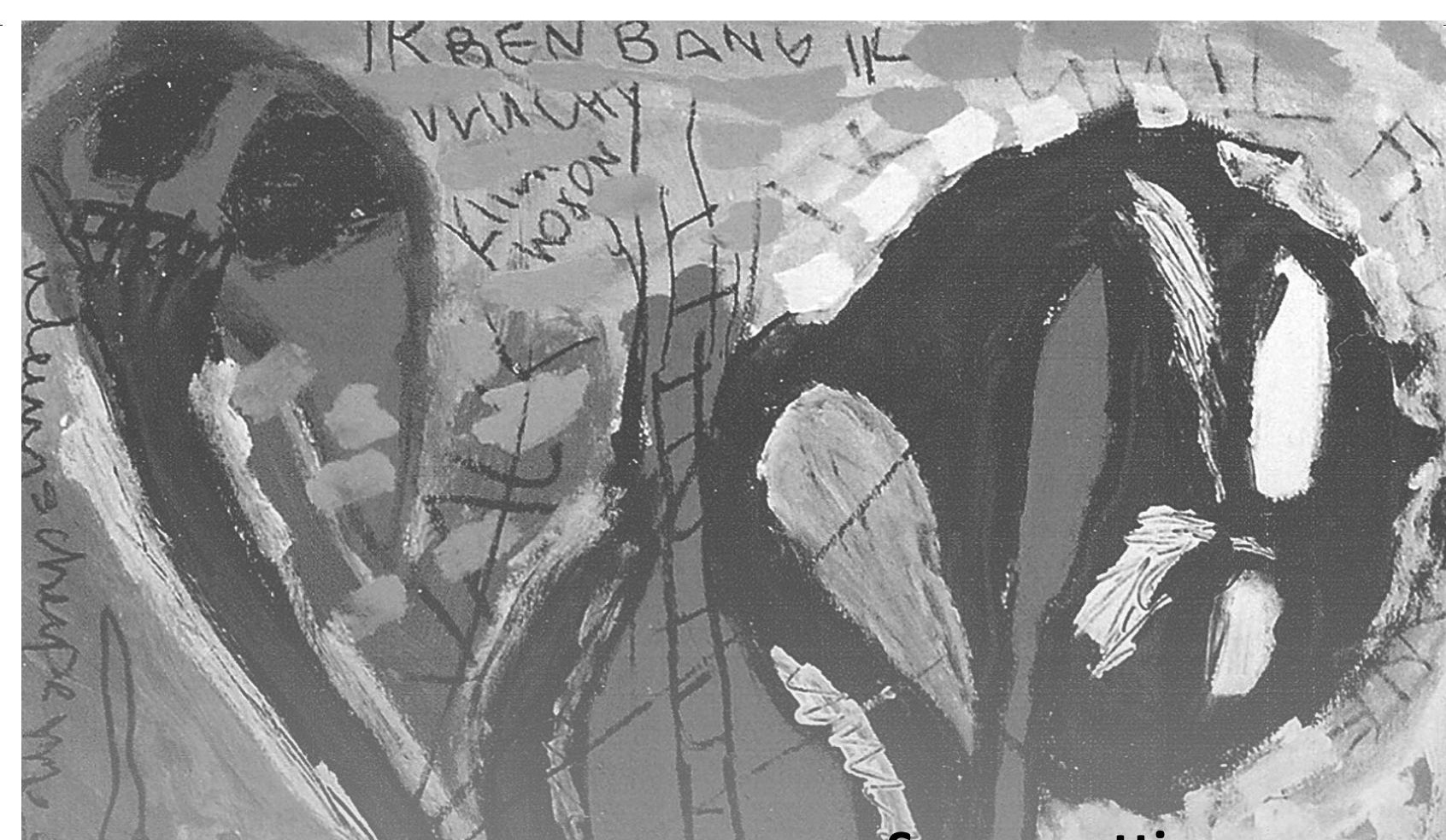

\section{Samenvatting}


Multiple sclerose (MS) is een chronische inflammatoire demyeliniserende aandoening van het centrale zenuwstelsel en de meest voorkomende neurologische aandoening op jongvolwassen leeftijd. Het klinisch beeld van MS is divers en omvat zowel lichamelijke als neuropsychiatrische symptomen. Vermoeidheid is één van de meest voorkomende en hinderlijke symptomen van MS. De oorzaak van vermoeidheid is nog steeds onbekend en de behandelingmogelijkheden zijn beperkt. Vermoeidheid bij MS kan niet geheel door biologische factoren worden verklaard en derhalve zou een psychologische benadering kunnen bijdragen aan de verklaring en behandeling van vermoeidheid bij MS. De doelstelling van dit proefschrift was om het concept MS-gerelateerde vermoeidheid beter te begrijpen vanuit een psychologisch perspectief. We hebben ons gericht op de toegevoegde waarde van psychologische factoren naast biologische factoren, zoals de ernst van de ziekte en cerebrale witte stofafwijkingen. We bestudeerden de invloed van vermoeidheid op cognitie, de ziektespecificiteit van MS-gerelateerde vermoeidheid en de mate waarin het verklaard kan worden door depressie, negatieve affectiviteit en cognitief gedragsmatige factoren.

Hoofdstuk 1 betreft een algemene inleiding en beschrijft het ziektebeeld MS en MSgerelateerde vermoeidheid. Er worden twee casussen gepresenteerd om de klinische presentatie van vermoeidheid en de invloed op het dagelijkse leven te illustreren. Ten slotte worden de doelstelling, de onderzoeksvragen en de opbouw van dit proefschrift beschreven.

In Hoofdstuk 2 wordt een kritisch overzicht gegeven van de bestaande literatuur over de bijdrage van psychologische factoren aan MS-gerelateerde vermoeidheid. Allereerst wordt aandacht besteed aan de definitie en het meten van vermoeidheid bij MS. Vervolgens hebben we ons gericht op conceptuele kwesties, namelijk de relatie tussen MS gerelateerde vermoeidheid enerzijds en stemming, angst en cognitief functioneren anderzijds. Daarnaast hebben we de invloed van persoonlijkheid en cognitief gedragsmatige factoren op vermoeidheid bij MS in kaart gebracht. Ten slotte hebben we aanbevelingen gedaan voor de klinische praktijk en verder onderzoek.

In Hoofdstuk 3 onderzochten we de invloed van lichamelijke en mentale vermoeidheid op zowel cognitieve klachten als cognitieve prestaties bij 80 patiënten met MS. Er werd een uitgebreide neuropsychologische testbatterij gebruikt met diverse taken die relatief veel mentale inspanning vereisen. De resultaten laten zien dat mentale vermoeidheid, samen met angst en depressie, een substantieel deel van cognitieve klachten verklaart. Lichamelijke vermoeidheid draagt niet bij aan cognitieve klachten. Voorts zijn zowel lichamelijke als mentale vermoeidheid niet gerelateerd aan de snelheid van informatieverwerking, aandacht, geheugen en executief functioneren. We adviseren om het neuropsychologisch onderzoek bij MS patiënten uit te breiden met onderzoek van angst, 
depressie en vermoeidheid gegeven hun invloed op cognitieve klachten. Omdat vermoeidheid bij MS patiënten niet gerelateerd is aan cognitieve prestaties, is uitgebreid neuropsychologisch onderzoek bij vermoeide MS patiënten gerechtvaardigd. Juist vanwege het voorkomen van relatief subtiele cognitieve tekorten bij MS en de impact hiervan op het dagelijks functioneren, is uitgebreid neuropsychologisch onderzoek noodzakelijk om cognitieve tekorten te kunnen objectiveren.

In Hoofdstuk 4 hebben we ons gericht op mentale vermoeidheid bij MS en de ziektespecificiteit hiervan. We hebben 40 MS patiënten vergeleken met 19 gezonde controle proefpersonen en 20 patiënten met colitis ulcerosa (CU), een niet-neurologische, chronische en intermitterende auto-immuunziekte. Mentale vermoeidheid werd niet alleen gemeten met een zelfrapportagevragenlijst (subjectieve mentale vermoeidheid), maar ook middels een taak die volgehouden mentale inspanning vergt (objectieve mentale vermoeidheid). In beide patiëntenpopulaties exploreerden we de relaties tussen de mate van subjectief en objectief gemeten vermoeidheid en de ernst van de ziekte. Vervolgens hebben we in de drie verschillende groepen de relaties onderzocht tussen enerzijds de subjectieve en objectieve maat van mentale vermoeidheid en anderzijds cerebrale witte stof laesies gemeten middels magnetische resonantie imaging en depressieve klachten. Onze bevindingen laten zien dat MS patiënten meer mentale vermoeidheid ervaren dan beide controlegroepen, maar dat de drie groepen niet verschilen wat betreft de objectieve maat van mentale vermoeidheid. De ernst van de ziekte en de totale hoeveelheid cerebrale witte stof laesies hangen niet samen met beide maten van mentale vermoeidheid. Depressieve klachten correleren alleen in de groep gezonde controle proefpersonen met de subjectieve maat van mentale vermoeidheid. Concluderend heeft het onderscheid tussen subjectief en objectief gemeten mentale vermoeidheid niet bij kunnen dragen aan ons inzicht in het wel of niet ziektespecifiek zijn van mentale vermoeidheid bij MS.

In Hoofdstuk 5 onderzochten we wederom de ziektespecificiteit van vermoeidheid bij MS door 88 MS patiënten te vergelijken met $76 \mathrm{CU}$ patiënten. We hebben ons gericht op de bijdrage van ziekte-ernst, depressie en negatieve affectiviteit aan zowel lichamelijke als mentale vermoeidheid. Hoewel MS patiënten zowel meer lichamelijke als mentale vermoeidheid ervaren dan CU patiënten, vonden we geen groepsverschillen ten aanzien van de bijdrage van ziekte-ernst, depressie en negatieve affectiviteit aan zowel lichamelijke als mentale vermoeidheid. Deze studie laat zien dat ziekte-ernst een onafhankelijke bijdrage levert aan lichamelijke vermoeidheid en niet aan mentale vermoeidheid, terwijl het tegenovergestelde het geval is voor negatieve affectiviteit. Depressie levert zowel een bijdrage aan lichamelijke als aan mentale vermoeidheid. Hoewel MS patiënten meer vermoeidheid ervaren dan CU patiënten, zijn de correlaten niet 
specifiek voor MS en ondersteunen de resultaten een transdiagnostische benadering van vermoeidheid bij MS.

In Hoofdstuk 6 hebben we de invloed van catastrofale (mis)interpretaties op vermoeidheid en lichamelijke beperkingen onderzocht in een groep van 262 MS patiënten. We hebben een cognitief gedragsmatig model vergeleken met een traditioneel biomedisch model middels structural equation modeling. Exploratief gebruik van deze methode heeft ons geleid naar een geïntegreerd cognitief gedragsmatig model, waarin catastroferen over vermoeidheid een sleutelrol vervult en de relatie tussen vermoeidheid en vermoeidheid gerelateerde angst en vermijdingsgedrag medieert. In dit geïntegreerde model draagt ziekte-ernst indirect bij aan vermoeidheid, via zowel vermoeidheid gerelateerde angst en vermijdingsgedrag als lichamelijke beperkingen. Depressie blijkt een negatief gevolg te zijn van lichamelijke beperkingen en draagt direct bij aan zowel vermoeidheid als catastroferen over vermoeidheid. Onze studie laat zien dat niet alleen de ernst van de symptomen, maar met name catastroferen over vermoeidheid, vermoeidheid gerelateerde angst en vermijding, in combinatie met depressie, significante determinanten zijn van vermoeidheid en lichamelijke beperkingen bij MS patiënten. De resultaten suggereren dat modificatie van catastroferende gedachten over vermoeidheid een veelbelovende interventiemethode kan zijn om ervoor te zorgen dat MS patiënten hun doelen in het dagelijkse leven kunnen bereiken.

Ten slotte worden in Hoofdstuk 7 de belangrijkste bevindingen van dit proefschrift samengevat, bediscussieerd en in het perspectief van de context van dit proefschrift en de recente literatuur geplaatst. Tevens worden hier methodologische aspecten bediscussieerd en aanbevelingen beschreven voor toekomstig onderzoek en de klinische praktijk. Rekening houdend met de methodologische beperkingen, heeft het huidige proefschrift onze kennis en begrip van MS-gerelateerde vermoeidheid vergroot en inzicht verschaft in de relatie met psychologische variabelen. De bevindingen van dit proefschrift ondersteunen de conclusie dat een psychologische benadering van MSgerelateerde vermoeidheid veelbelovend is en dat deze gebruikt kan worden om interventies te ontwikkelen ten einde vermoeidheid te verminderen en de kwaliteit van leven van MS patiënten te verbeteren. 


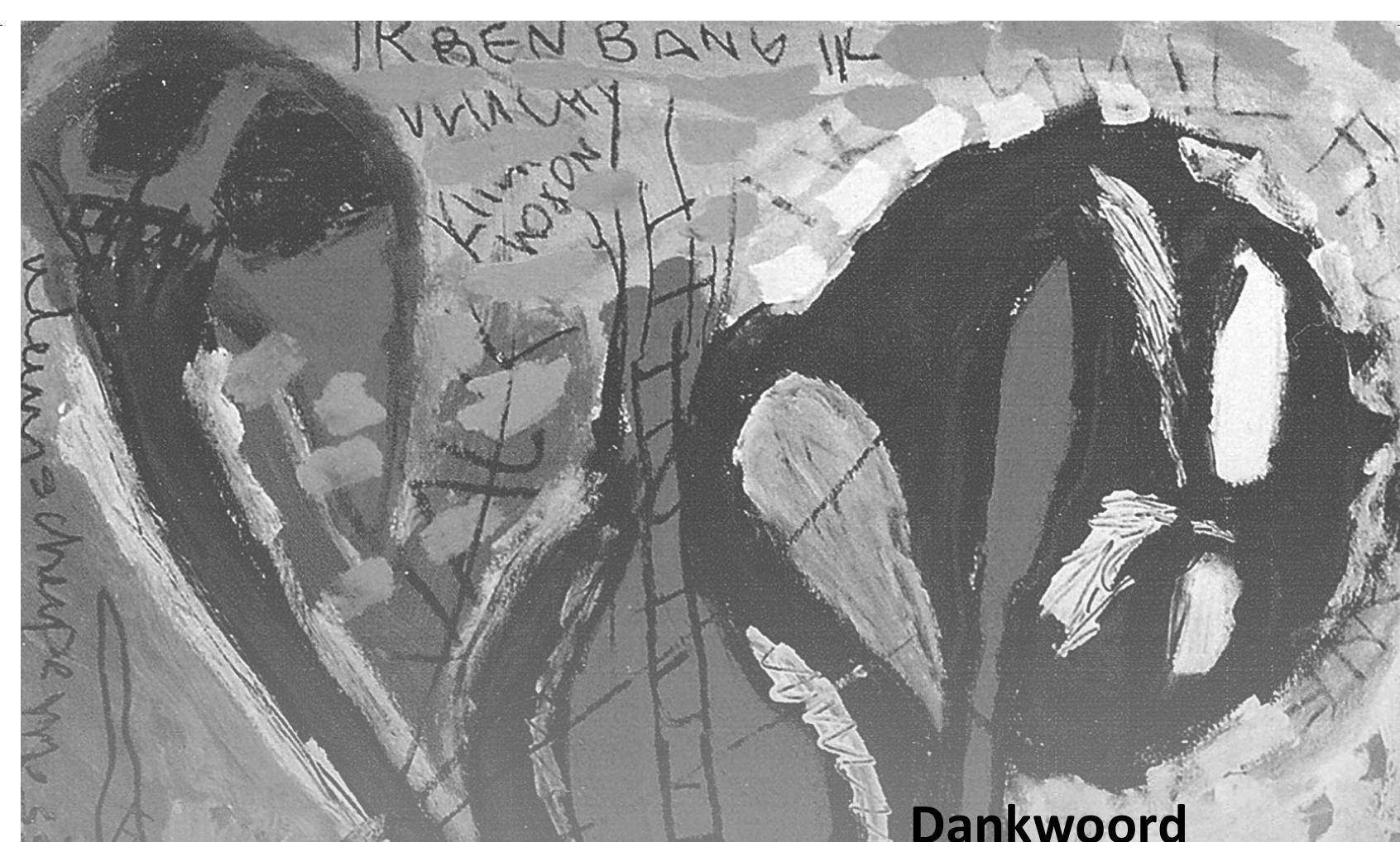

Dankwoord

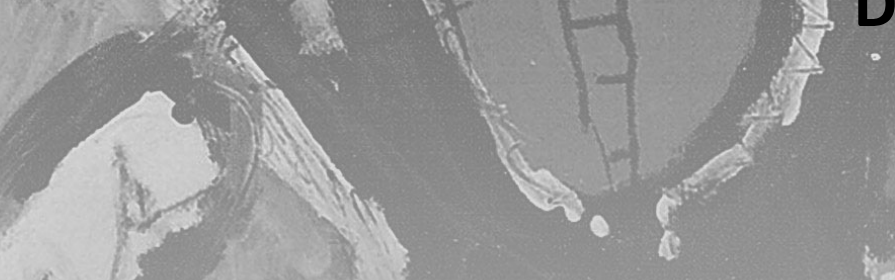


Mijn onderzoekstocht begon ergens in 2003 toen we samen met Marcel van den Hout brainstormden over de psychologie van vermoeidheid bij MS. Nu, ruim 6 jaar later, is het boekje af! Hierbij wil ik iedereen bedanken die op een of andere manier heeft bijgedragen aan de voltooiing van dit proefschrift. Een aantal mensen wil ik in het bijzonder noemen.

Allereerst wil ik alle personen die hebben meegedaan aan het onderzoek bedanken voor hun medewerking. Zonder uw bereidheid en inzet was dit proefschrift er nooit gekomen. Ik wil u hartelijk bedanken voor uw bijdrage en kostbare energie!

De leden van de leescommissie en de corona bedank ik voor het lezen en beoordelen van mijn proefschrift.

Een woord van dank gaat uit naar mijn (multidisciplinaire) promotieteam dat mij de afgelopen jaren heeft begeleid. Het was voor mij soms best lastig om naast alle klinische werkzaamheden en onderwijsactiviteiten ook nog onderzoek te doen en een proefschrift te schrijven. Promotieteam, bedankt voor het vertrouwen, jullie input en alle bemoedigende woorden!

Mijn drie (!) promotoren, Frans Verhey, Raymond Hupperts en Johan Vlaeyen, bedankt voor jullie wetenschappelijke expertise en deskundige, stimulerende en inspirerende begeleiding.

Annelien Duits, co-promotor en mijn dagelijkse begeleider. Annelien, het is ontzettend fijn dat de deur (en mailbox) bij jou altijd open staat. Bedankt voor alles, je collegialiteit, alle steun, de consistentie en alle puntjes op de i! Hopelijk kunnen nog vele promovendi van jouw begeleiding profiteren!

Beste Frans, Raymond, Johan en Annelien, dit proefschrift is het resultaat van een zeer geslaagde samenwerking tussen dokters en psychologen. Ik hoop dat we deze samenwerking in de toekomst zullen voortzetten.

Speciale dank gaat uit naar Christianne Vertommen-Mertens. Beste Christianne, jij was vanaf het begin bij het onderzoek betrokken en met veel enthousiasme en inzet heb jij een belangrijke bijdrage geleverd aan de dataverzameling. Je was niet alleen als psychodiagnostisch medewerker bij het onderzoek betrokken, maar ook als stagiaire tijdens je afstudeerstage voor GGK. Bedankt voor al jouw hulp!

Verder wil ik alle anderen die sinds 2004 direct of indirect als stagiaire, APNIO of onderzoeksassistent een bijdrage hebben geleverd aan het onderzoek bedanken: Inge Verlinden, Erik Gorsselink, Esther Goltstein, Michelle Lacroix, Ewoud Vet, Climmy van den Nieuwenhof, Heidi Lansdaal, Rianne Petersen en Renée Weerens. Jullie hebben heel wat werk verzet, o.a. het bellen en testen van de patiënten, het vullen van enveloppen 
en het invoeren en controleren van data. Ook werd ik ontlast doordat een aantal van jullie zowel klinische als onderwijstaken van mij overnamen. Bedankt!

Alle (oud)-collega's van het MS-team van het MUMC, bedankt voor de samenwerking en de gezellige MDO's. Bertine Timmermans en Riny Wieërs (MS-verpleegkundigen), bedankt voor alle hulp en natuurlijk voor de koffie met chocola!

Dr. Ton van Diepen (neuroloog) en Siert Janzon (MS-verpleegkundige) van het Atrium Medisch Centrum Parkstad te Heerlen, bedankt voor jullie bijdrage. Dankzij jullie inzet konden we de " $n$ " van de laatste studie aanzienlijk vergroten.

Prof. dr. R.J. Brummer, bedankt voor uw bijdrage bij de start van het onderzoek en het zoeken naar een goede controlegroep. Alle andere collega's van de afdeling interne geneeskunde van het MUMC, in het bijzonder Mariëlle Romberg-Camps en Martine Hesselink-van de Kruijs, bedankt voor de prettige manier waarop we hebben samen gewerkt. Beste Mariëlle, leuk dat we nu weer collega's zijn. Succes met jouw laatste loodjes!

Collega's van de afdeling Radiologie van het MUMC, hartelijk bedankt voor alle hulp. Frans Bakers, bedankt voor de tijd en energie die je hebt gestoken in het beoordelen van de MRI's. Dhr. Schoenmakers en Marc Geerlings, bedankt voor de technische en logistieke ondersteuning hierbij.

Erik Schouten, Nico Rozendaal, Eva van den Bussche en Richel Lousberg, bedankt voor alle statistische hulp en waardevolle adviezen.

Alle oud-collega's van het MUMC, bedankt voor de fijne samenwerking van de afgelopen jaren. Een speciaal woord van dank voor mijn oud-collega's van de afdeling Medische Psychologie met wie ik 10 jaar samen werkte en lief en leed deelde. Bedankt voor jullie collegialiteit, de mentale en praktische ondersteuning en de gezelligheid. Ik kijk met veel plezier terug op deze periode. We houden contact! Reinhilde, wanneer gaan we weer squashen?

Alle Orbis-collega's wil ik bedanken voor de belangstelling en de ruimte die ik kreeg bij de afronding van mijn proefschrift. In het bijzonder, de collega's van de afdeling Medische Psychologie en Psychiatrie; het voelt alsof ik al jaren bij jullie werk! Ik hoop dat ik nog lang en met veel plezier een bijdrage kan leveren aan de patiëntenzorg binnen het Orbis Medisch Centrum. 
Lieve vrienden, vriendinnen en (schoon)familie, bedankt voor jullie goede zorgen, belangstelling en alle ontspannende en gezellige momenten.

Lieve Joyce en Farida, wat fijn dat jullie achter mij staan tijdens de verdediging van dit proefschrift! Ik ben trots op onze vriendschap.

Lieve pa en ma, bedankt voor de goede basis en dat jullie altijd voor ons klaar staan!

Lieve Stephan, wat hebben we het toch goed samen. Laten we hopen dat we nog heel lang samen kunnen genieten met onze lieve kleine Lara. Carpe diem!

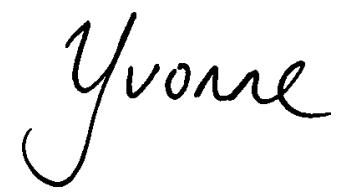

Maastricht, december 2009 


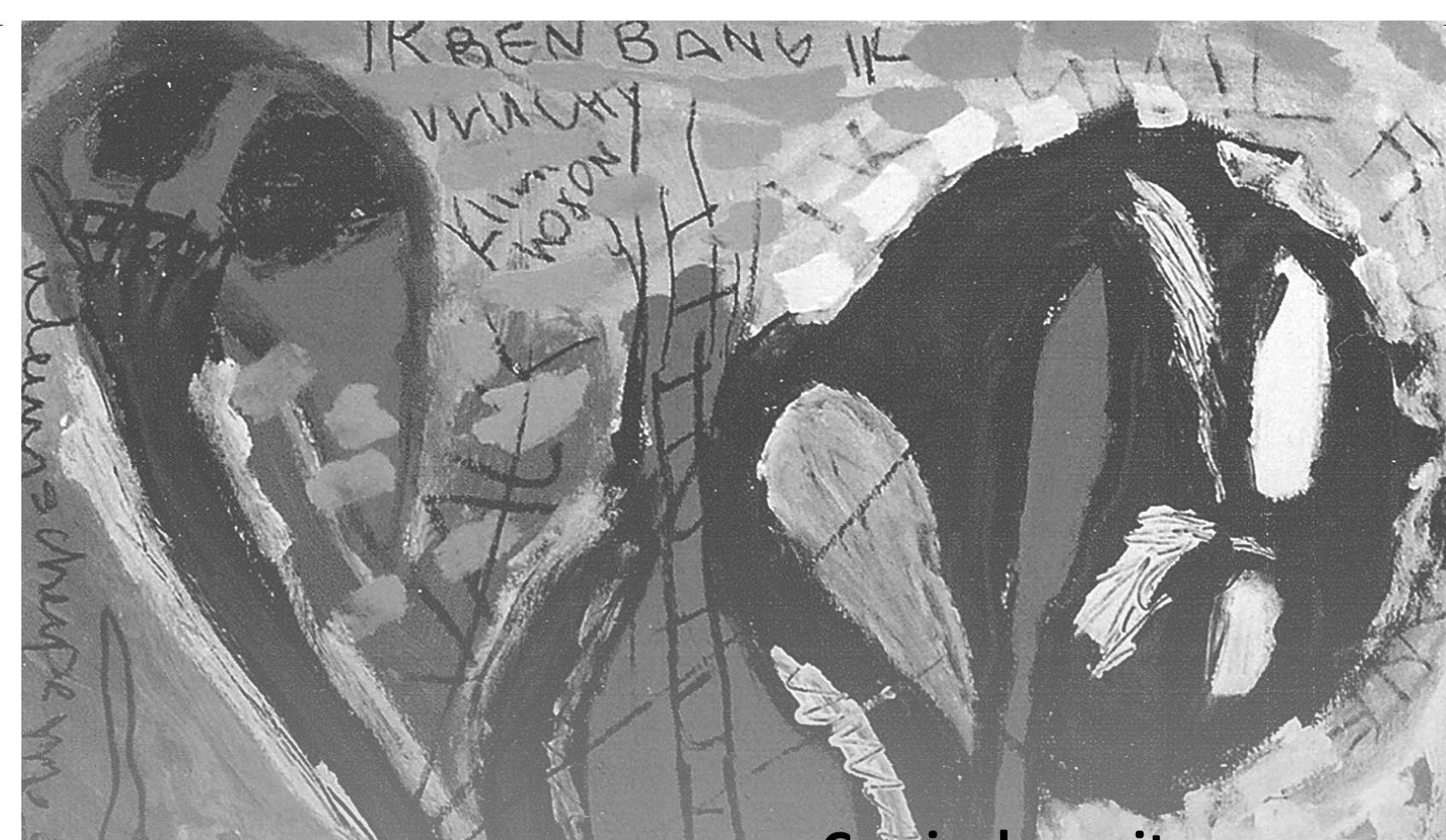

\section{Curriculum vitae}


Yvonne Bol werd op 12 april 1975 geboren te Vlissingen. In 1993 behaalde zij haar VWO-diploma aan het Christelijke Scholengemeenschap Walcheren in Middelburg. Daarna ging zij Gezondheidswetenschappen studeren aan de Universiteit Maastricht (destijds Rijksuniversiteit Limburg). Zij verdiepte zich in de neuro- en ouderenpsychologie en studeerde in 1998 cum laude af in de Geestelijke Gezondheidkunde. Na haar afstuderen werkte ze enkele maanden als psycholoog op haar voormalige stageplaats, de RIAGG afdeling Ouderen in Sittard (nu Orbis Geestelijke Gezondheidszorg). In 1999 kwam ze in dienst van het Academisch Ziekenhuis Maastricht (inmiddels Maastricht Universitair Medisch Centrum, MUMC), waar ze de postdoctorale opleiding tot gezondheidszorgpsycholoog volgde op de afdeling Medische Psychologie. Na haar GZregistratie in januari 2001, combineerde ze haar klinische activiteiten in het MUMC enige tijd met werkzaamheden in verpleeghuis de Zeven Bronnen in Maastricht. Van september $2002 \mathrm{t} / \mathrm{m}$ december 2008 werkte ze fulltime als gezondheidszorgpsycholoog op de afdeling Medische Psychologie van het MUMC, waar ze patiëntenzorg combineerde met onderwijsactiviteiten bij de Faculteit der Geneeskunde. In 2004 startte ze het onderzoek dat beschreven is in dit proefschrift. Sinds januari 2009 is ze als gezondheidszorgpsycholoog werkzaam bij Orbis Medisch en Zorgconcern te Sittard-Geleen. Ze is verbonden aan de afdeling Medische Psychologie en Psychiatrie (Orbis Medisch Centrum/Orbis Geestelijke Gezondheidszorg) en werkzaam voor o.a. het Academisch MS Centrum Limburg en Orbis Revalidatie. Yvonne Bol woont in Maastricht samen met Stephan Boumans en hun dochter Lara. 